\title{
Polymer with Competing Depolymerization Pathways: Chain Unzipping versus Chain Scission
}

\author{
Partha Sarathi Addy ${ }^{1+}$, Manisha Shivrayan ${ }^{1 \dagger}$, Morgan Cencer ${ }^{2}$, Jiaming Zhuang ${ }^{1}$, Jeffrey S. \\ Moore 2,3 and S. Thayumanavan*1,4
}

${ }^{1}$ Department of Chemistry, University of Massachusetts, Amherst, Massachusetts 01003, USA. 2Department of Chemistry, University of Illinois, Urbana, Illinois 61801, USA. ${ }^{3}$ Beckman Institute for Advanced Science and Technology, University of Illinois, Urbana, Illinois 61801, USA. ${ }^{4}$ Molecular and Cellular Biology Program, University of Massachusetts, Amherst, Massachusetts 01003, USA.

\section{Table of contents:}

1. Materials and methods

2. NMR based degradation study of 1 and 5

3. NMR based stability evaluation of $\mathrm{P} 1$ and $\mathrm{P} 2$ polymer

4. Characterization of the final product of NICS mediated P2 degradation

5. Determination of rate constant of NICS

6. Time dependent polymeric degradation study by NMR

7. Theoretical modelling study

8. Comparative degradation study of $\mathrm{P} 1$ and $\mathrm{P} 4$

9. Nanoparticle formulation and characterization of $\mathrm{P} 1$ based particles

10. UV-Vis based dye release from $P 1$ based particles

11. Characterization of $\mathrm{P} 4$ based particles

12. UV-Vis based dye release from $P 4$ based particles

13. Comparison of dye release efficiency between P1and P4 based particles

14. Synthetic scheme of the polymer

15. Synthetic procedures

16. NMR spectra

17. Mass spectra

18. Additional NMR spectra for $P 1$ polymer

19. ESI-MS spectra of polymer P1
Page S1

Page S2-S3

Page S4-S5

Page S6

Page 57

Page S8-S12

Page S13-S15

Page S16

Page S17-S18

Page S19

Page S20

Page S21

Page S22

Page S23

Page S24-S27

Page S28-S37

Page S38-S41

Page S42-S43

Page S44

\section{Materials and methods:}

All solvents and starting materials were purchased from Fischer Scientific or Sigma-Aldrich and used without further purification. All the reactions were monitored by TLC using polygramR SILG/UV254 precoated $(0.25 \mathrm{~mm})$ silica gel TLC plates. Column chromatography was done with silica gel (230-400 mesh). NMR data were obtained with $400 \mathrm{MHz}$ and $500 \mathrm{MHz}$ Bruker NMR instruments. The following abbreviations are used to describe peak patterns where appropriate: $\mathrm{s}$ = singlet, $\mathrm{d}=$ doublet, $\mathrm{t}=$ triplet, $\mathrm{q}=$ quartet, $\mathrm{m}=$ multiplet, app. $=$ apparently and $\mathrm{b}=$ broad signal. All coupling constants $(J)$ are given in Hz. Mass spectra were recorded in ESI+ mode. 
(a)

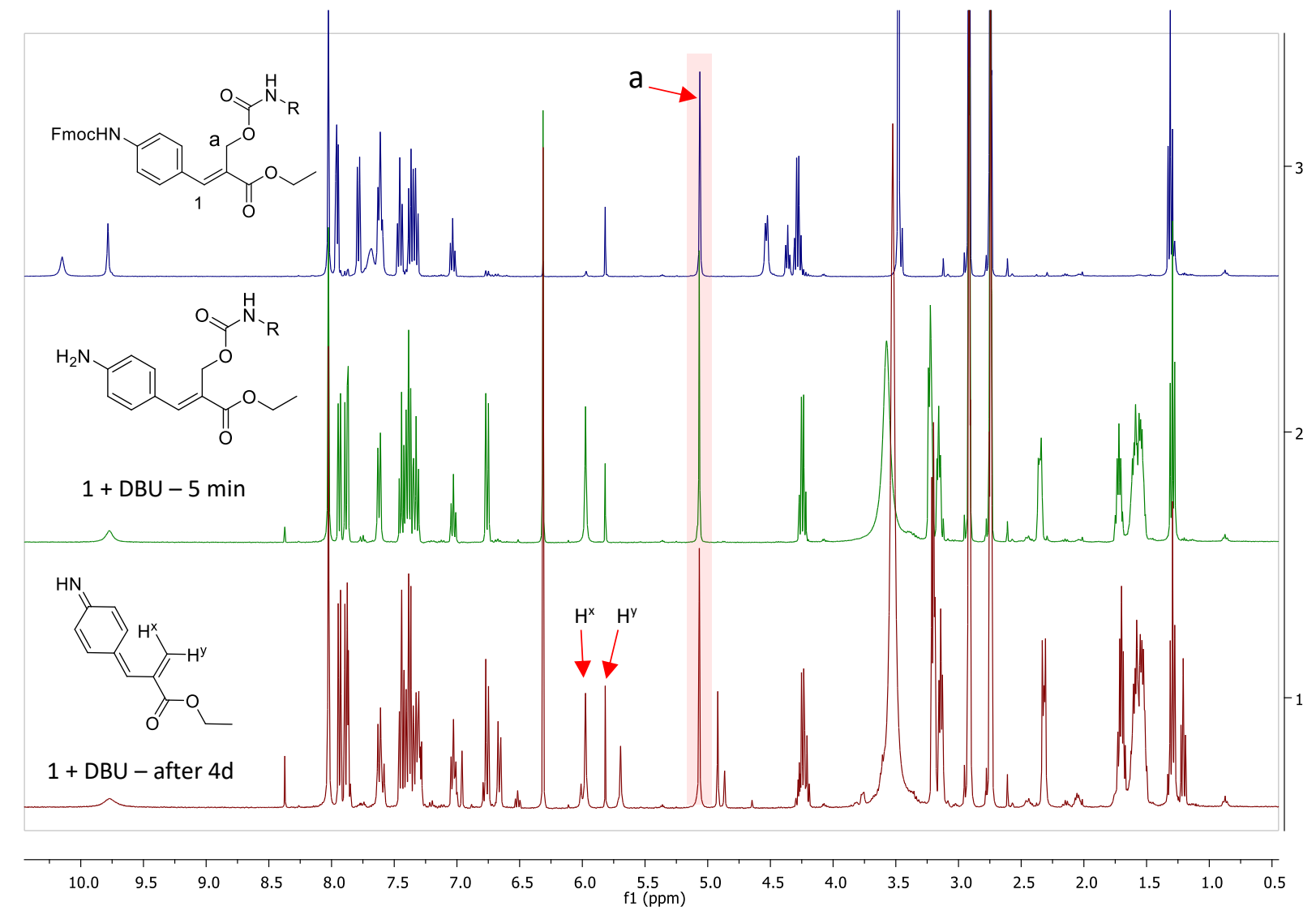

(b)

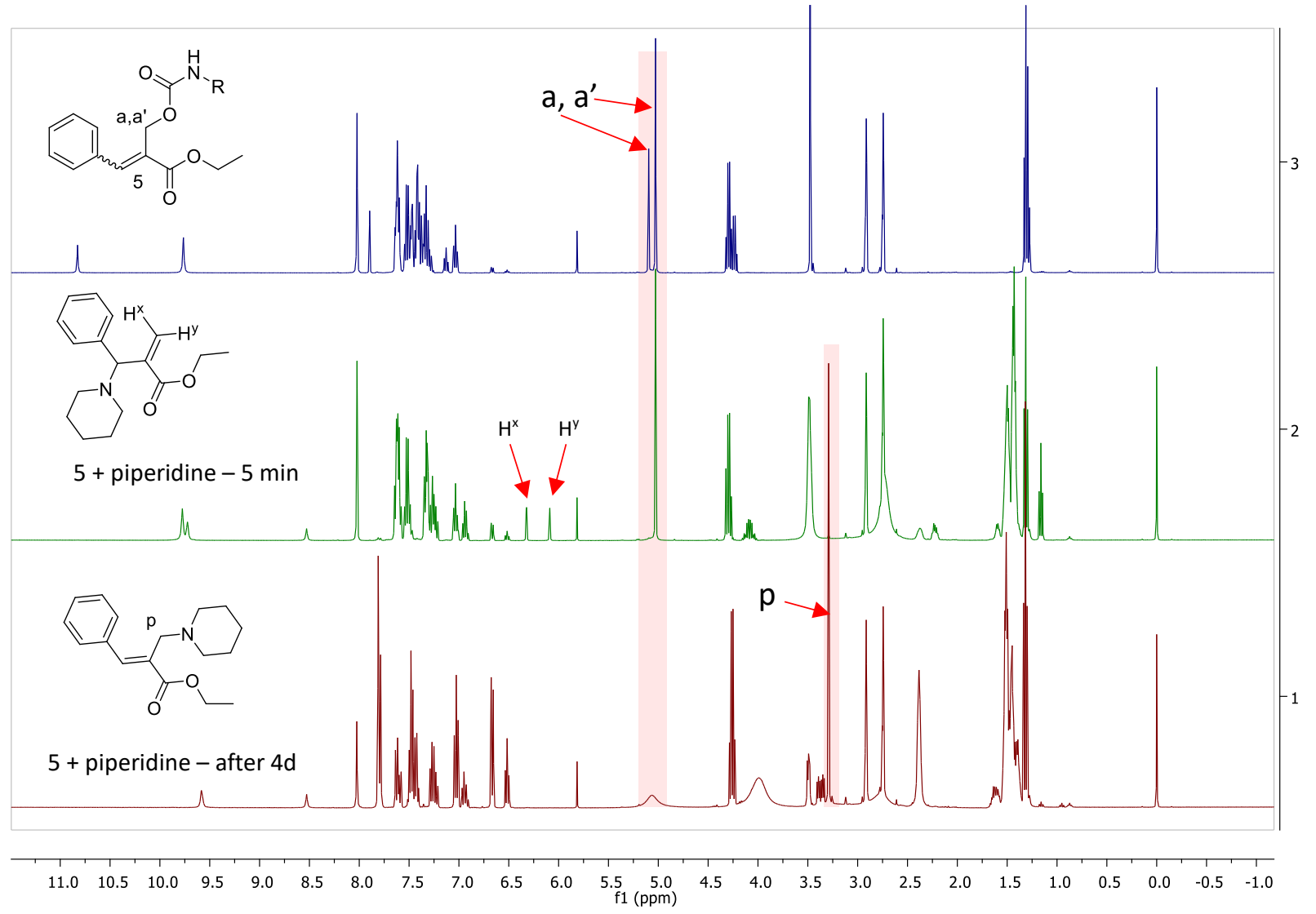

Figure S1a: Time dependent degradation study and ${ }^{1} \mathrm{H}$ NMR (in DMF-d 7 ) of (a) 1 after DBU treatment; (b) 5 after piperidine treatment. 
(a)
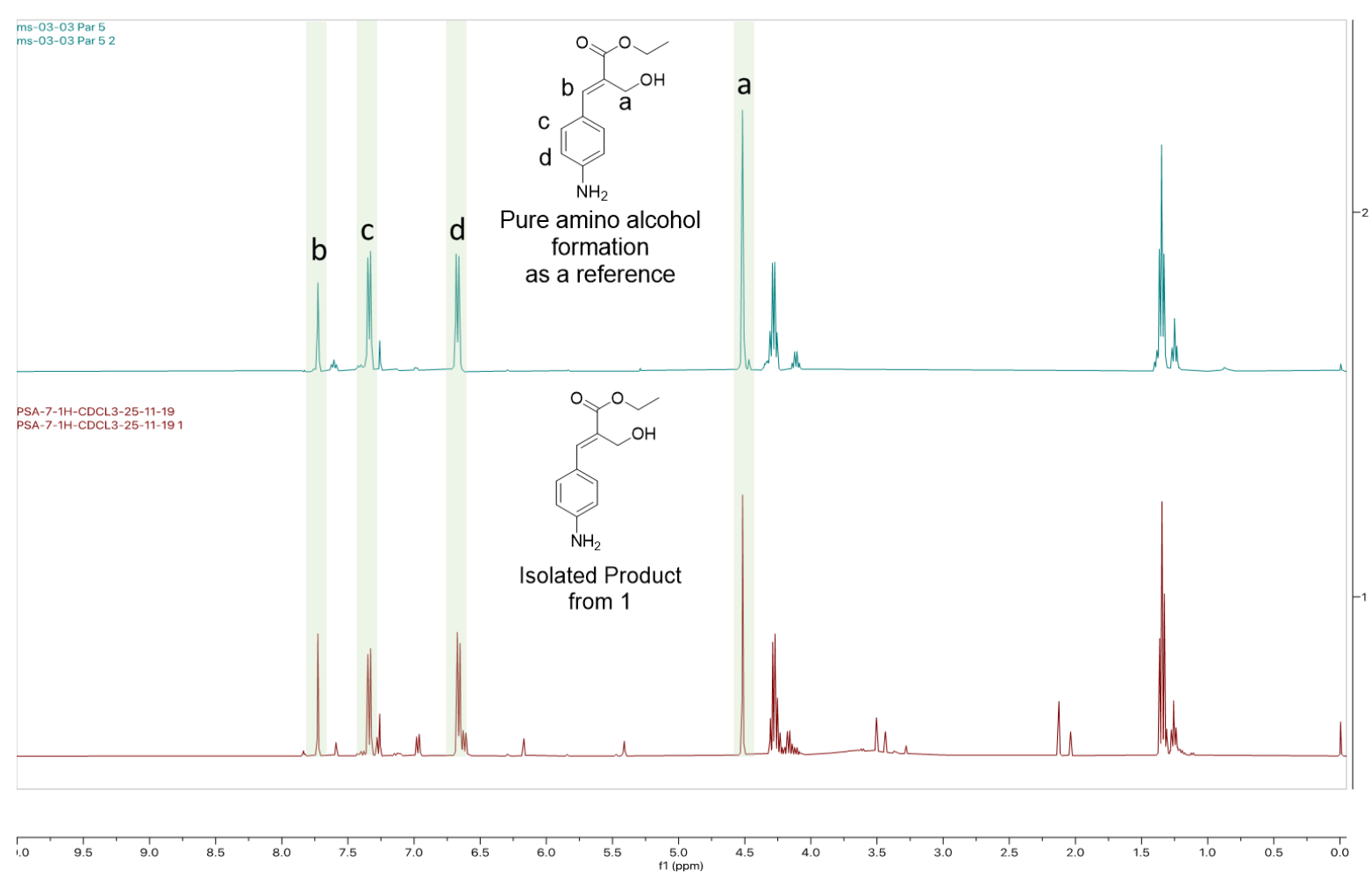

(b)

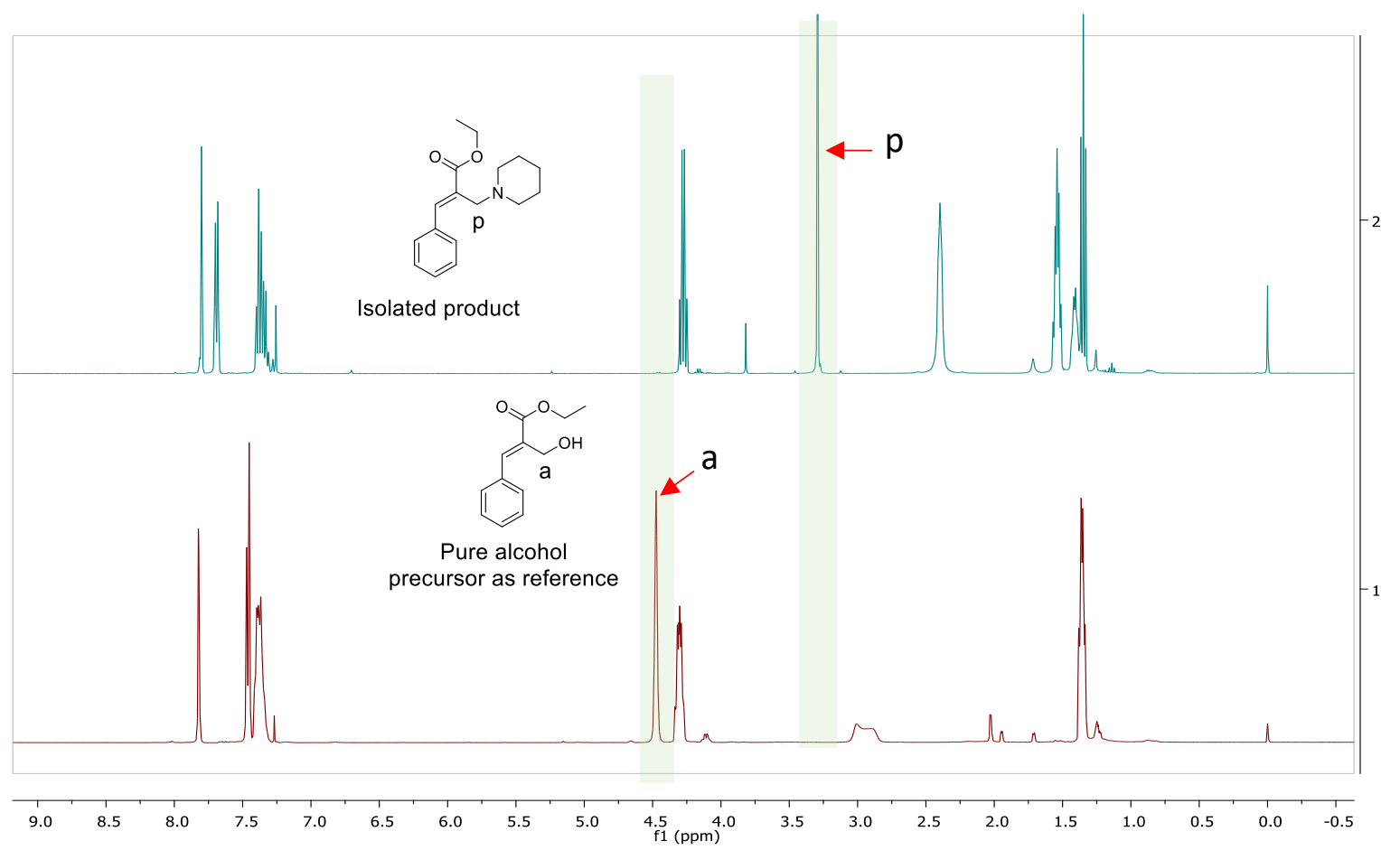

Figure S1b: ${ }^{1} \mathrm{H}$ NMR (in $\mathrm{CDCl}_{3}$ ) of the degraded product generated from (a) 1 after DBU treatment; (b) 5 after piperidine treatment (highlights were used to compare the product with the reference peaks). 


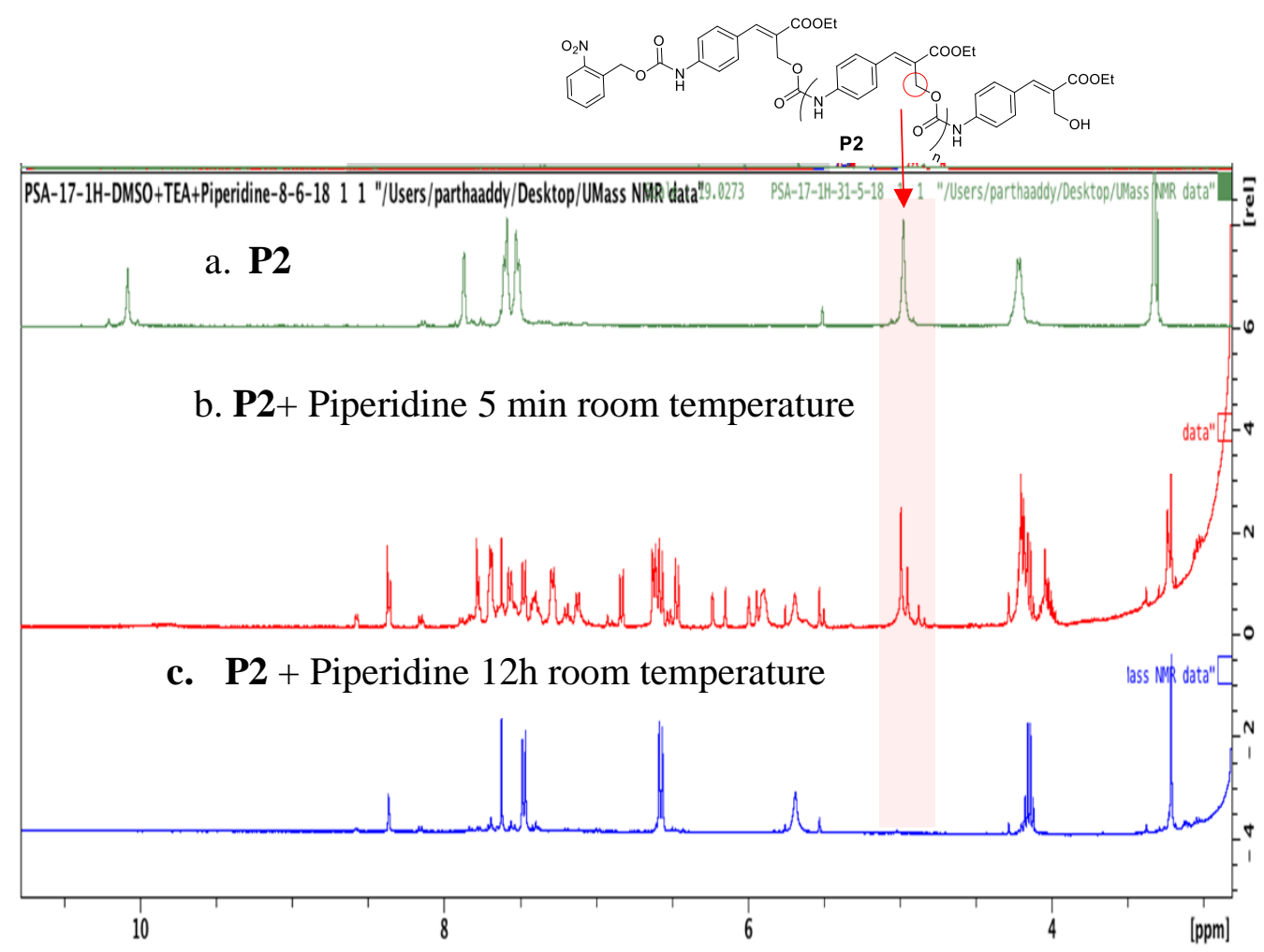

Figure S2a: $1 \mathrm{mg}$ of $\mathbf{P 2}$ was taken in $0.5 \mathrm{~mL}$ DMSO- $\mathrm{d}_{6}$ and $10 \mu \mathrm{L}$ Piperidine was added to it and incubated at room temperature. ${ }^{1} \mathrm{H}-\mathrm{NMR}$ (in DMSO-d 6 ) of P2 (a) before; (b) 5 min after; (c) 12 hours after piperidine addition.

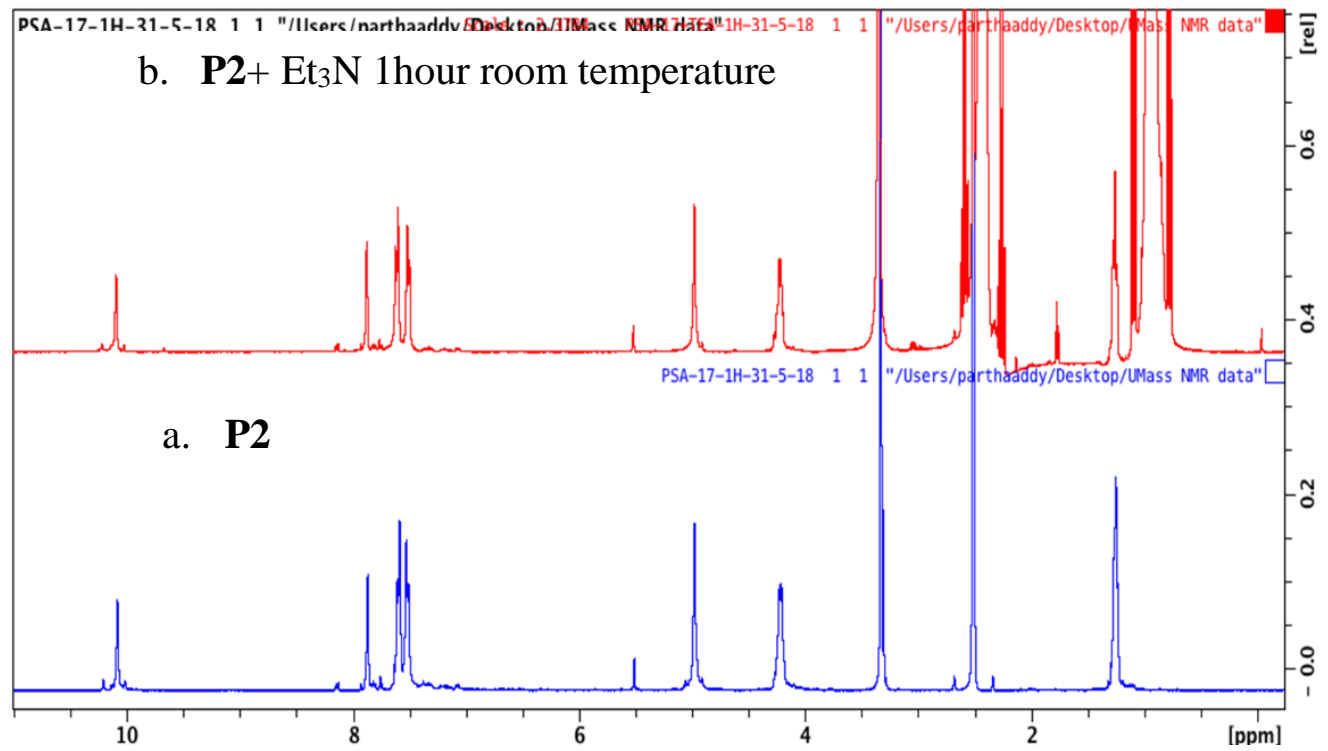

Figure S2b: $1 \mathrm{mg} \mathbf{P 2}$ was taken in $0.5 \mathrm{~mL}$ DMSO- $\mathrm{d}_{6}$ and $10 \mu \mathrm{L}$ triethylamine $\left(\mathrm{Et}_{3} \mathrm{~N}\right)$ was added to it and incubated for 1 hour at room temperature. ${ }^{1} \mathrm{H}-\mathrm{NMR}$ (in DMSO- $\mathrm{d}_{6}$ ) of $\mathbf{P 2}$ (a) before treatment with triethylamine; (b) after treatment with triethylamine (even after 12 hours incubation no change was observed). 

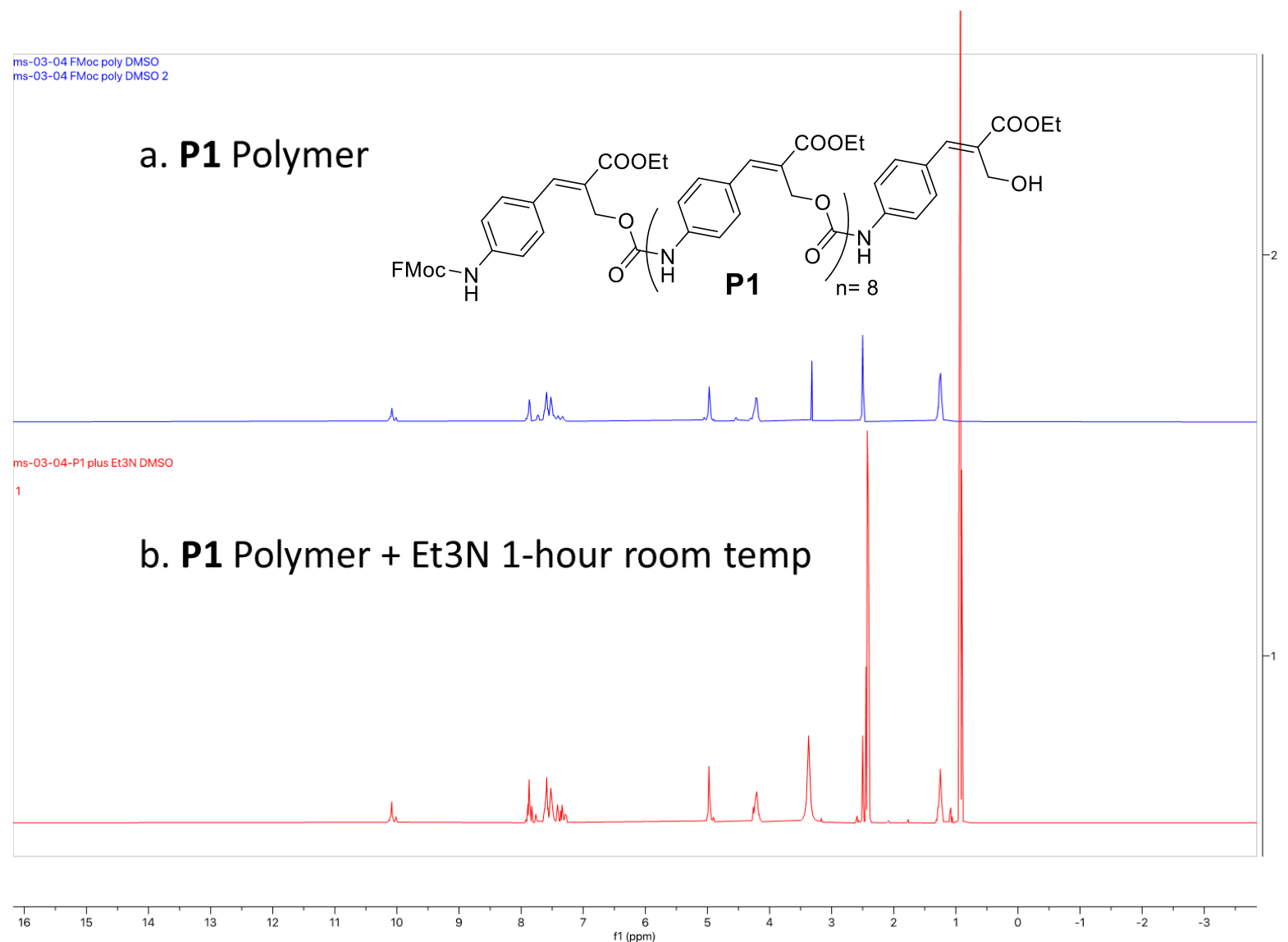

Figure S2c: $1 \mathrm{mg}$ P1 was taken in $0.5 \mathrm{~mL}$ DMSO-d $\mathrm{d}_{6}$ and $10 \mu \mathrm{L}$ triethylamine $\left(\mathrm{Et}_{3} \mathrm{~N}\right)$ was added to it and incubated for 1 hour at room temperature. ${ }^{1} \mathrm{H}-\mathrm{NMR}$ (in DMSO- $\mathrm{d}_{6}$ ) of P1 (a) before treatment with triethylamine ; (b) after treatment with triethylamine (even after 12 hours incubation no change was observed). 


\section{Characterization of the final products after polymer degradation:}

a)

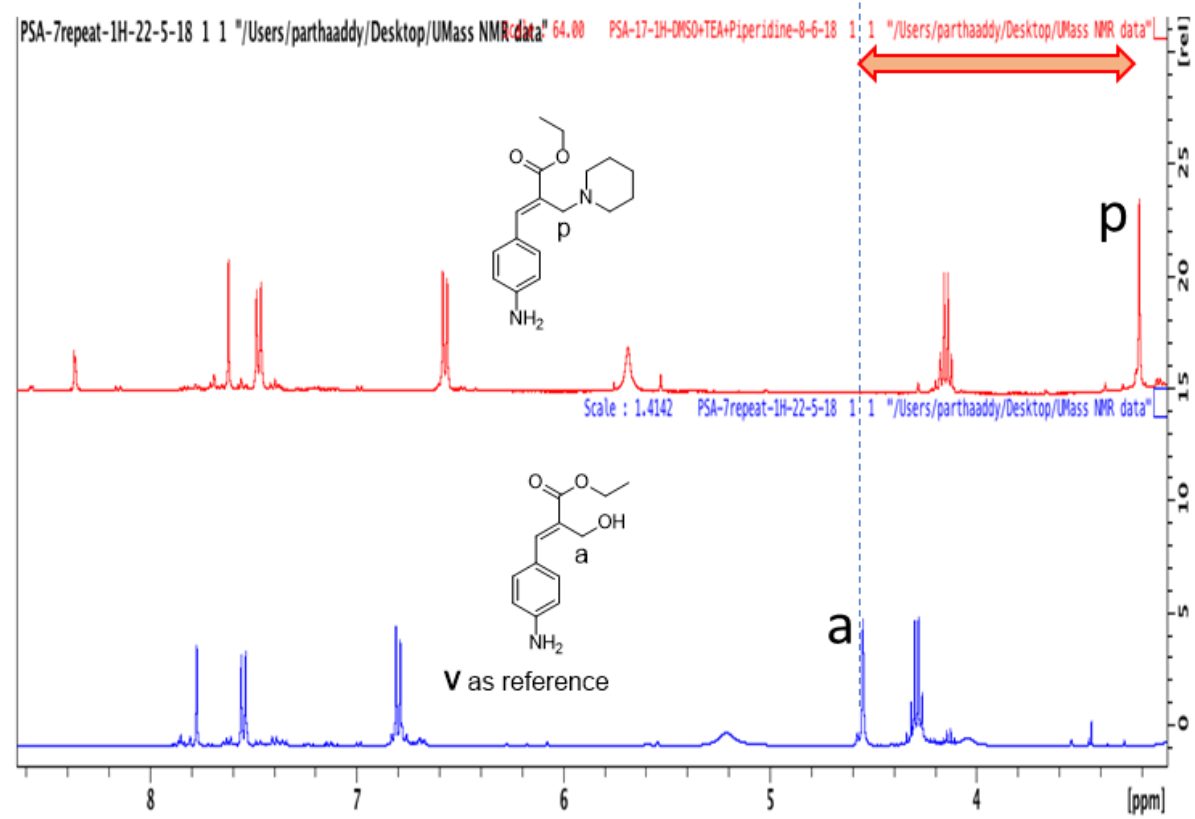

b)

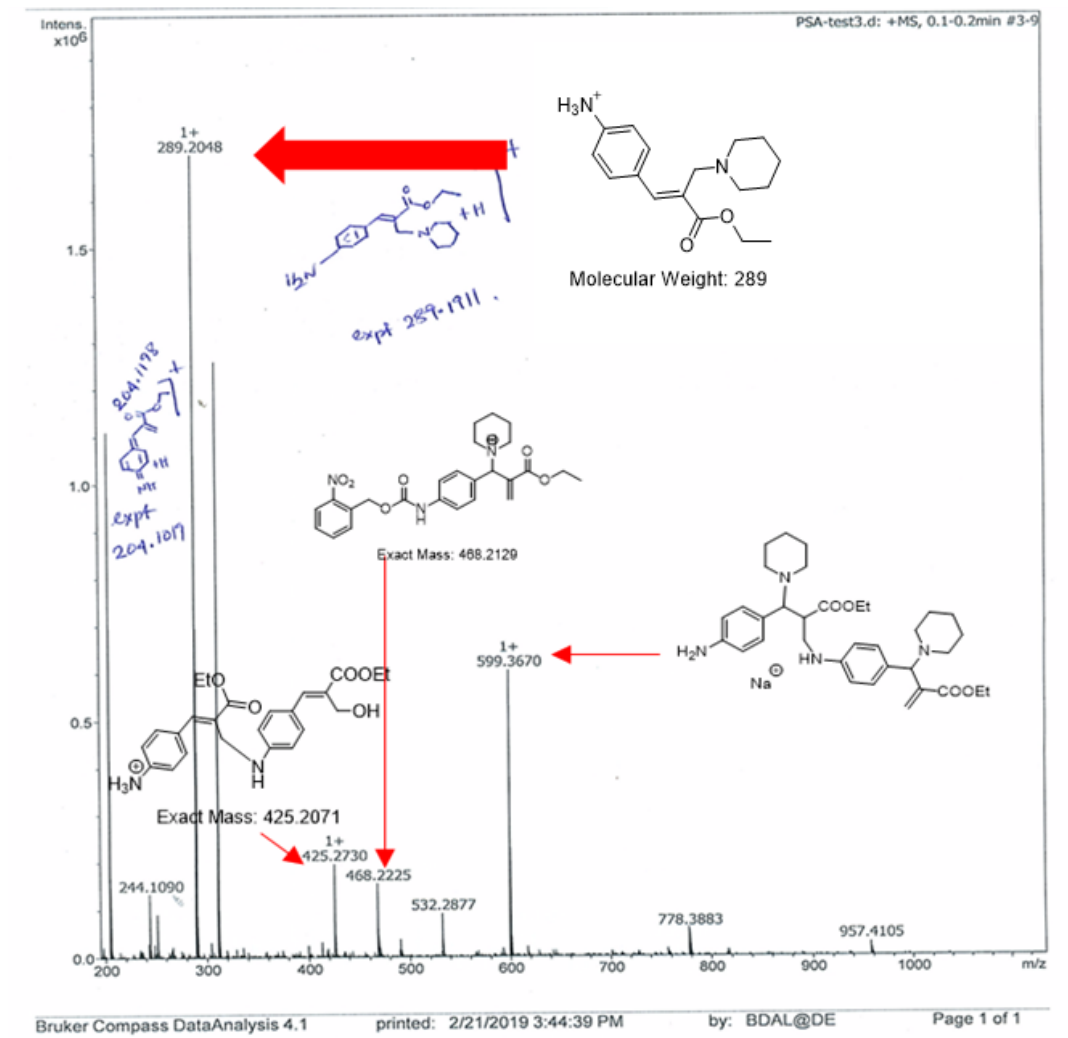

Figure S3: Characterization of the final product of piperidine mediated NICS based degradation of $\mathbf{P} 2$ by (a) ${ }^{1} \mathrm{H}-\mathrm{NMR}$ (in DMSO- $\mathrm{d}_{6}$ ), upon comparison to $\mathbf{V}$, the NMR of the product found to be similar except the highlighted allyl methylene protons; (b) ESI-MS analysis. 


\section{Determining the kinetic parameters of piperidine mediated polymer degradation:}

The conjugated polymer absorbs at $315 \mathrm{~nm}$, which was used to spectrophotometrically monitor it's time dependent degradation. The rate for polymer degradation reaction was measured under pseudo-first order reaction condition, where the polymer was used as the limiting reagent (10 $\mu \mathrm{M})$ and varying concentrations of piperidine was used in significant excess (more than 10-fold). Reactions were performed in dimethyl formamide (DMF) at room temperature. Pseudo-first order rate $\left(\mathrm{k}_{\mathrm{Pip}}\right)$ constant was determined for each different piperidine concentration using the following equation:

$$
\ln [\mathrm{A}]=\ln \left[\mathrm{A}_{0}\right]-\mathrm{k}_{\mathrm{B}} \mathrm{t}
$$

Plotting each pseudo-first order rate constant against the corresponding piperidine concentration resulted the second-order rate constant $\left(\mathrm{k}_{2}\right)$ according to the following equation:

(a)

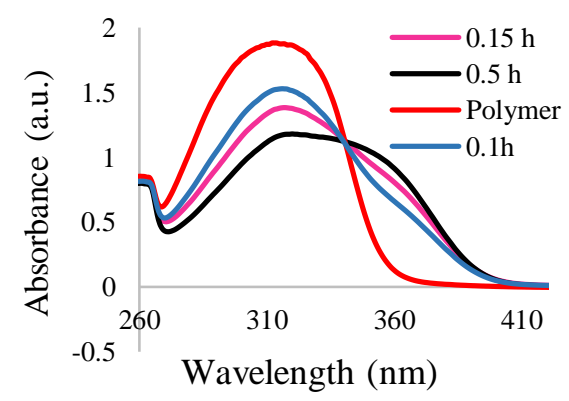

(c)

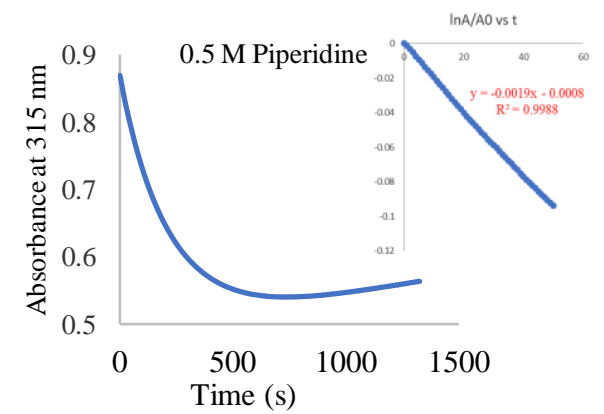

$$
\mathrm{K}_{\text {Pip }}=\mathrm{k}_{2} *[\mathrm{Pip}]
$$

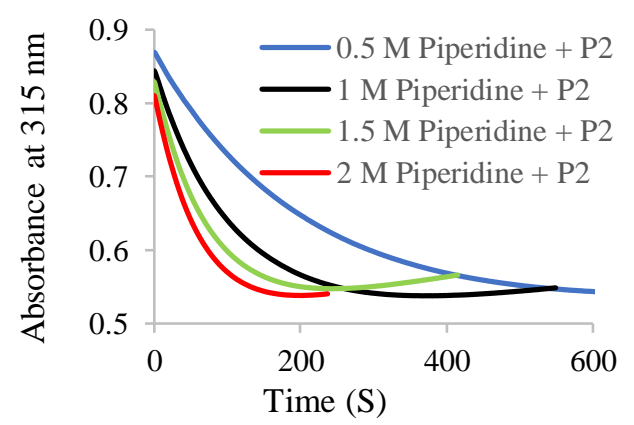

(d)

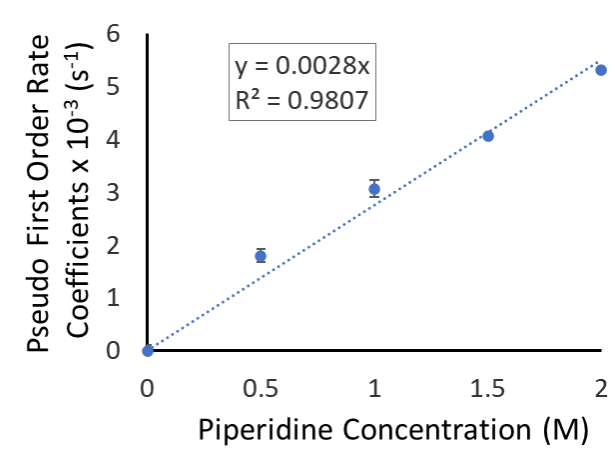

Figure S4a: Evaluation of the kinetic parameters of the reaction between $\mathbf{P 2}$ and piperidine. Rate of product formation was measured under pseudo-first order conditions, where $10 \mu \mathrm{M}$ of polymer was mixed with an excess of piperidine (0.5-2 M) in DMF at room temperature. (a) representative time dependent UV-Vis spectra of the polymer $(20 \mu \mathrm{M})$ upon piperidine treatment; (b) Pseudo first order rate constant versus concentration of piperidine plot to determine the actual rate constant for polymer degradation; Absorbance at $315 \mathrm{~nm}$ vs Time (s) plot of (c) $0.5 \mathrm{M}$ piperidine treated $\mathbf{P 2}$ $(10 \mu \mathrm{M})$ in DMF; (d) $10 \mu \mathrm{M} \mathbf{P} 2$ with different concentrations of piperidine $(0.5-2 \mathrm{M})$ in DMF. 
a

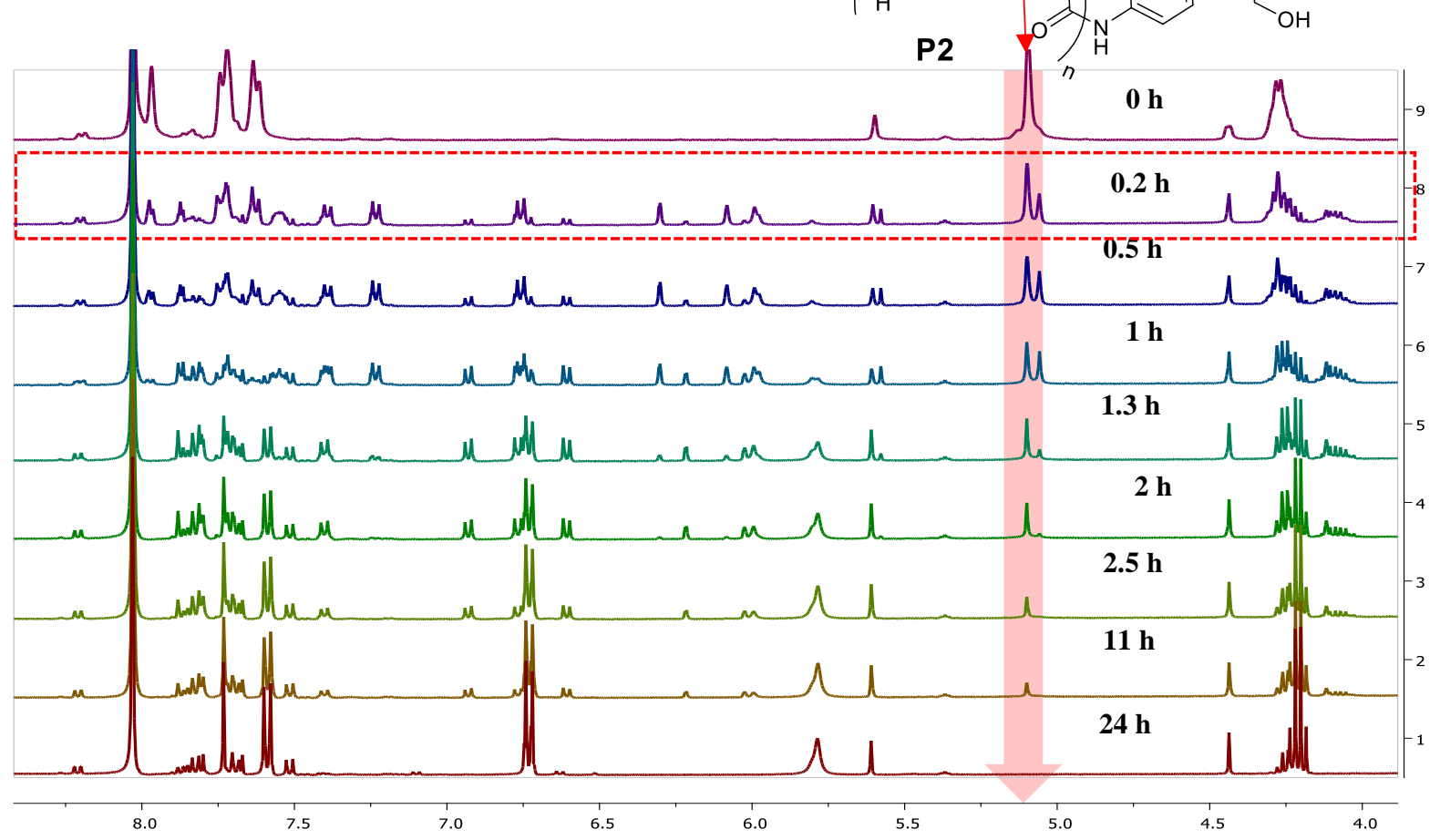

b

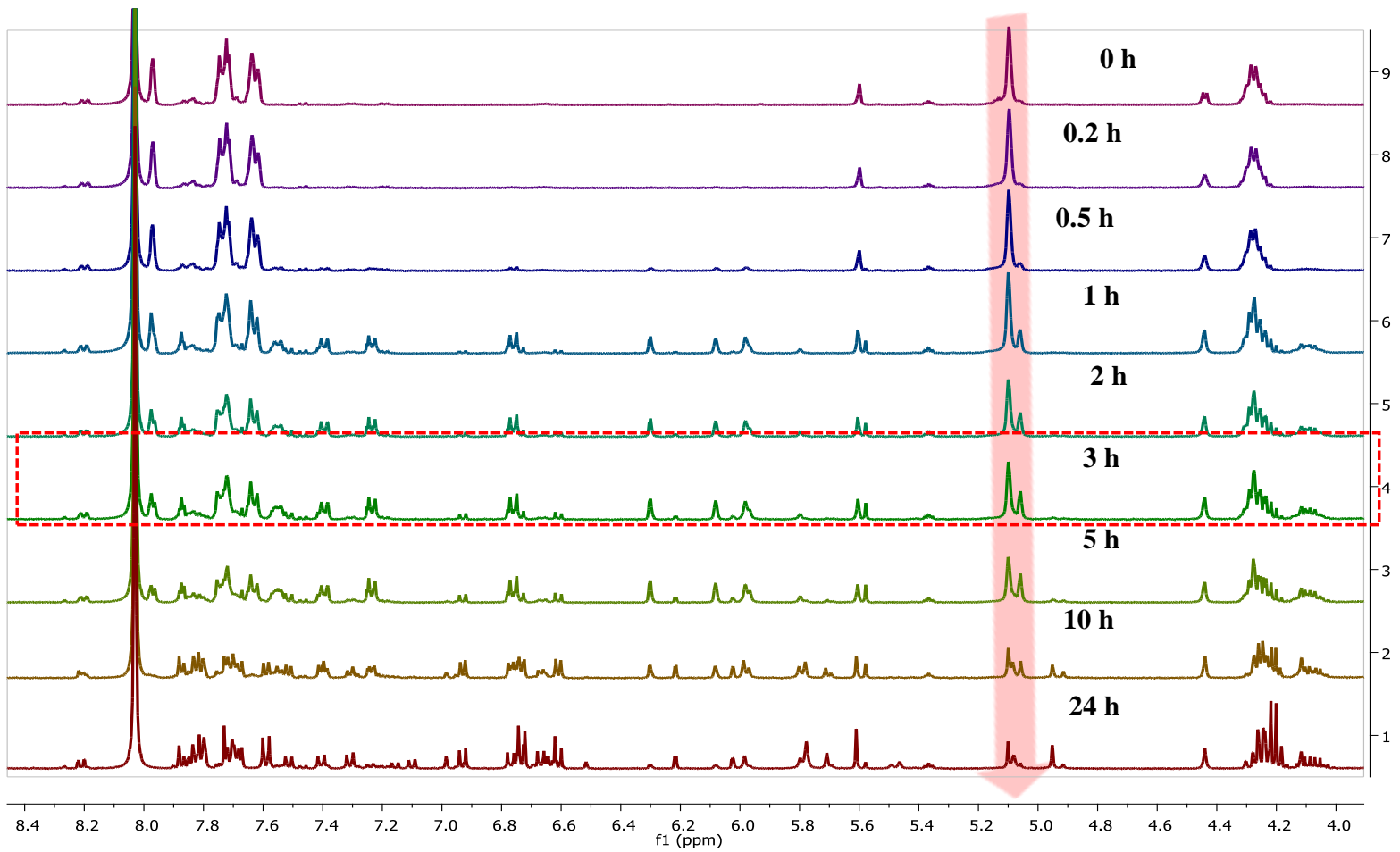

Figure S4b: Representative time dependent ${ }^{1} \mathrm{H}-\mathrm{NMR}$ (in DMF-d $\mathrm{d}_{7}$ ) of (a) $0.5 \mu$ moles $\mathbf{P 2}$ with 150 $\mu$ moles piperidine; (b) $0.5 \mu$ moles $\mathbf{P 2}$ with $5 \mu$ moles piperidine. The inset box showed the $50 \%$ degraded polymer spectrum. We monitored the peak at $5.27 \mathrm{ppm}$, which is highlighted in the spectra above. 


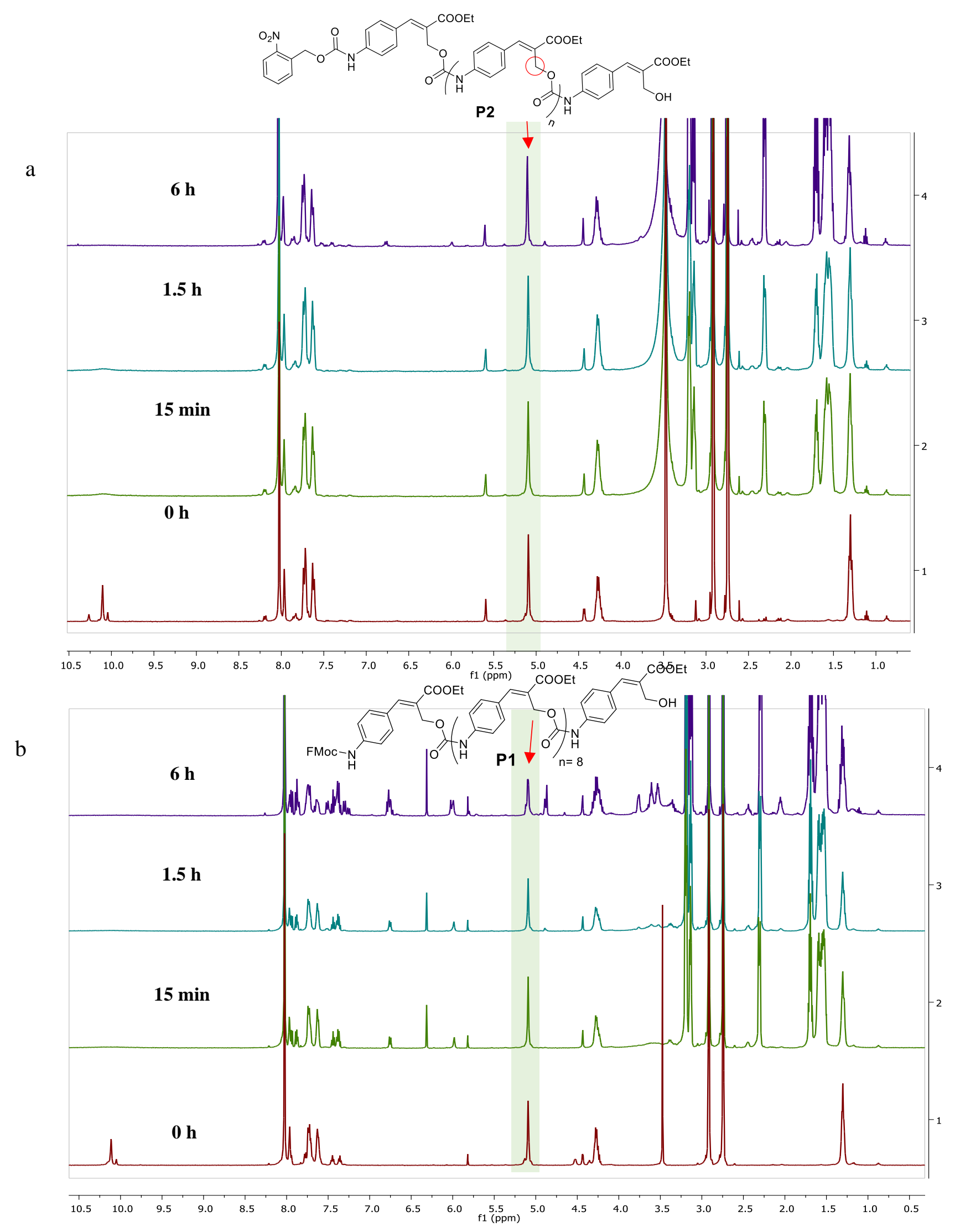

Figure S5: ${ }^{1} \mathrm{H}-\mathrm{NMR}$ (in DMF-d $\mathrm{d}_{7}$ ) to monitor selective head to tail depolymerization in P1 and P2 upon DBU treatment $(0.5 \mu$ moles polymer $+50 \mu$ moles DBU in $0.5 \mathrm{~mL} \mathrm{DMF-d} 7$,$) and P2$ was found to be more stable. P1 and P2 polymers were treated with DBU and ${ }^{1} \mathrm{H}-\mathrm{NMR}$ spectra recorded at different time points as mentioned. (a) P2, after DBU treatment; (b) P1, after DBU treatment. 


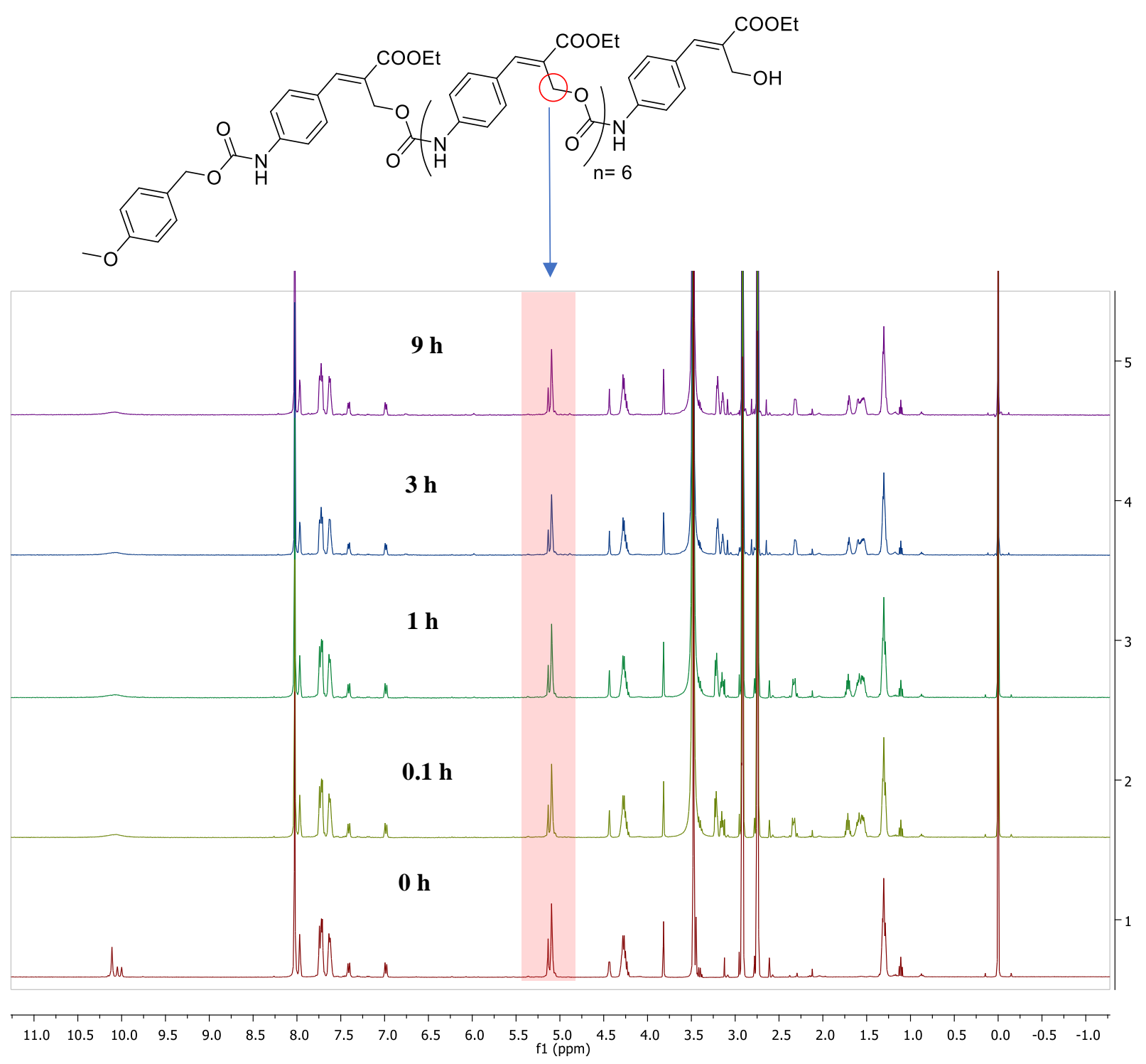

Figure S6: Time dependent analysis of P3 (0.5 $\mu$ moles) upon DBU treatment (10 $\mu$ moles $)$ via ${ }^{1} \mathrm{H}-\mathrm{NMR}$ (in DMF-d 7 ). We found that $\mathbf{P 2}$ exhibited some depolymerization at longer incubation times (>10 hours). Our NMR analysis suggested that the o-nitrobenzyl group is susceptible to slow deprotection with DBU. To unambiguously confirm that DBU does not access the NICS pathway, we synthesized $\mathbf{P 3}$ with $p$-methoxybenzyl carbamate as a more robust capping moiety. This polymer did not exhibit any degradation over the extended period of time. 


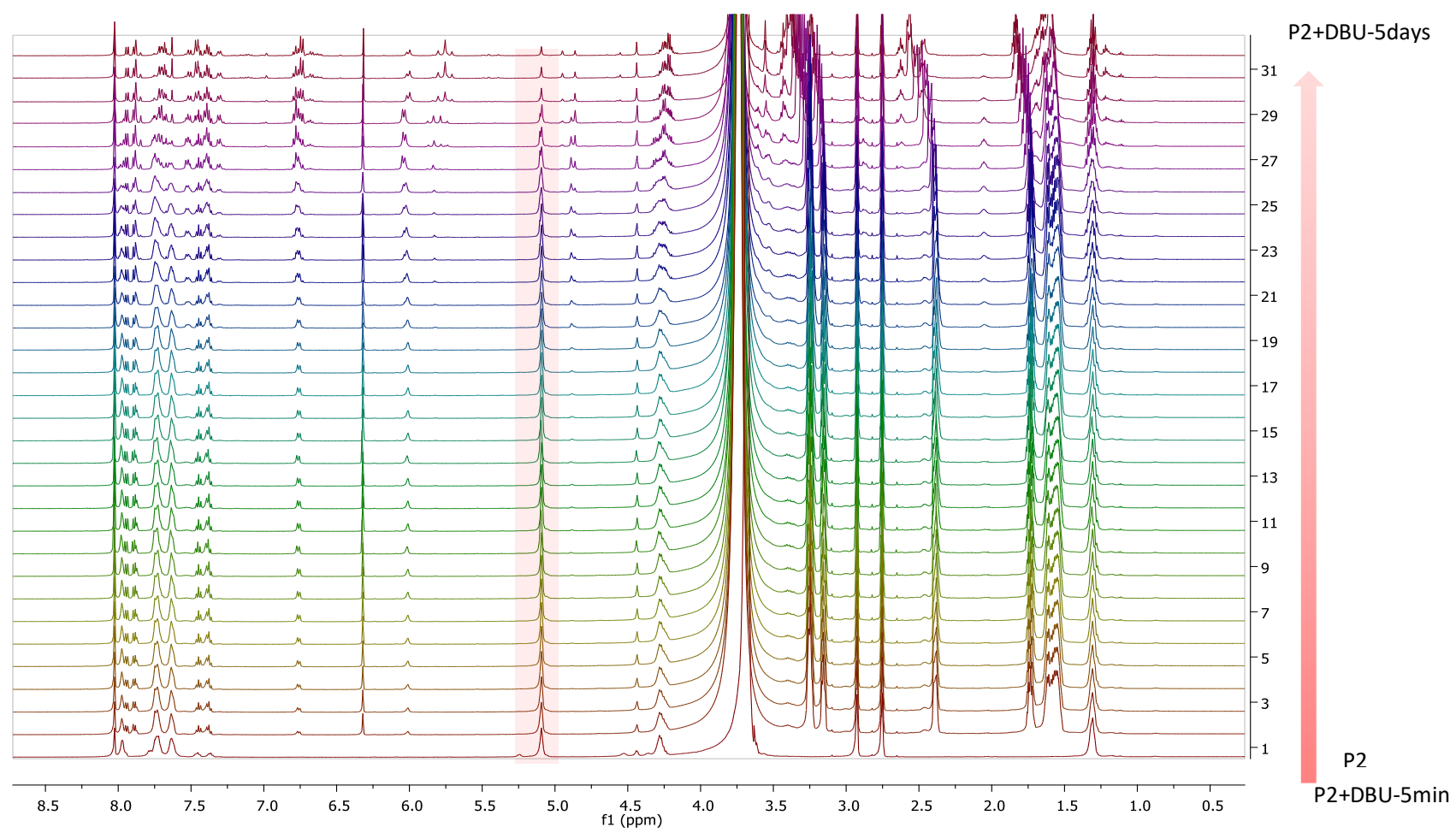

Figure S7: Time dependent detailed ${ }^{1} \mathrm{H}-\mathrm{NMR}$ (in DMF- $\mathrm{d}_{7}$ ) of $0.5 \mu$ moles P1 treated with $50 \mu$ moles DBU.

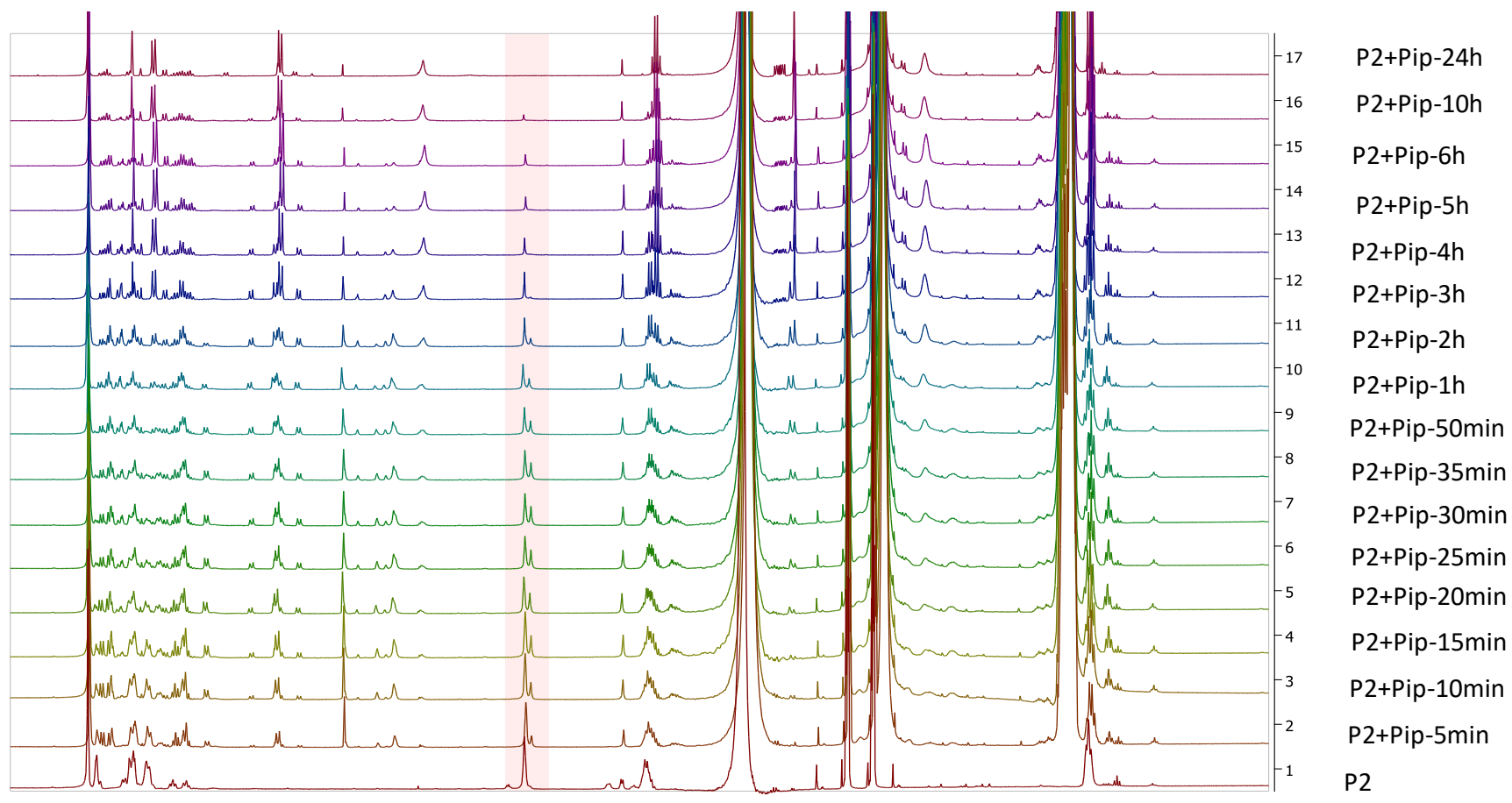

Figure S8: : Time dependent detailed ${ }^{1} \mathrm{H}-\mathrm{NMR}$ (in DMF-d 7 ) of $0.5 \mu$ moles $\mathbf{P 1}$ treated with $50 \mu$ moles Piperidine. 
a

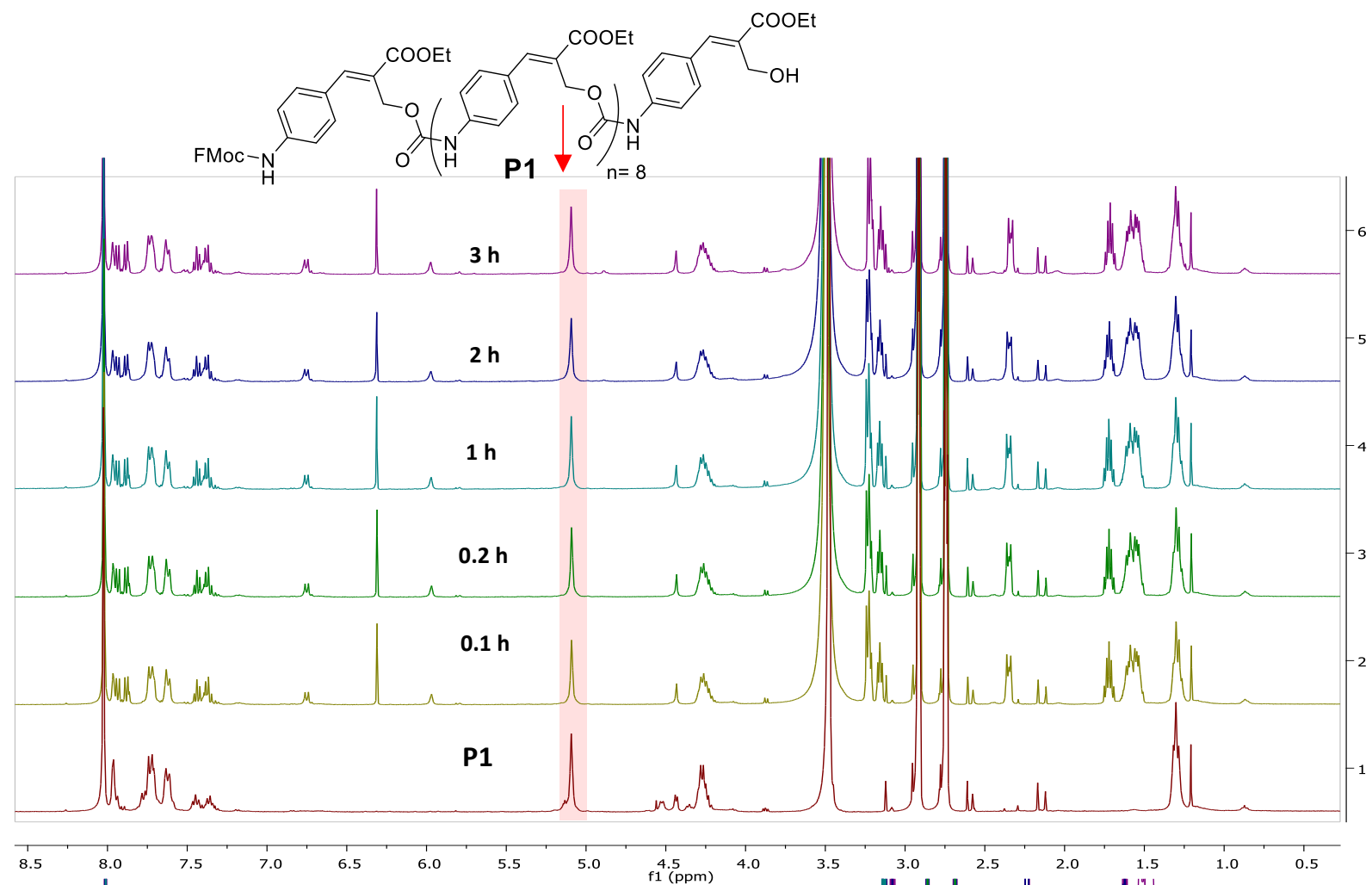

$\mathrm{b}$

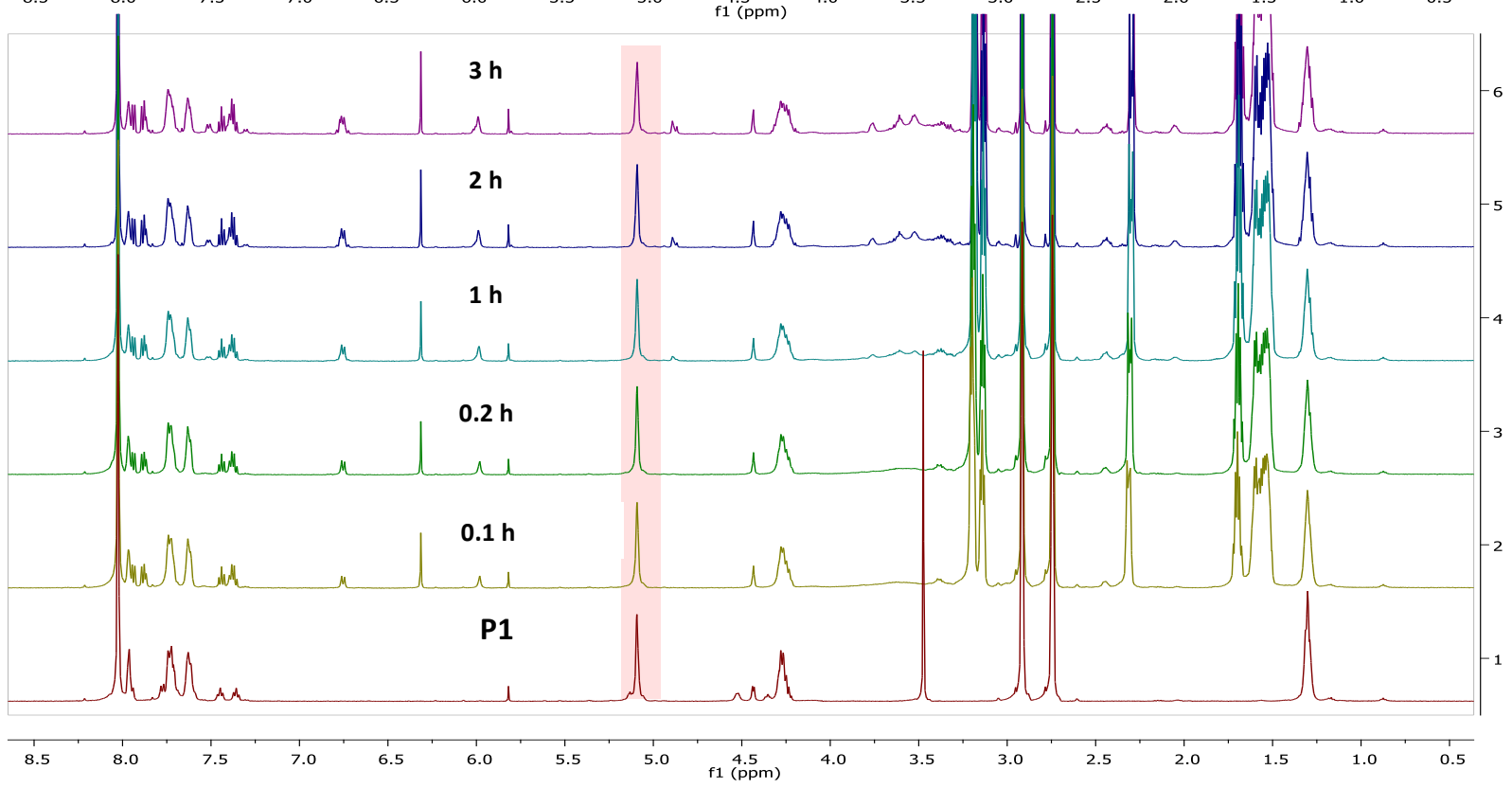

Figure S9: ${ }^{1} \mathrm{H}$ NMR (in $\mathrm{DMF}-\mathrm{d}_{7}$ ) study to find effect of concetration variation on head to tail depolymerization. (a) $0.5 \mu$ moles of P1 was treated with $10 \mu$ moles of DBU; (b) ) $0.5 \mu$ moles of P1 was treated with $50 \mu$ moles of DBU. 


\section{Model Information}

All models for this system are rule based models using the BioNetGen language (Harris, L. A. et al. Bioinfomatics 2016, 32, 3366-3368) and simulation was completed by using BioNetGen on the command line. All model files are included in the zip file included in the supplemental information. The files can be run in BioNetGen by changing the file extension from .txt to .bngl. In order to cover the variation the experimental system is capable of, three models were made.

Model 1 (Scission-only.txt): This model simulates polymer with a nitrobenzene cap, so the only reaction piperidine can have with the polymer is attacking the backbone. It includes the following rules: 1) piperidine can cause backbone scission. 2) Once scission happens head-to-tail depolymerization proceeds from the scission site. 3) piperidine rearrangement occurs quickly. 4) piperidine can attack monomer freed by head to tail depolymerization.

Model 2 (Unzipping-only.txt): This model simulates polymer with an Fmoc cap reacting with DBU only. It includes the following rules: 1) DBU can remove the trigger (Fmoc) unit. 2) Once the trigger has been removed head to tail depolymerization starts.

Model 3 (Both-unzipping-and-scission.txt): This model simulates polymer with an Fmoc cap reacting with piperidine. It includes the following rules. Piperidine can remove the trigger. 2) piperidine can cause backbone scission. 3) Once scission or trigger removal happens head-to-tail depolymerization proceeds from the scission or trigger site. 4) piperidine rearrangement occurs quickly. 5) piperidine can attack monomer freed by head to tail depolymerization.

Polymer dispersity is an important feature that can greatly affect the degradation behavior. For the model, the dispersity was calculated and included in the model by using the following steps. The $\mathrm{M}_{\mathrm{n}}$ was calculated to be $2470 \mathrm{~g} / \mathrm{mol}$ by multiplying the degree of polymerization (10, as determined by NMR) by the molar mass of the repeat unit. Then, the $\mathrm{M}_{\mathrm{w}}$ was calculated by multiplying the $\mathrm{M}_{\mathrm{n}}$ by the PDI (1.32 as determined by GPC). The GPC trace indicated that the mass distribution was roughly a normal Gaussian distribution. Therefor, the standard deviation was calculated using the equation $\delta^{2}=\mathrm{M}_{\mathrm{n}} * \mathrm{M}_{\mathrm{w}}-\mathrm{M}_{\mathrm{n}}^{2}$ (Sheu, W. S. J. Chem. Ed. 2001, 78, 4, 554). The Gaussian distribution was then calculated using the previously determined $\delta$ and the $\mathrm{M}_{\mathrm{n}}$ as the mean. The distribution was normalized over 9-13 mers, due to NMR evidence implying that the vast majority of the purified polymer was chains with 9 to 13 units. In the model the overall polymer concentration was multiplied by the normalized fraction of each mer type in the mixture. 
For example, a polymer concentration of $0.5 \mu$ moles would be $21 \%$ 9-mers, $21 \% 10$-mers, $20 \%$ 11-mers, $20 \% 12$-mers, and 18\% 13-mers. In the model, the starting seed species for the reaction include all 9-13 mers, and any relevent trigger molecules (i.e., DBU or piperidine).

The model is run for 86400 seconds ( 24 hours) of reaction time with 100,000 simulation steps for fast degradation reactions, and for 500,000 seconds (138.8 hours, or 5.8 days) for slow systems.

Tests with model 2 shows that the degradation rate for DBU triggered degradation is concentration independent as long as the concentration of $\mathrm{DBU}$ is equal to or greater than the concentration of polymer end groups (Figure S29). The rate coefficient of head to tail depolymerization was not determined experimentally, however, it was found that a rate coefficient of $0.0002 \mathrm{~s}^{-1}$ gives matching degradation rates for the beginning of the degradation. At later times, the experimental degradation slows more than the simulated degradation. This could be due to the dispersity in the model not completely matching the experimental dispersity, or could be due to some secondary process occuring, such as water in the reaction solvent interferring in the degradation.
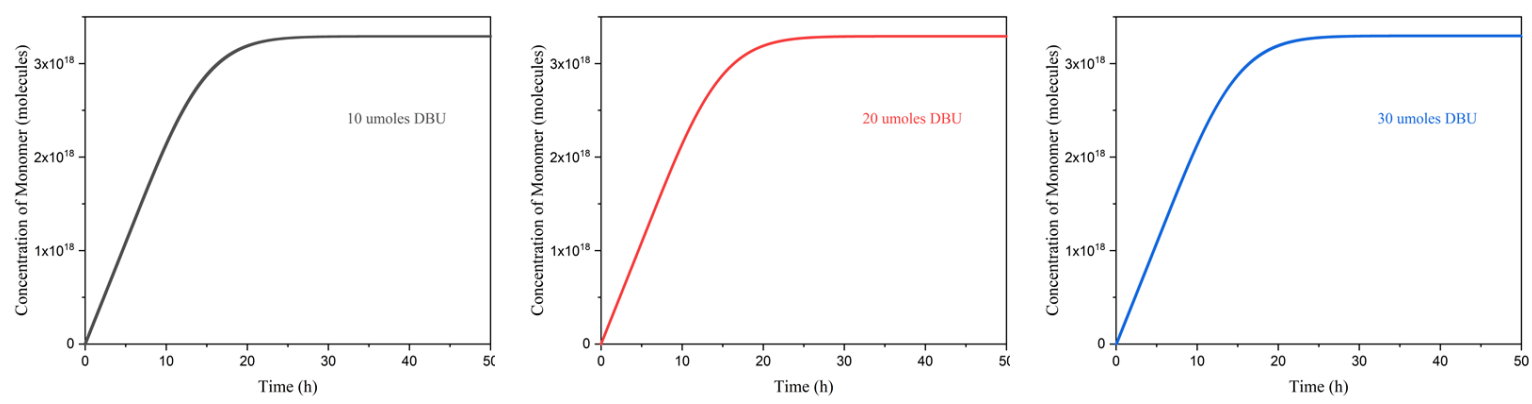

Figure S10: Monomer concentration vs time for DBU concentration ranging from 10-30 $\mu$ moles with $0.5 \mu$ moles of P1 
For model 1 and model 3 we found that the concentration of piperidine has a large affect on the rate of degradation (Figure S11).

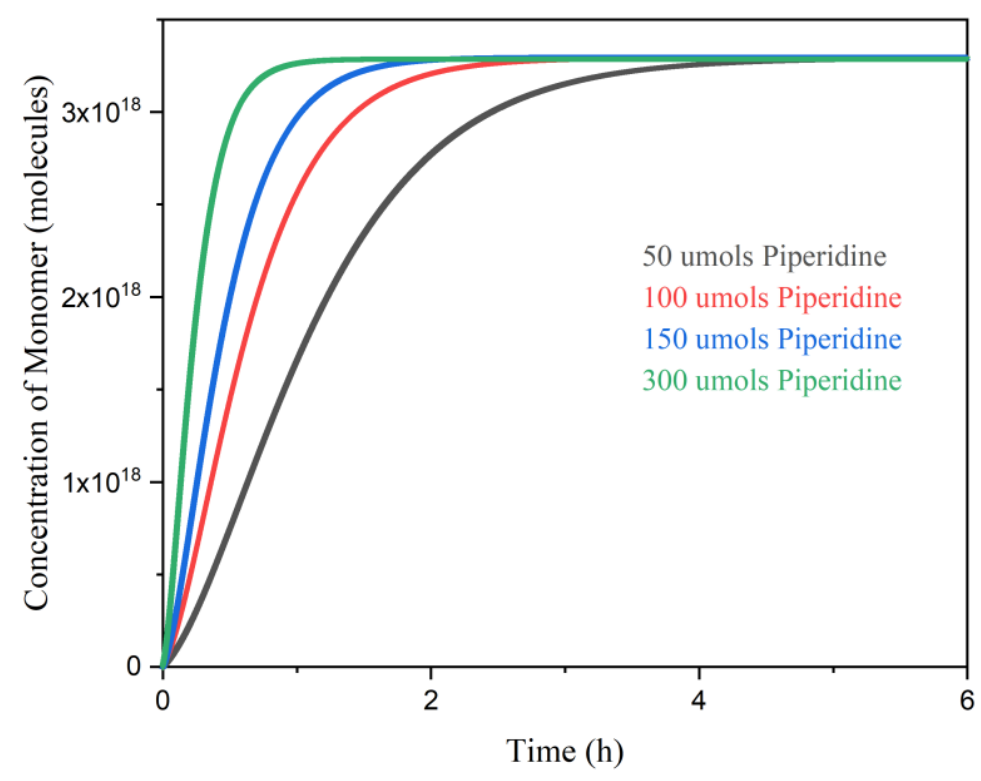

Figure S11: Monomer concentration vs time for piperidine concentration ranging from 50-300 $\mu$ moles with $0.5 \mu$ moles of P2

Experimentally, degradation was measured by the decrease in of double bonds in the backbone. In the model we can track each component of the degradation (i.e., polymer, 9-mer, 8-mer, etc), but cannot directly track the number of double bonds. In order to track degradation through double bonds the model results were processed post simulation to correlate each mixture component with the number of backbone double bonds it contained (i.e., a dimer has one backbone double bond while a trimer has two), then the total concentration of backbone double bonds was tracked to determine overall rates and degradation times. This post simulation processing was primarily completed using the pandas package in python 3.6. 
a)

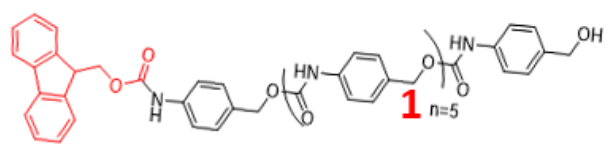

b)

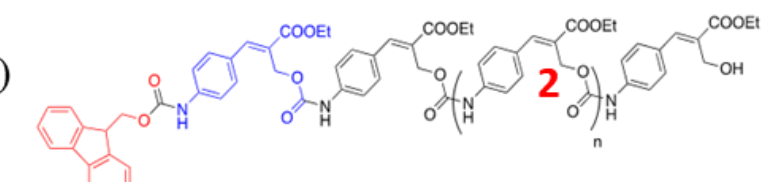

c)

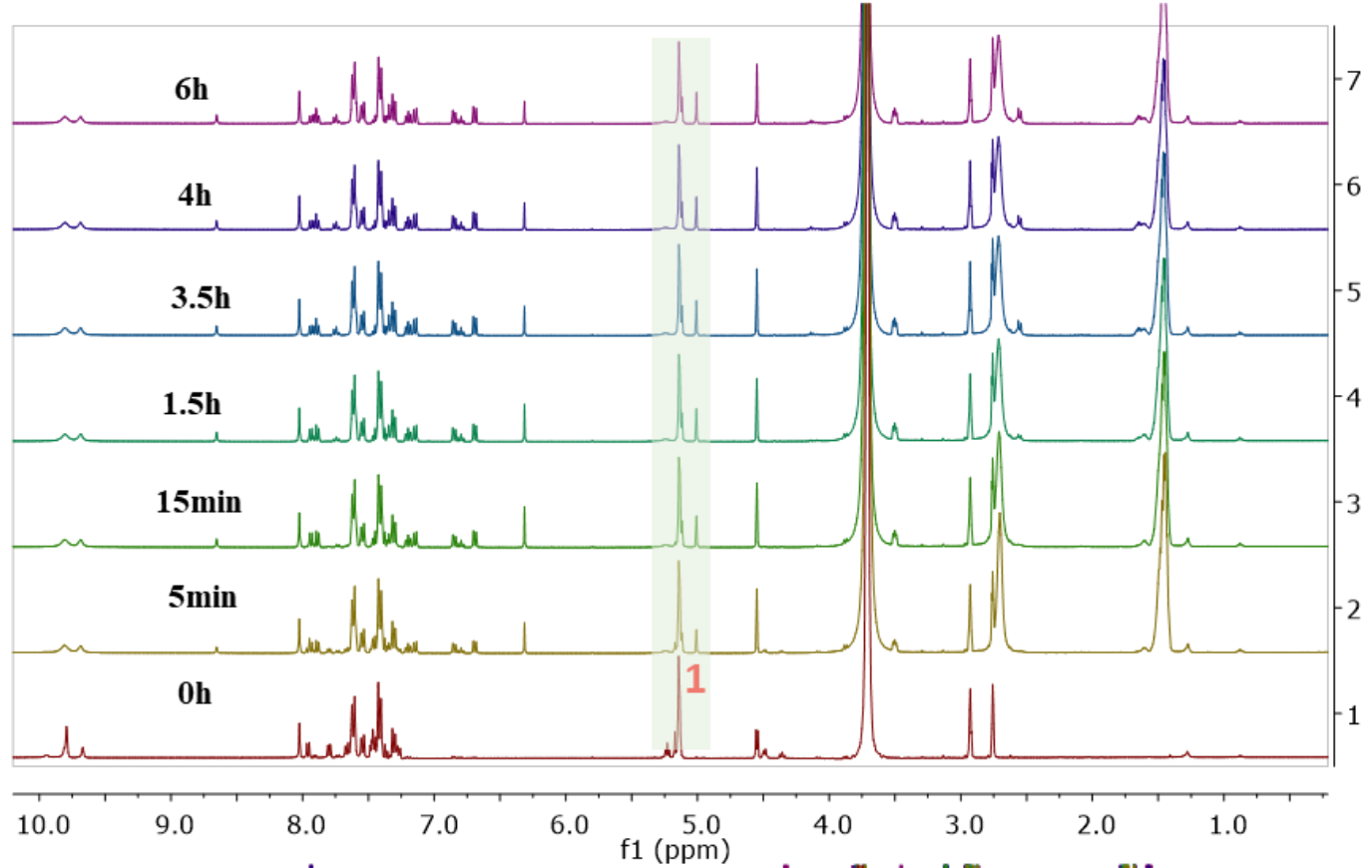

d)

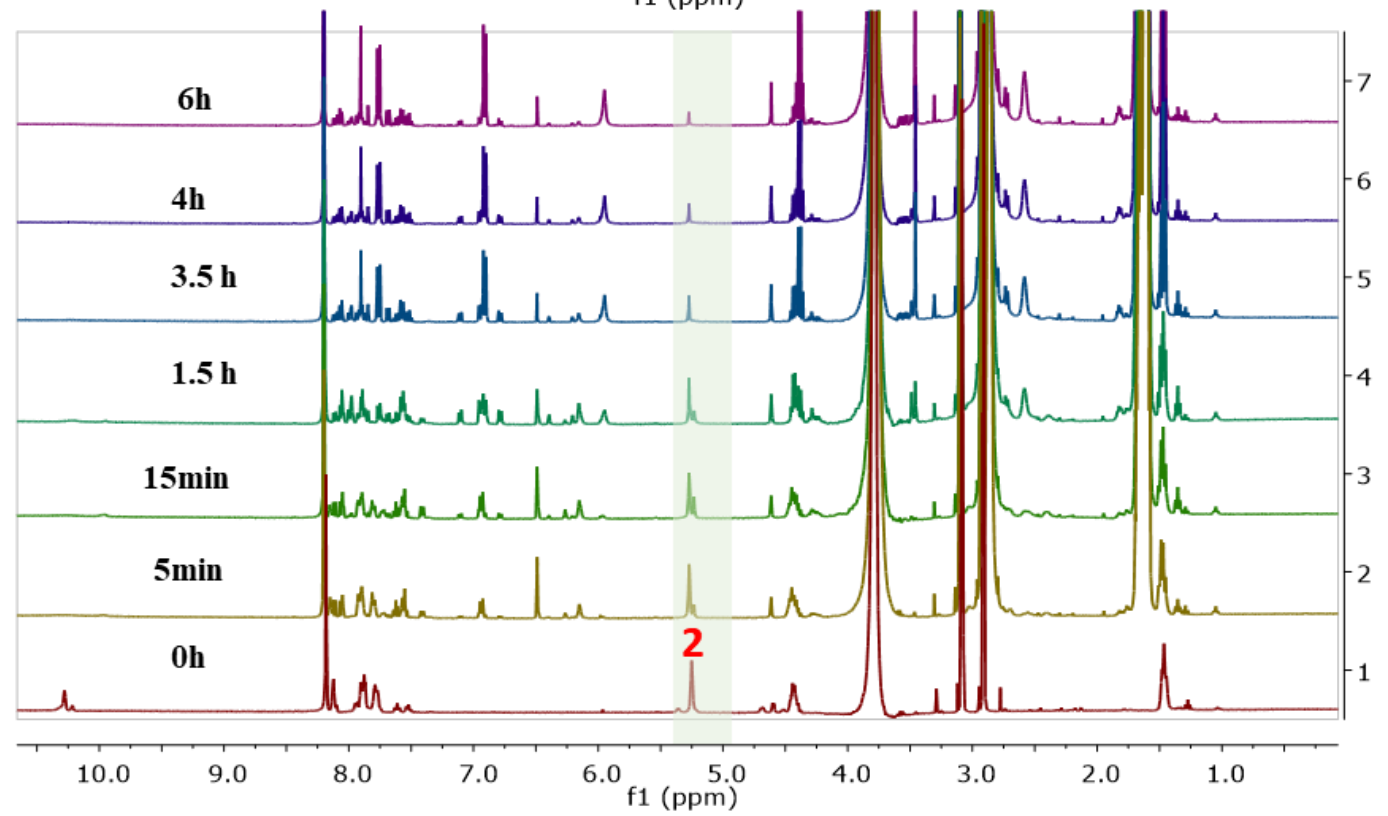

Figure S12: Structure of (a) P4; (b) P1; ${ }^{1} \mathrm{H}-\mathrm{NMR}$ (in DMF-d $\mathrm{d}_{7}$ ) $0.5 \mu$ moles polymer $+50 \mu$ moles piperidine (c) Piperidine treated P4; (d) Piperidine treated P1. 


\section{Nanoparticle formulation:}

$0.5 \mathrm{mg}$ of polymer was dissolved in $0.2 \mathrm{~mL}$ of dichloromethane. To this solution $25 \mu \mathrm{L}$ of Nile red (from $1 \mathrm{mg} / \mathrm{mL}$ stock solution in dichloromethane) solution was added and vortexed for 10 seconds. In a separate vial $1 \mathrm{~mL}$ of $0.5 \mathrm{wt} \%$ polyvinyl alcohol (PVA) solution was made and the previously made solution of polymer and dye was added to it and sonicated (using Qsonica Q125 Sonicator Ultrasonic Homogenizer W/ Probe 125W) for 2 seconds at $40 \%$ amplitude. This suspension was stirred for 12 hours in room temperature to evaporate the organic solvent. After that the solution was centrifuged at $14000 \mathrm{rpm}$ for 10 minutes at $4{ }^{\circ} \mathrm{C}$. The supernatant was discarded, and the solid residue was re-dispersed, and the same steps were repeated twice. After the third wash the solid residue was resuspended in 1x PBS buffer and centrifuged at $2000 \mathrm{rpm}$ for 2 minutes to get rid of any solid residue. This final solution of nanoparticles $(1 \mathrm{mg} / \mathrm{ml})$ was then

used for characterization by DLS and TEM (Figure 5a, S13 and S15). From DLS analysis the encapsulated dye particle size was found to be around $250 \mathrm{~nm}$ (Figure S13). 


\section{DLS Data of P1 based nanoparticles:}
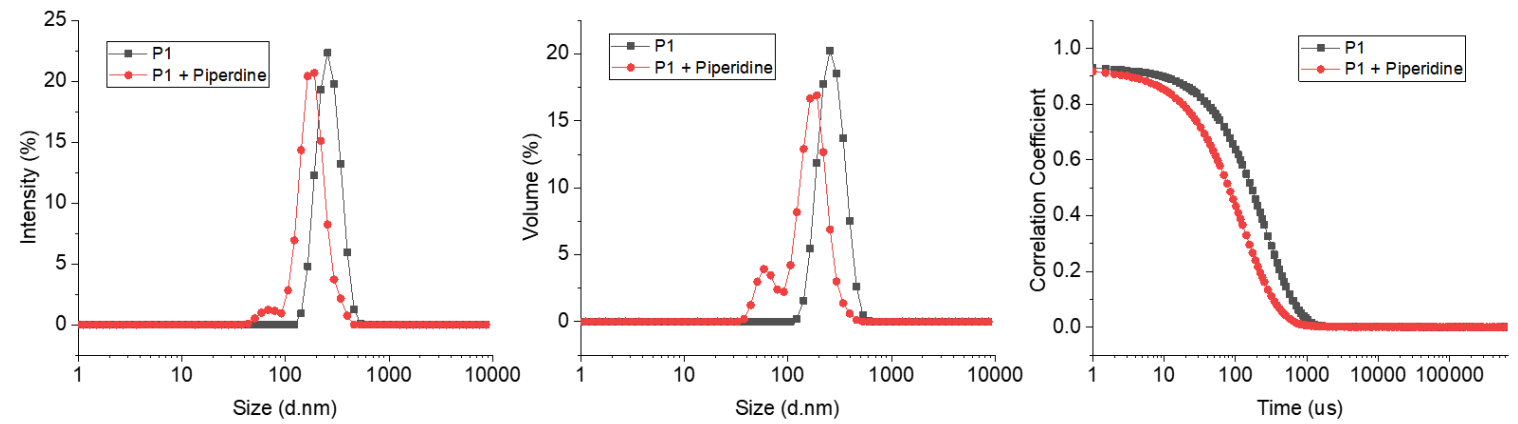

Figure S13: DLS data of the Nile red encapsulated polymer nanoparticles before and after piperidine treatment. Comparison of both data proves polymer nanoparticle degradation upon introduction of piperidine as stimulus in the medium. 


\section{UV-Vis analysis of piperidine initiated dye release from P1-based nanoparticles:}
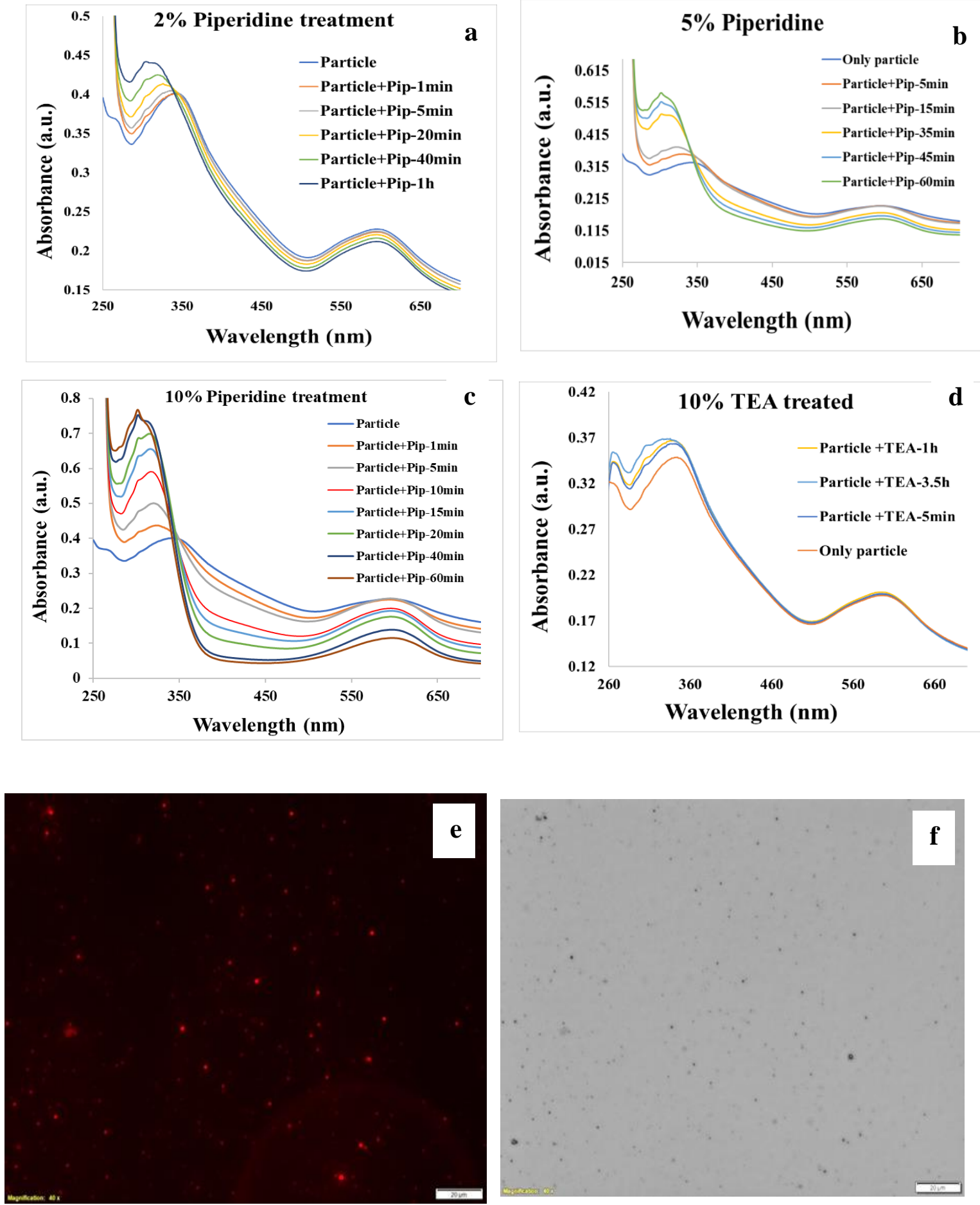

Figure S14: UV-Vis spectra of Nile red encapsulated polymer nanoparticles after a) 2 volume $\%$ piperidine; b) 5 volume \% piperidine; c) 10 volume $\%$ piperidine and d) 10 volume $\% \mathrm{Et}_{3} \mathrm{~N}$ treatment. Nile red encapsulated polymeric nanoparticles under microscope (Scale bar $20 \mu \mathrm{m}$ ):

e) Fluorescence image and f) Bright field image. 


\section{DLS Data of P4 based nanoparticles:}
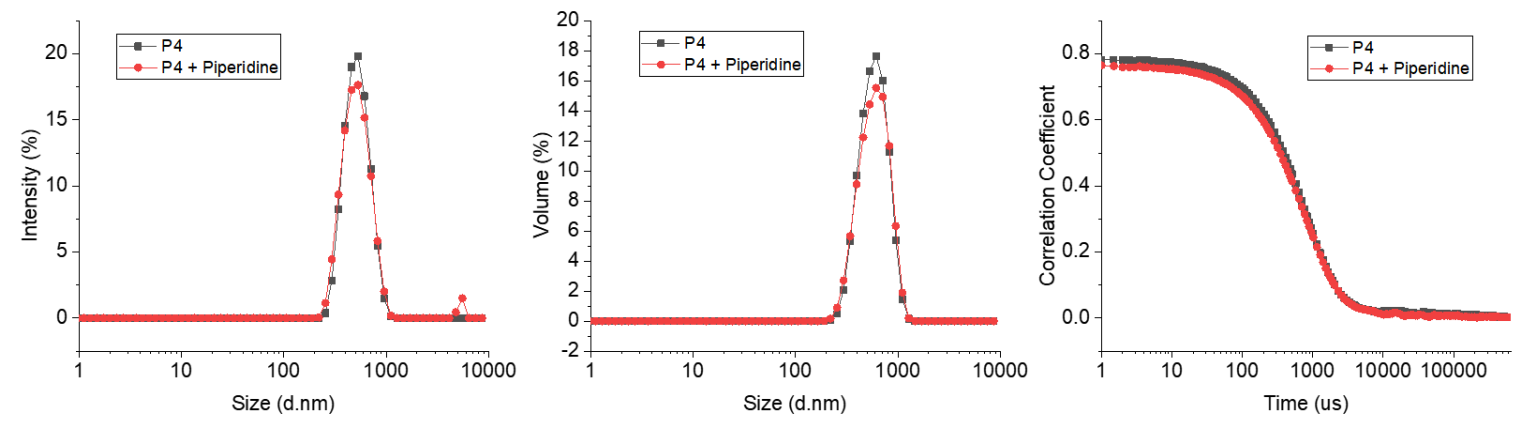

Figure S15: DLS data of the Nile red-encapsulated $\mathbf{P 4}$ polymer nanoparticle before and after piperidine treatment. Comparison of both data proves polymer nanoparticle degradation upon introduction of piperidine as stimulus in the medium. 
UV-Vis analysis of piperidine initiated dye release from P4 based nanoparticles:
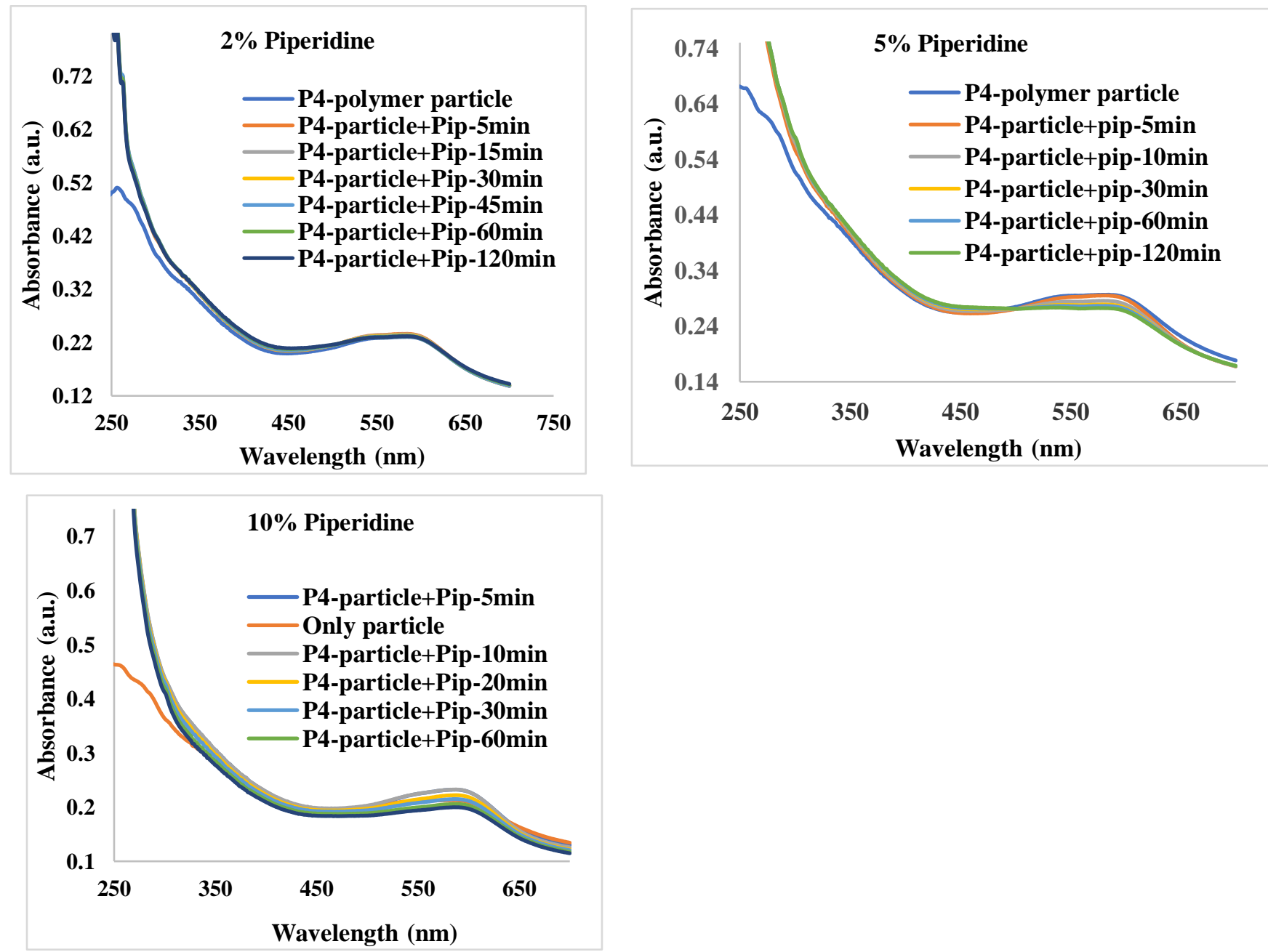

Figure S16: UV-Vis spectra of Nile red encapsulated $\mathbf{P 4}$ based nanoparticles after a) 2 volume \% piperidine; b) 5 volume $\%$ piperidine; c) 10 volume $\%$ piperidine treatment. 
Comparison of dye release efficiency between P1 and P4 based nanoparticles:
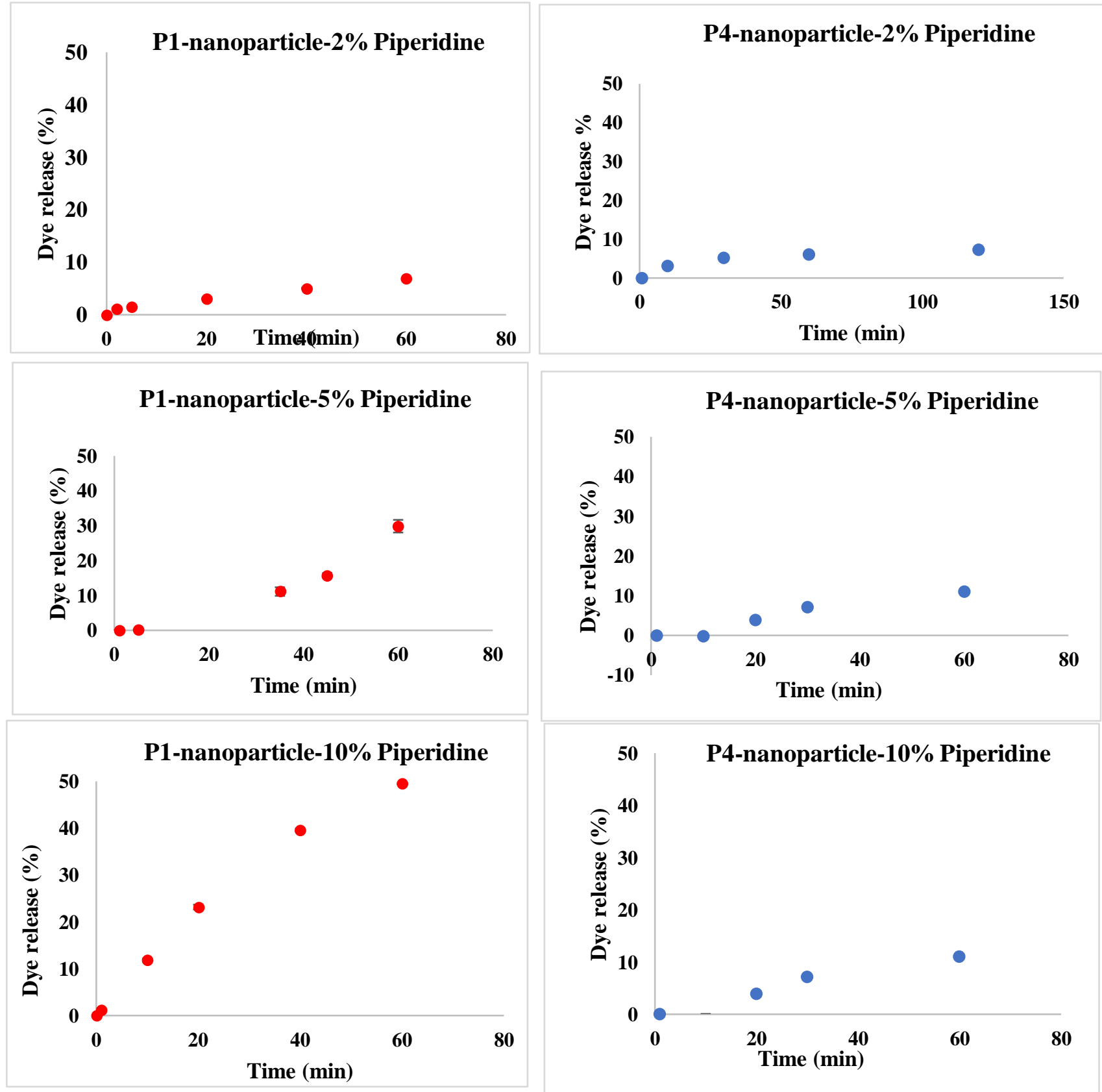

Figure S17: UV-Vis based Dye release study upon different amount of piperidine treatment. (a) Left panel corresponds to $\mathbf{P 1}$ based polymeric nanoparticles. (b) right panel corresponds to P4 based nanoparticles. 

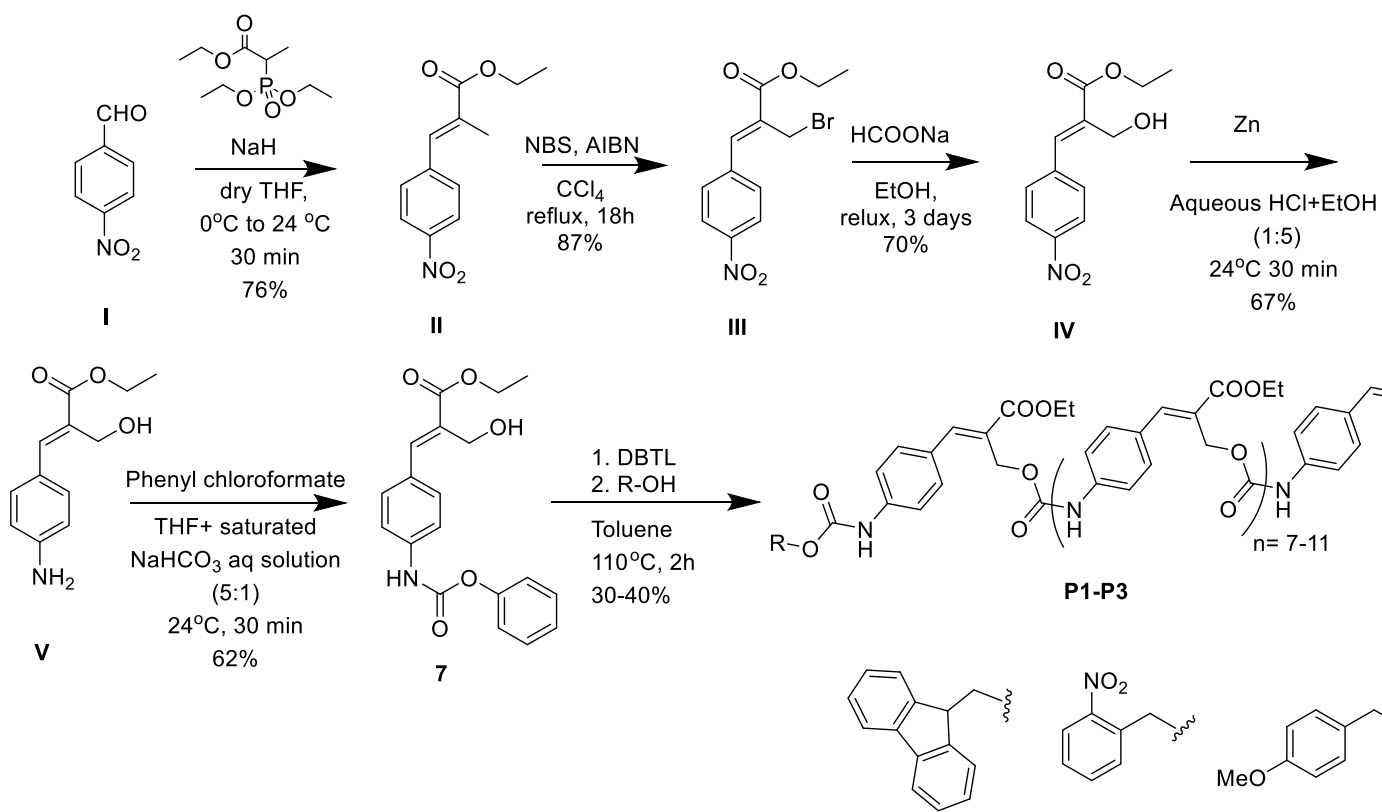

IV $67 \%$

P1

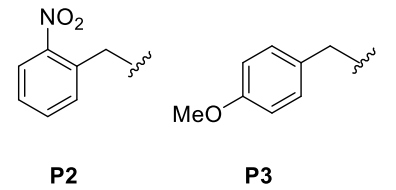

Scheme S1: Synthesis of the multisite triggerable degradable polymers P1, P2 and P3. 


\section{Synthetic procedures:}

Ethyl (E)-2-methyl-3-(4-nitrophenyl)acrylate (II): Sodium hydride (190 mg, 8 mmoles) was taken in $25 \mathrm{~mL}$ dry THF on ice. To this suspension $1.7 \mathrm{~mL}$ (1.89 g, 7.94 mmoles) Triethyl-2phosphonopropionate was added in dropwise fashion. The resulting solution was stirred at $0{ }^{\circ} \mathrm{C}$ for 30 minutes. In another round bottome flask $1 \mathrm{~g}$ ( 6.6 mmoles) 4-Nitrobenzaldehyde was dissolved in $5 \mathrm{~mL}$ dry THF and this solution was addded to the previous one slowly. This reaction mixture was stirred at room temperature for $2 \mathrm{~h}$ under argon atmosphere. A $10 \mathrm{~mL}$ saturated solution of ammonium choride was added slowly to quench the reaction. The product was exracted in ethyl acetate and washed with water and brine for three time consecutively. Then purified by flash column chromatography to obtain $1.4 \mathrm{~g}$ pure white product. Yield $74 \% ; \mathrm{R}_{\mathrm{f}}: 0.4$ in 5:1 Hexane-Ethylacetate; ${ }^{1} \mathrm{H} \mathrm{NMR}\left(400 \mathrm{MHz}, \mathrm{CDCl}_{3}\right) \delta \mathrm{ppm}: 8.25(\mathrm{~d}, J=8.8 \mathrm{~Hz}, 2 \mathrm{H}), 7.68(\mathrm{~s}, 1 \mathrm{H})$, $7.52(\mathrm{~d}, J=8.8 \mathrm{~Hz}, 2 \mathrm{H}), 4.29(\mathrm{q}, J=7.2 \mathrm{~Hz}, 2 \mathrm{H}), 2.11(\mathrm{~s}, 3 \mathrm{H}), 1.35(\mathrm{t}, J=7.2 \mathrm{~Hz}, 3 \mathrm{H}) ;{ }^{13} \mathrm{C} \mathrm{NMR}$ $\left(100 \mathrm{MHz}, \mathrm{CDCl}_{3}\right) \delta \mathrm{ppm}: 167.7,147.1,142.5,135.9,132.2,130.1,123.6,61.2,14.1$. HRMS (ESI-TOF-MS) (m/z): [M+H] $]^{+}$Calculated for $\mathrm{C}_{12} \mathrm{H}_{14} \mathrm{NO}_{4} 236.0917$ found 236.0914.

Ethyl (Z)-2-(bromomethyl)-3-(4-nitrophenyl)acrylate (III): To a solution of Ethyl (E)-2methyl-3-(4-nitrophenyl)acrylate, II $\left(620 \mathrm{mg}, 2.64\right.$ mmoles) in $20 \mathrm{~mL}$ carbontetrachloride $\left(\mathrm{CCl}_{4}\right)$ N-Bromosuccinimide ( $560 \mathrm{mg}, 3.2 \mathrm{mmoles}$ ) was added. The reaction mixture was reluxed at 76 ${ }^{\circ} \mathrm{C}$ for 18 hours under argon atmosphere. Then it was cooled to room temperature and solvent was evaporated and the crude was dissolved in dichloromethane (DCM) and washed with brine solution. Then the product was purified by flash column choromatography to get $720 \mathrm{mg}$ pale yellow crystals. Yield 90\%; Rf : 0.5 in 4:1 Hexane-Ethylacetate; ${ }^{1} \mathrm{H}$ NMR (400 $\left.\mathrm{MHz}, \mathrm{CDCl}_{3}\right) \delta$ ppm: $8.31(\mathrm{~d}, J=8.4 \mathrm{~Hz}, 2 \mathrm{H}), 7.81(\mathrm{~s}, 1 \mathrm{H}), 7.72(\mathrm{~d}, J=8.8 \mathrm{~Hz}, 2 \mathrm{H}), 4.36(\mathrm{q}, J=7.0 \mathrm{~Hz}, 2 \mathrm{H}), 4.30$ $(\mathrm{s}, 2 \mathrm{H}), 1.39(\mathrm{t}, J=7.1 \mathrm{~Hz}, 3 \mathrm{H}) ;{ }^{13} \mathrm{C} \mathrm{NMR}\left(100 \mathrm{MHz}, \mathrm{CDCl}_{3}\right) \delta \mathrm{ppm}: 165.2,147.8,140.6,139.4$, 132.3, 130.1, 124.0, 61.9, 25.3, 14.2. HRMS (ESI-TOF-MS) (m/z): $[\mathrm{M}+\mathrm{H}]^{+}$Calculated for $\mathrm{C}_{12} \mathrm{H}_{13} \mathrm{BrNO}_{4} 314.0022$ found 314.0120.

Ethyl (E)-2-(hydroxymethyl)-3-(4-nitrophenyl)acrylate (IV): Ethyl (Z)-2-(bromomethyl)-3-(4nitrophenyl)acrylate, III (500 mg, 1.6 mmoles) and sodium formate (1.1 g, 16 mmoles) were taken in $15 \mathrm{~mL}$ Ethanol. The solution was refluxed at $78{ }^{\circ} \mathrm{C}$ for 3 days. The solvent was evaporated in under vaccum. $30 \mathrm{~mL}$ ethylacetate was added to it and the organic layer was washed with water. Then the ehtyl acetate was evaporated to get the crude product which was purfied by flash column

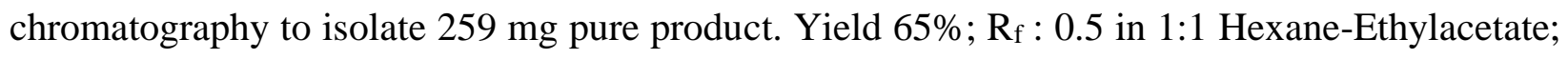


${ }^{1} \mathrm{H}$ NMR (400 MHz, $\left.\mathrm{CDCl}_{3}\right) \delta$ ppm: $8.27(\mathrm{~d}, J=8.5 \mathrm{~Hz}, 2 \mathrm{H}), 7.81(\mathrm{~s}, 1 \mathrm{H}), 7.63(\mathrm{~d}, J=8.5 \mathrm{~Hz}$, $2 \mathrm{H}), 4.41(\mathrm{~s}, 2 \mathrm{H}), 4.34(\mathrm{q}, J=7.1 \mathrm{~Hz}, 2 \mathrm{H}), 1.38(\mathrm{t}, J=7.1 \mathrm{~Hz}, 3 \mathrm{H}) ;{ }^{13} \mathrm{C} \mathrm{NMR}\left(100 \mathrm{MHz}, \mathrm{CDCl}_{3}\right)$ $\delta$ ppm: 167.2, 147.9, 141.0, 139.5, 134.3, 130.4, 123.8, 61.6, 57.7, 14.3. HRMS (ESI-TOF-MS) $(\mathrm{m} / \mathrm{z}):[\mathrm{M}+\mathrm{H}]^{+}$Calculated for $\mathrm{C}_{12} \mathrm{H}_{14} \mathrm{NO}_{5} 252.0865$ found 252.0866.

Methyl (E)-3-(4-aminophenyl)-2-(hydroxymethyl)acrylate (V): To a stirring solution of Ethyl (E)-2-(hydroxymethyl)-3-(4-nitrophenyl)acrylate, IV (250 mg, 1mmol) in $10 \mathrm{~mL}$ methanol and $1 \mathrm{~mL}$ Conc. $\mathrm{HCl}$, metallic $\mathrm{Zn}$ was added in 5 batches ( total $650 \mathrm{mg}, 10 \mathrm{mmoles}$ ). The reaction was stirred at room temperature for 30 mintues. Completion of the reaction was monitored by TLC. Then the solution was filtered through celite bed and solvent was evaporated to obtain $210 \mathrm{mg}$ yellowish solid which is directly used for next step without further purfication. $R_{f}: 0.2$ in $1: 1$ Hexane-Ethylacetate; ${ }^{1} \mathrm{H}$ NMR (400 MHz, $\left.\mathrm{CDCl}_{3}\right) \delta$ ppm: $7.78(\mathrm{~s}, 1 \mathrm{H}), 7.34(\mathrm{~d}, J=8.4 \mathrm{~Hz}, 2 \mathrm{H})$, $6.67(\mathrm{~d}, J=8.4 \mathrm{~Hz}, 2 \mathrm{H}), 4.55(\mathrm{~s}, 2 \mathrm{H}), 4.28(\mathrm{q}, J=7.2 \mathrm{~Hz}, 2 \mathrm{H}), 1.37(\mathrm{t}, J=7.2 \mathrm{~Hz}, 3 \mathrm{H}) ;{ }^{13} \mathrm{C} \mathrm{NMR}$ $\left(100 \mathrm{MHz} \mathrm{CDCl}_{3}\right) \delta$ ppm: 168.5, 147.9, 143.0, 131.8, 127.2, 124.6, 114.7, 60.8, 58.1, 14.3.

Ethyl (E)-2-(hydroxymethyl)-3-(4-((phenoxycarbonyl)amino)phenyl)acrylate (7): In a mixed solvent of $10 \mathrm{~mL}$ THF and 5mL saturated bicarbonate, Methyl (E)-3-(4-aminophenyl)-2(hydroxymethyl)acrylate, V (200 mg, 0.91 mmoles) was taken. To this solution phenyl chloroformate was added $(113 \mu \mathrm{L}, 0.91$ mmoles) slowly and stirred for 30 minutes at room temperature. After completion of the reaction $20 \mathrm{~mL}$ ethylacetate was added to it and the organic layer was washed with brine and water for couple of times. Then the ethylacetate was evaporated and the crude was purified by flash column chromatograhy to obtain $190 \mathrm{mg}$ pure product as pale yellow solid. Yield 62\%, Rf 0.4 in 1:1 Hexane-Ethylacetate; ${ }^{1} \mathrm{H}$ NMR (400 MHz, $\left.\mathrm{CDCl}_{3}\right) \delta$ ppm: $7.81(\mathrm{~s}, 1 \mathrm{H}), 7.58-7.47(\mathrm{~m}, 4 \mathrm{H}), 7.47$ - $7.34(\mathrm{~m}, 2 \mathrm{H}), 7.28-7.24(\mathrm{~m}, 2 \mathrm{H}), 7.21-7.18(\mathrm{~m}, 2 \mathrm{H}), 4.50$ $(\mathrm{d}, J=6.6 \mathrm{~Hz}, 2 \mathrm{H}), 4.33(\mathrm{q}, J=7.1 \mathrm{~Hz}, 2 \mathrm{H}), 2.32(\mathrm{~s}, 1 \mathrm{H}), 1.37(\mathrm{t}, J=7.1 \mathrm{~Hz}, 3 \mathrm{H}) ;{ }^{13} \mathrm{C} \mathrm{NMR}(100$ $\left.\mathrm{MHz} \mathrm{CDCl}_{3}\right) \delta$ ppm: 168.1, 151.5, 150.4, 141.8, 138.5, 130.9, 130.2, 130.0, 129.5, 125.9, 121.6, 118.5, 61.2, 58.0, 14.3. HRMS (ESI-TOF-MS) (m/z): $[\mathrm{M}+\mathrm{Na}]^{+}$Calculated for $\mathrm{C}_{19} \mathrm{H}_{20} \mathrm{NO}_{5} \mathrm{Na}$ 364.1155 found 364.1220 . 


\section{General method for poylmer synthesis:}

The toluene solution of the monomer, $7(100 \mathrm{mg}, 0.30 \mathrm{mmol})$ was heated at $110^{\circ} \mathrm{C}$ for 10 minutes under argon atmosphere. To this solution DBTL catalyst $(9 \mu \mathrm{L}, 0.015 \mathrm{mmol})$ was added quickly in presence of argon flow and the heating was continued for 15 minutes. Finally, a toluene solution of the capping agent (2-Nitrobenzylalcohol for P2, 9-Fluorenylmethyl alcohol for P1, methoxy benzyl alcohol for P3) was added, and the reaction was continued for 2 hours at $110{ }^{\circ} \mathrm{C}$ under argon following precipitation from diethyl ether to produce the desired Polymers P1, P2 and P3. The molecular weight distribution and molecular weight of the product $\mathbf{P} 2$ were determined by THF-GPC using THF as the eluent, revealing an $M \mathrm{n}$ of 4600 and $P D$ 1.2. The degree of polymerization was determined to be $\sim 14$ by ${ }^{1} \mathrm{H}$ NMR analysis (Figure S28). For P1 the Mn was 4400 and PD 1.32 and degree of polymerization is 10 (Figure S29). For P3 Mn was 5000 and PD 1.12 and degree of polymerization is 8 (Figure S30).

Polymer P1: White powder, Yield 35\%; ${ }^{1} \mathrm{H}$ NMR (400 MHz, DMSO-d 6 ) $\delta$ ppm: 10.11 (s, 5H), 10.08 (s, 1H), 7.88 (s, 9H), $7.73(\mathrm{~m}, 3 \mathrm{H}), 7.62-7.56(\mathrm{~m}, 14 \mathrm{H}), 7.52-7.42(\mathrm{~m}, 14 \mathrm{H}), 7.40-7.38$ (m, 3H), 7.35-7.33 (m, 3H), 5.06 (s, 2H), 4.97 (s, 12H), 4.54 (s, 2H), 4.30 (s, 2H), 4.26-4.18 (m, 15H), 1.31-1.25 (m, 24H); $\left.{ }^{13} \mathrm{C} \mathrm{NMR} \mathrm{(100} \mathrm{MHz,} \mathrm{CDCl}_{3}\right) \delta$ ppm: 168.2, 167.3, 153.2, 145.4, 143.6, 141.4, 139.8, 130.9, 128.7, 127.8, 127.1, 124.9, 120.1, 118.5, 67.0, 61.3, 61.1, 60.3, 57.9, 53.4, 50.9, 47.0, 29.7, 14.3, 13.6. $\mathrm{Mn}=4.4 \mathrm{kDa} ; \mathrm{DP}=\sim 10 ; Đ=1.32$.

Polymer P2: Yellowish white powder, Yield 40\%; ${ }^{1} \mathrm{H}$ NMR (400 MHz, DMSO-d 6 ) $\delta$ ppm: 10.20 (s, 1H), $10.10(\mathrm{~s}, 4 \mathrm{H}), 10.00(\mathrm{~s}, 1 \mathrm{H}), 8.13(\mathrm{~m}, 2 \mathrm{H}), 7.87-7.77(\mathrm{~m}, 5 \mathrm{H}), 7.75-7.63(\mathrm{~m}, 3 \mathrm{H}), 7.62-$ $7.53(\mathrm{~m}, 17 \mathrm{H}), 5.51-7.48(\mathrm{~m}, 11 \mathrm{H}), 5.50$ (s, 2H), 5.05 (s, 2H), 4.98 (s, 9H), 4.26-4.19 (m, 15H), 1.29-1.06 (m, 29H); ${ }^{13} \mathrm{C}$ NMR (100 MHz, DMSO-d $) \delta$ ppm: 167.8, 167.0, 153.5, 153.2, 147.8, 144.8, 141.6, 141.3, 141.1, 140.8, 132.4, 131.4, 128.2, 125.4, 125.1, 118.6, 118.5, 118.3, 63.2, $61.2,60.8,59.9,55.6,14.7,14.6 . \mathrm{Mn}=4.6 \mathrm{kDa} ; \mathrm{DP}=\sim 13 ; \mathrm{Ð}=1.28$.

Polymer P3: White powder, Yield 30\%, ${ }^{1} \mathrm{H}$ NMR (400 MHz, DMSO-d 6 ) $\delta$ ppm 10.09 (s, 5H), $10.02(\mathrm{~s}, 3 \mathrm{H}), 7.87(\mathrm{~s}, 7 \mathrm{H}), 7.63-7.56(\mathrm{~m}, 21 \mathrm{H}), 7.53-7.51(\mathrm{~m}, 16 \mathrm{H}), 7.36(\mathrm{~m}, 7 \mathrm{H})$, 6.95-6.93 (m, 4H), 6.87 (s, 2H), 5.19-5.17 (m, 3H), 5.08 (s, 6H), 5.06-4.98 (m, 14H), 4.24-4.19 (m, 18H), 3.75 (s, 7H), 3.71 (s, 3H), 1.31-1.28 (m, 30H); ${ }^{13} \mathrm{C}$ NMR (100 MHz, DMSO-d $) \delta$ ppm: 168.1, 167.1, 159.6, 153.0, 145.1, 142.0, 139.6, 130.9, 130.3, 130.2, 128.8, 127.8, 125.1, 118.5, 114.1, 114.0, 67.1, 66.8, 61.3, 61.1, 60.3, 58.0, 55.3, 53.4, 31.9, 29.7, 29.4, 27.6, 27.1, 22.7, 14.3, 14.1, 13.7. $\mathrm{Mn}=\sim 5.0 \mathrm{kDa} ; \mathrm{DP}=\sim 8 ; \mathrm{Ð}=1.12$. 
Polymer P4: P4 was synthesized following the same method described above using the monomer phenyl (4-(hydroxymethyl)phenyl)carbamate (which was synthesised following the method described in J. Org. Chem. 2013, 78, 3159-3169) and 9-fluorenylmethyl alcohol was used as capping agent.

White powder, Yield 50\%, ${ }^{1} \mathrm{H}$ NMR (400 MHz, DMF-d7) $\delta$ ppm 10.27 (s, 1H), 9.80 (s, 9H), 9.68 (s, 2H), $7.96(\mathrm{~d}, J=8.1 \mathrm{~Hz}, 2 \mathrm{H}), 7.80(\mathrm{~d}, J=8.1 \mathrm{~Hz}, 2 \mathrm{H}), 7.68-7.61(\mathrm{~m}, 19 \mathrm{H}), 7.55$ (d, J-8.1 Hz, 2H), 7.49-7.45 (m, 5H), 7.43-7.41 (m, 19H), 7.32-7.26 (m, 6H), $5.23(\mathrm{t}, J=5.8 \mathrm{~Hz}, 1 \mathrm{H}), 5.15(\mathrm{~s}$, $22 \mathrm{H}), 4.55(\mathrm{~d}, J=5.8 \mathrm{~Hz}, 2 \mathrm{H}), 4.50(\mathrm{~d}, J=7.2 \mathrm{~Hz}, 2 \mathrm{H}), 4.36$ (t, $J=7.2 \mathrm{~Hz}, 1 \mathrm{H}) . \mathrm{Mn}=\sim 2.0 \mathrm{kDa} ; \mathrm{DP}$ $=\sim 10 ; \mathrm{Ð}=1.29$. 
NMR Spectra:

ms-02-188 par 3

ms-02-188 par

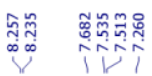

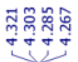

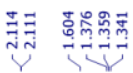

:
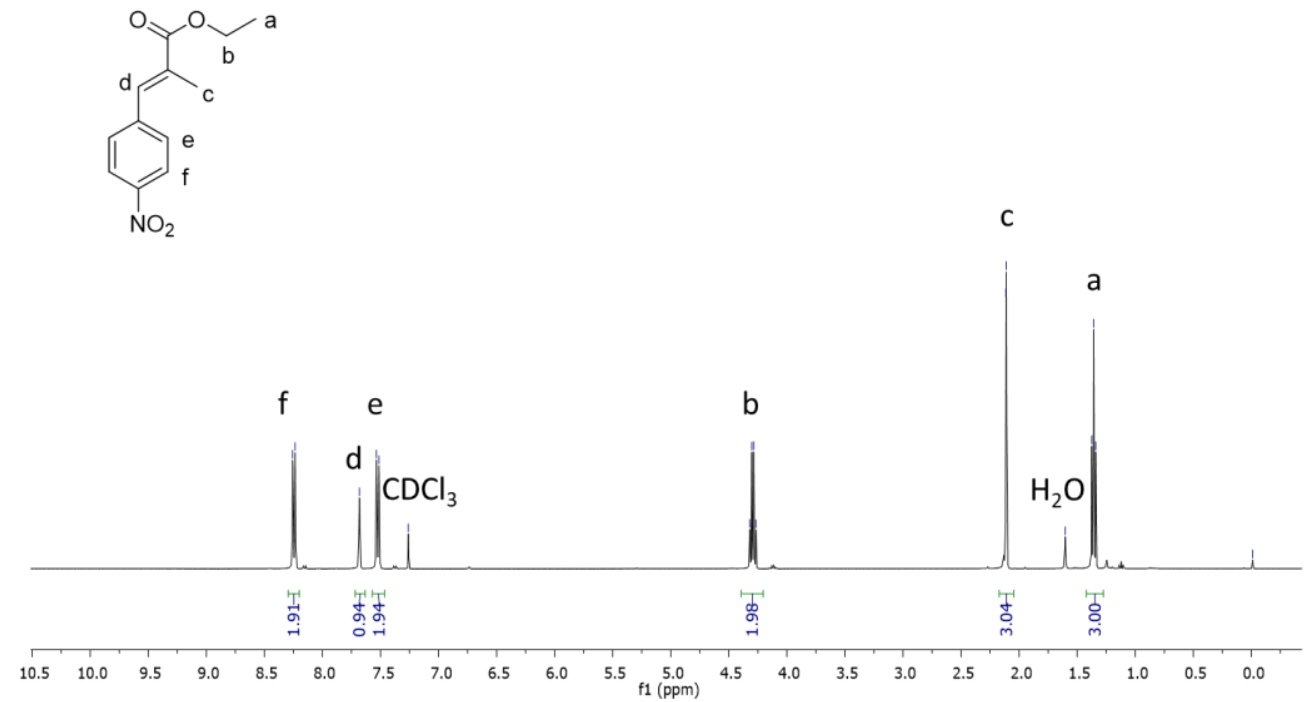

Figure S18: ${ }^{1} \mathrm{H}$ NMR of Compound II

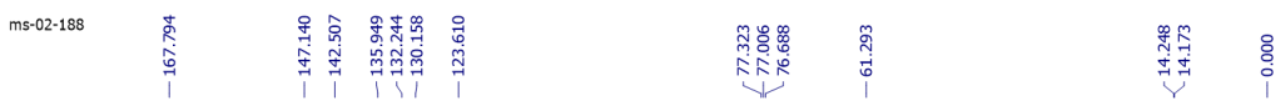<smiles>CCOC(=O)/C(C)=C/c1ccc([N+](=O)[O-])cc1</smiles>
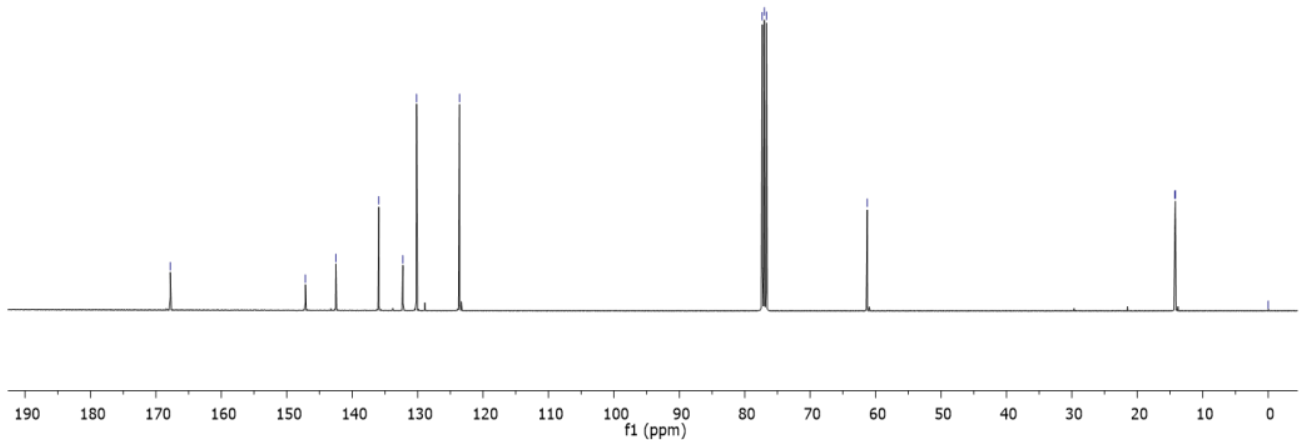

Figure S19: ${ }^{13} \mathrm{C}$ NMR of Compound II 

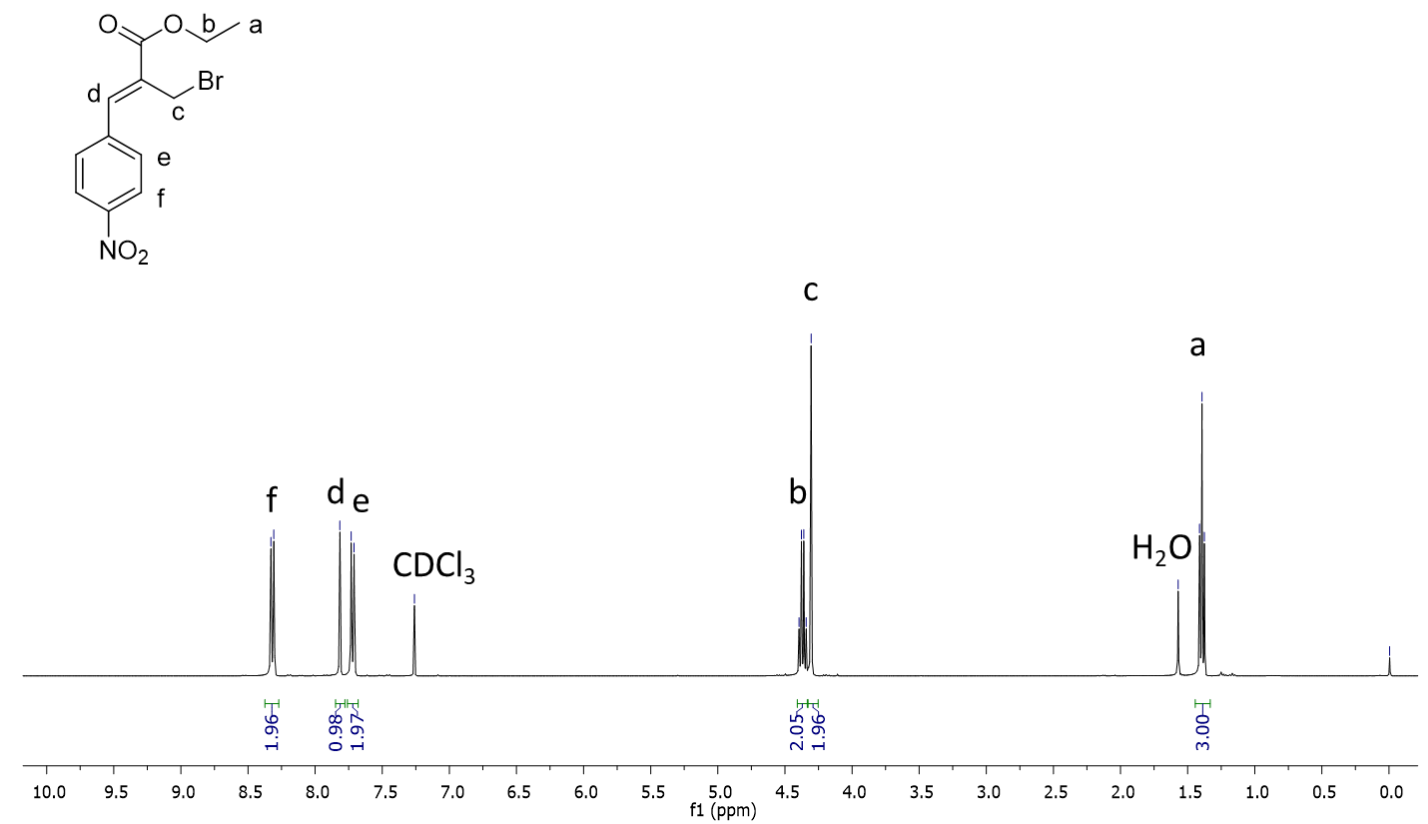

Figure S20: ${ }^{1} \mathrm{H}$ NMR of Compound III 


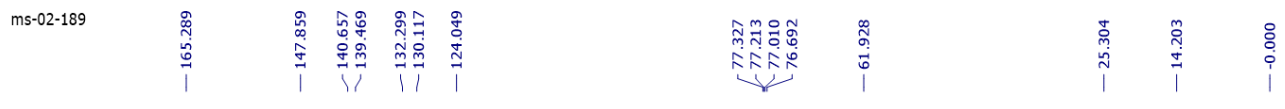<smiles>CCOC(=O)/C(=C/c1ccc([N+](=O)[O-])cc1)CBr</smiles>
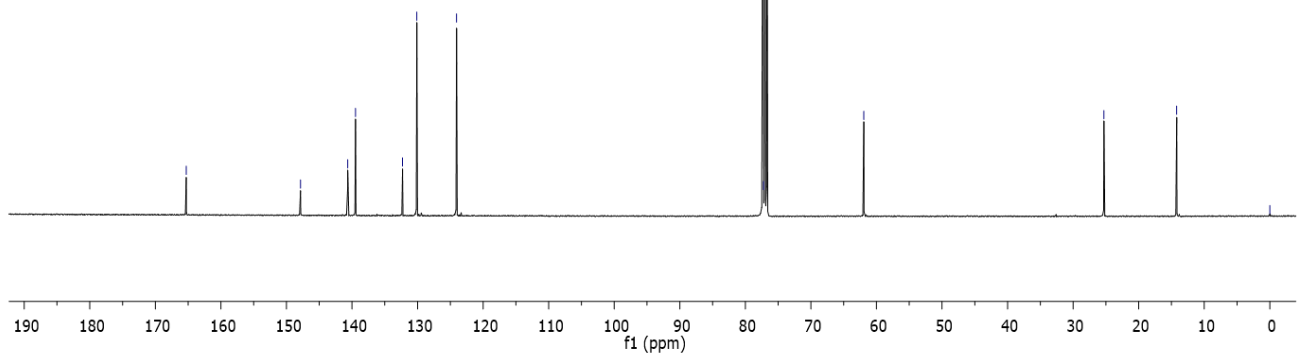

Figure S21: ${ }^{13} \mathrm{C}$ NMR of Compound III

ms-02-191 par 4 ms-02-191 par 4
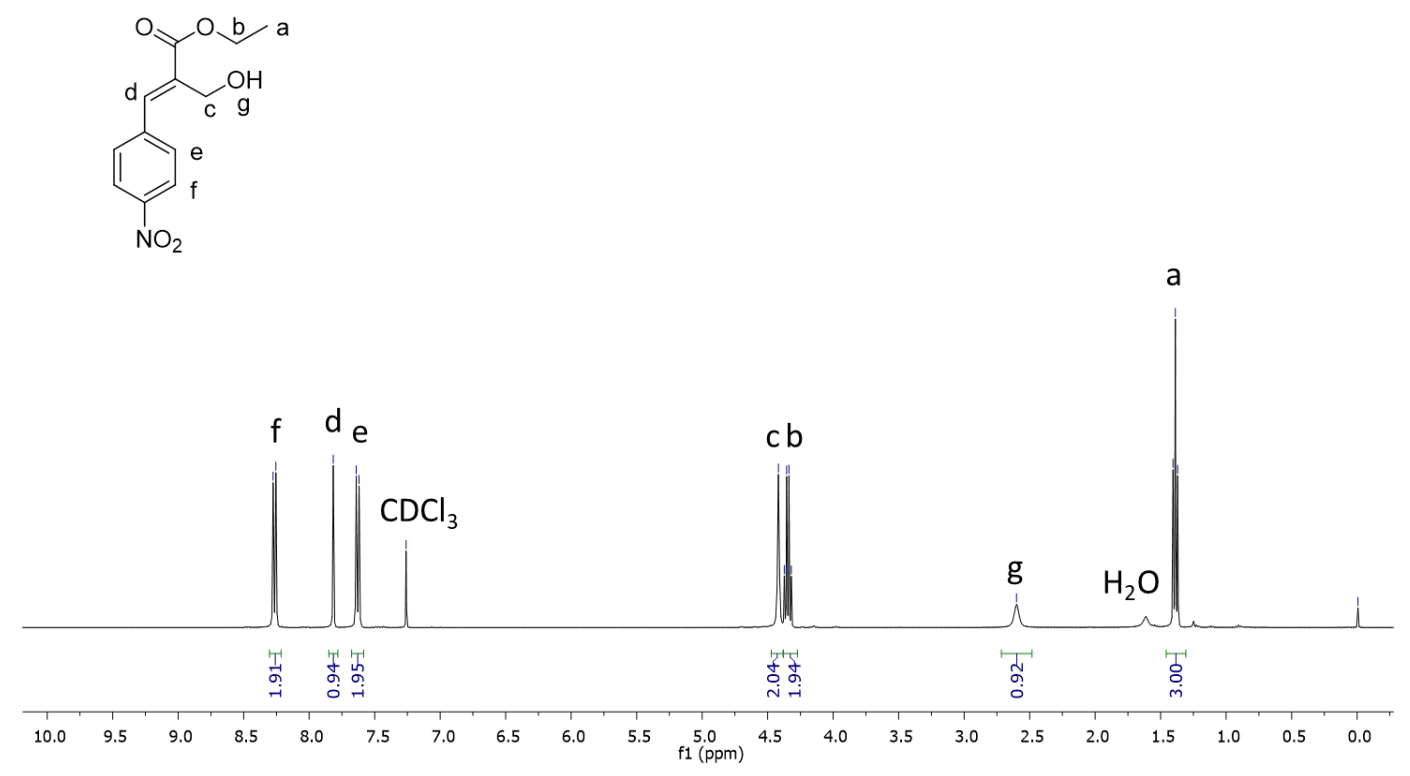

Figure S22: ${ }^{1} \mathrm{H}$ NMR of Compound IV 

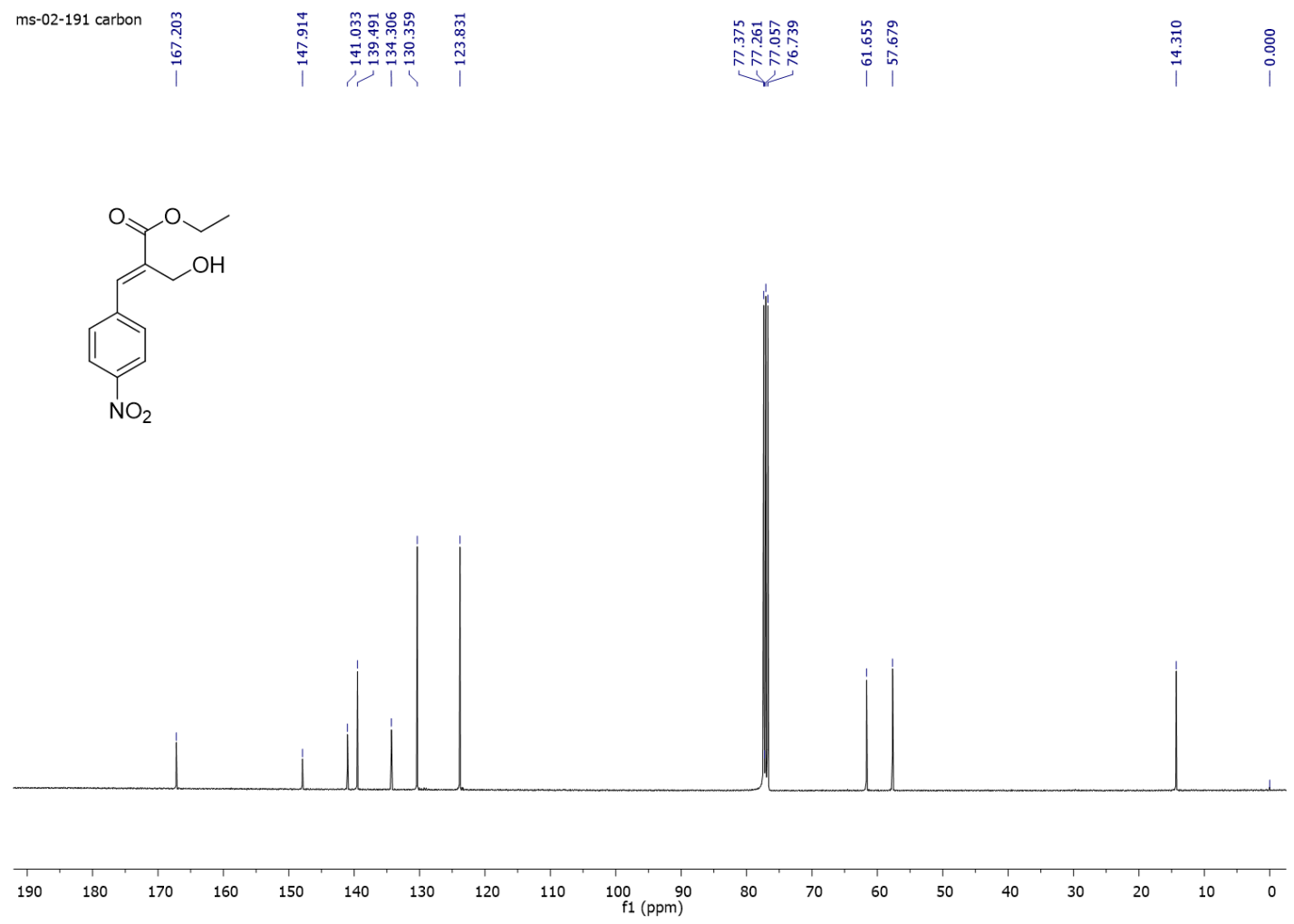

Figure S23: ${ }^{13} \mathrm{C}$ NMR of Compound IV
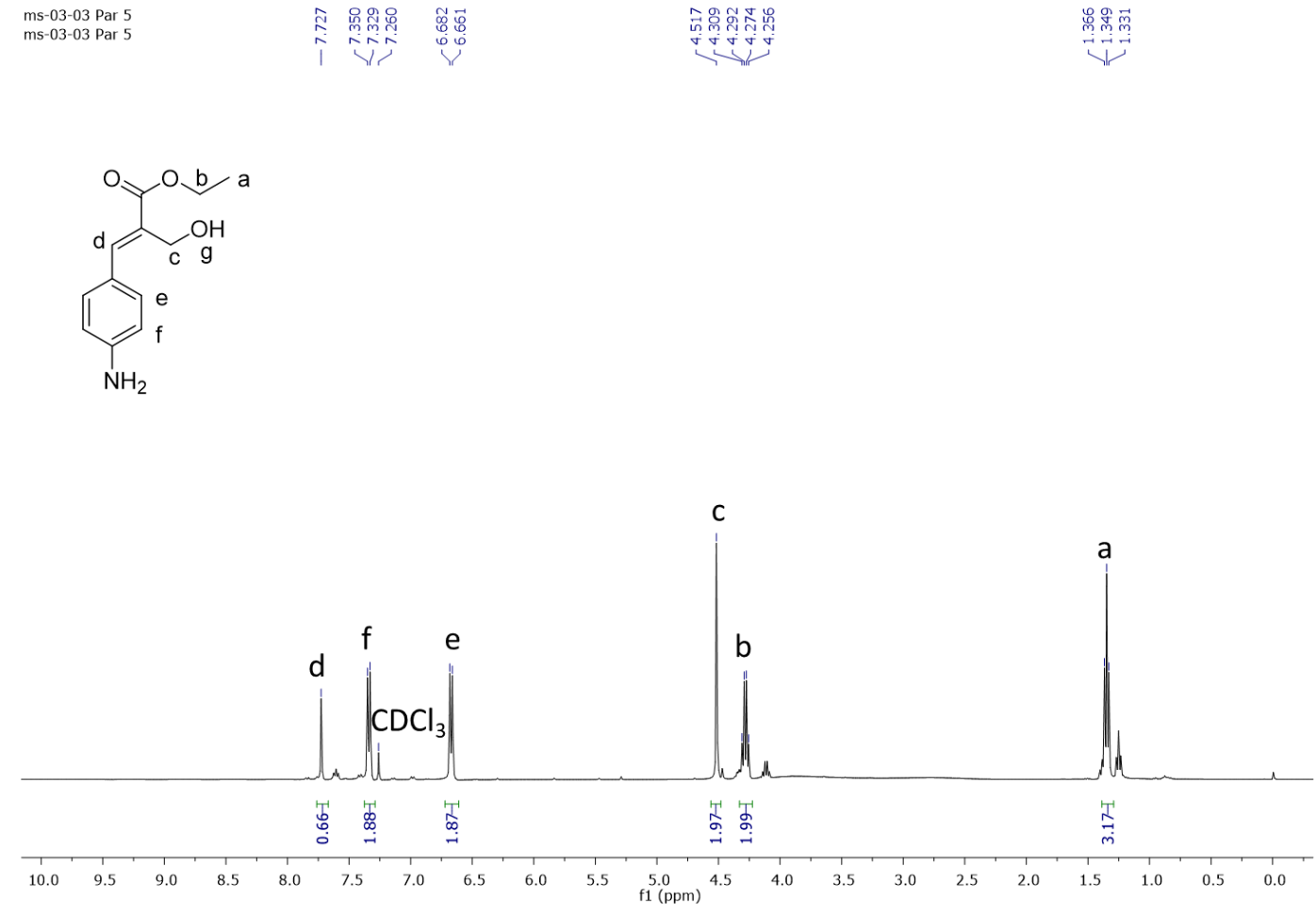

Figure S24: ${ }^{1} \mathrm{H}$ NMR of Compound $\mathbf{V}$ 


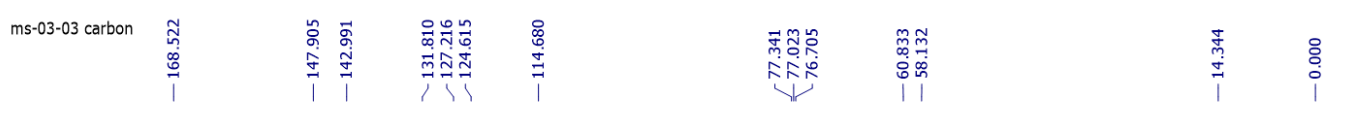
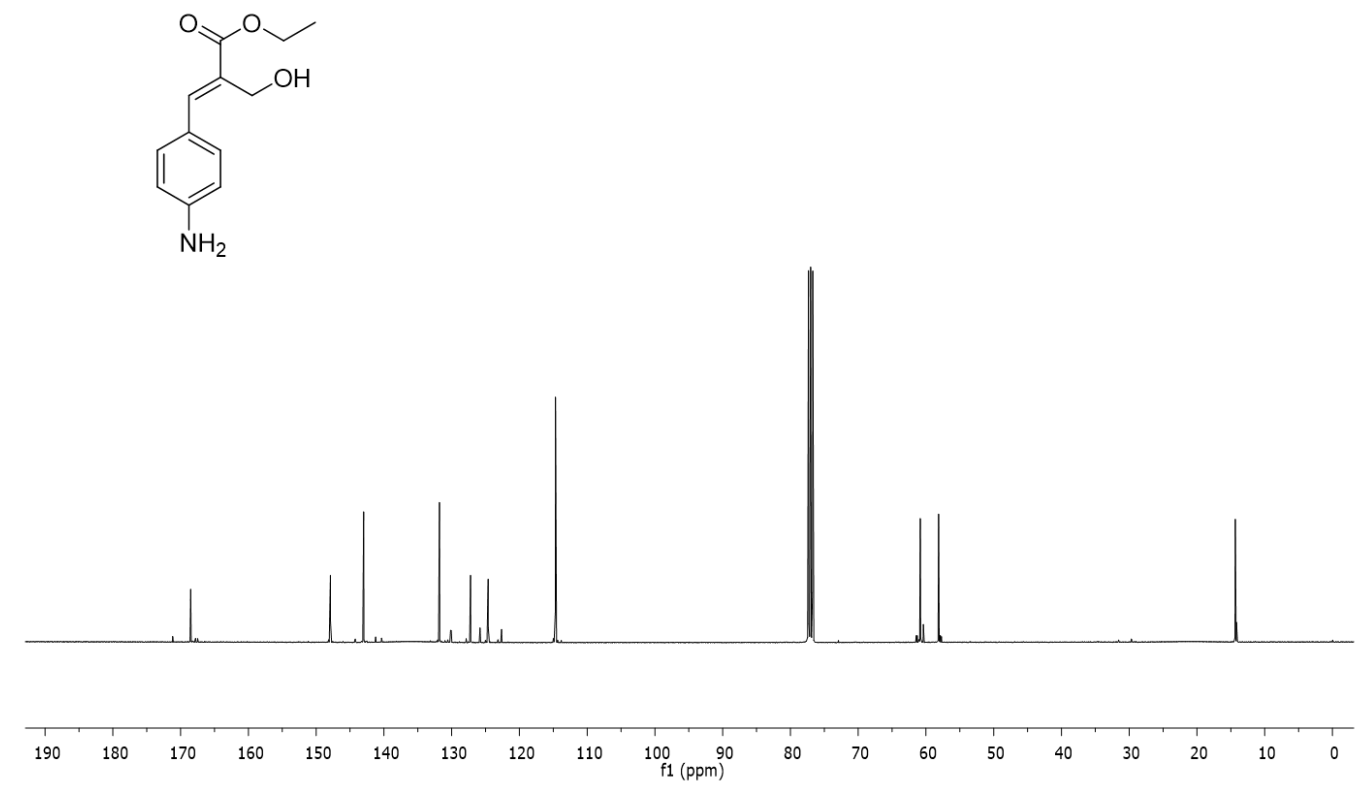

Figure S25: ${ }^{13} \mathrm{C}$ NMR of Compound V
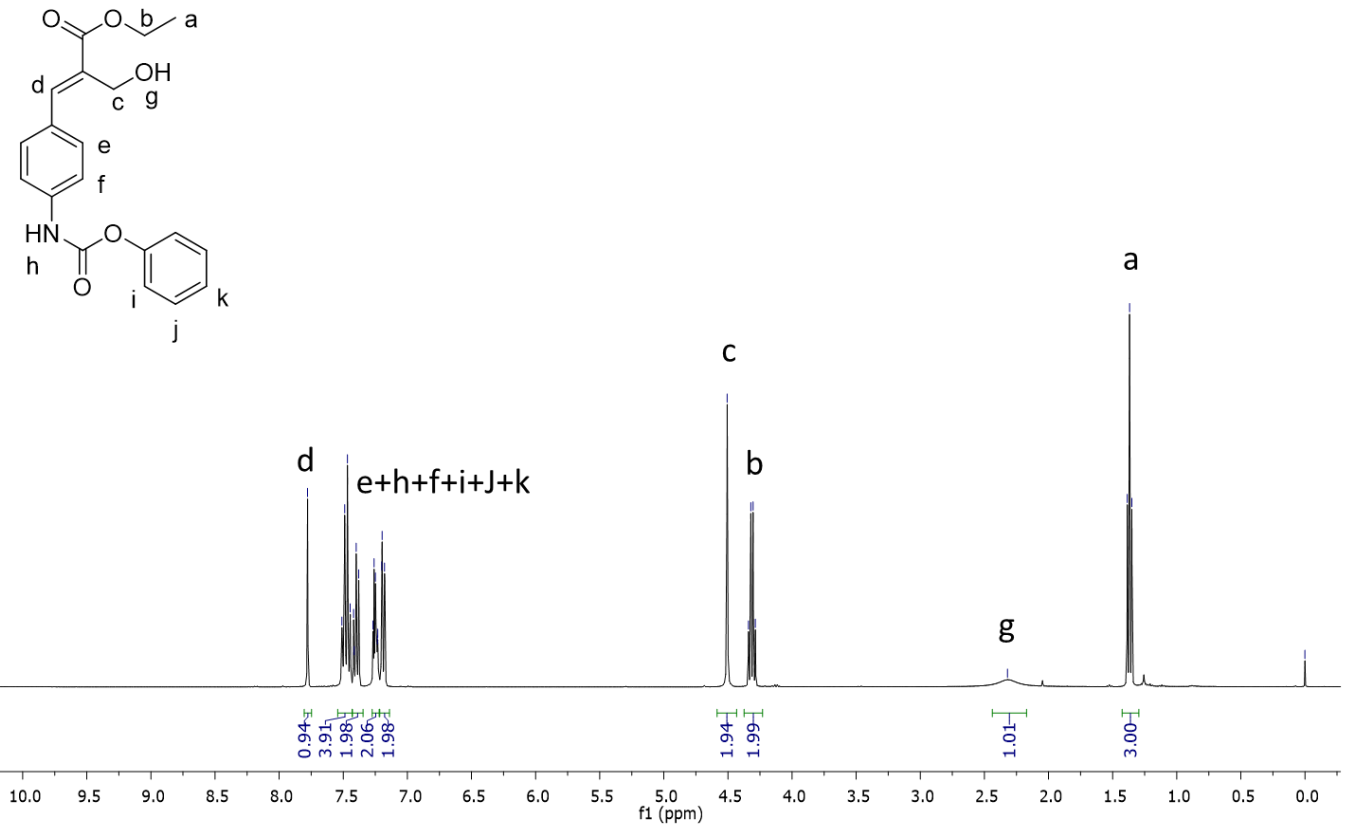

Figure S26: ${ }^{1} \mathrm{H}$ NMR of Compound 7 

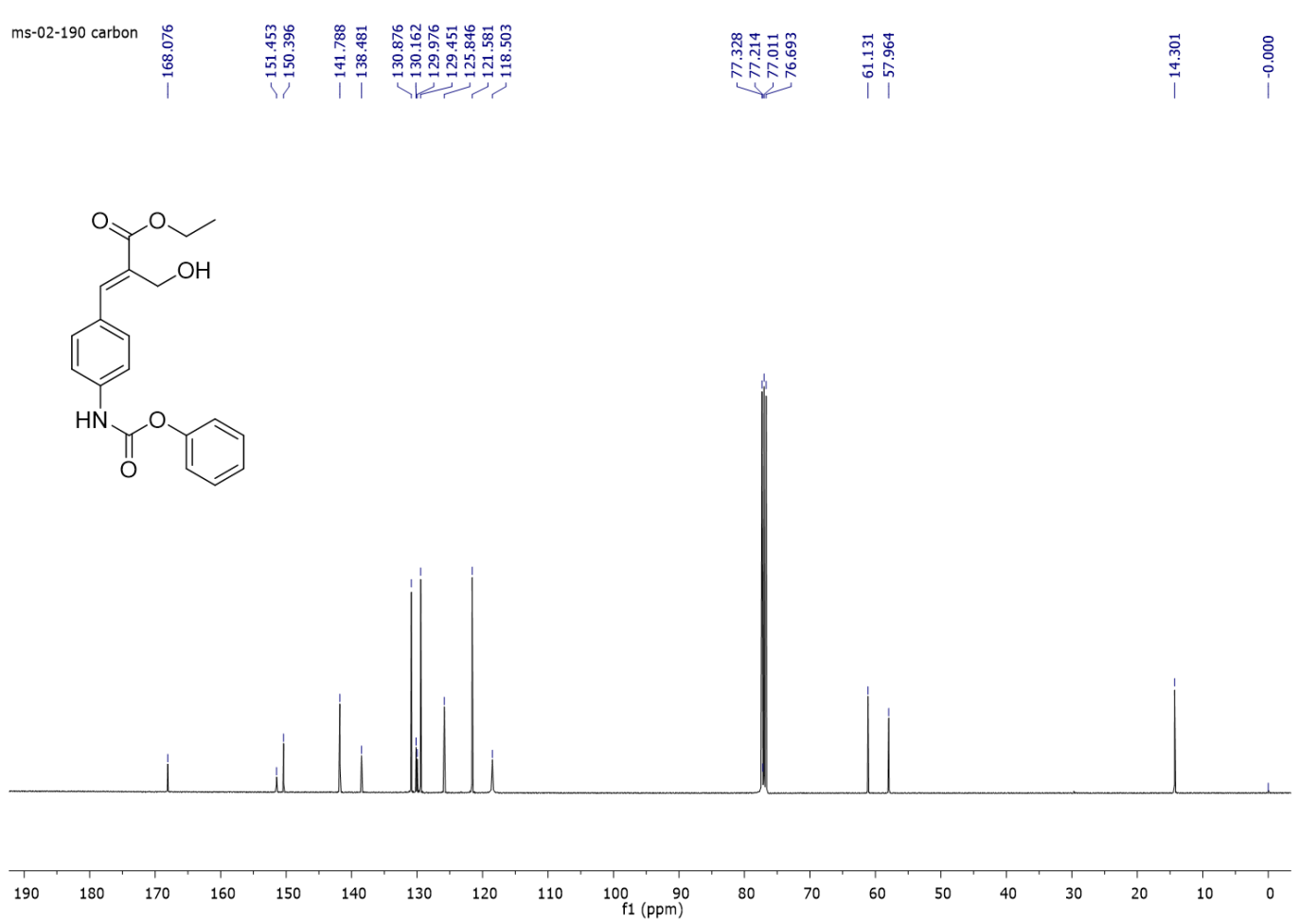

Figure S27: ${ }^{13} \mathrm{C}$ NMR of Compound 7
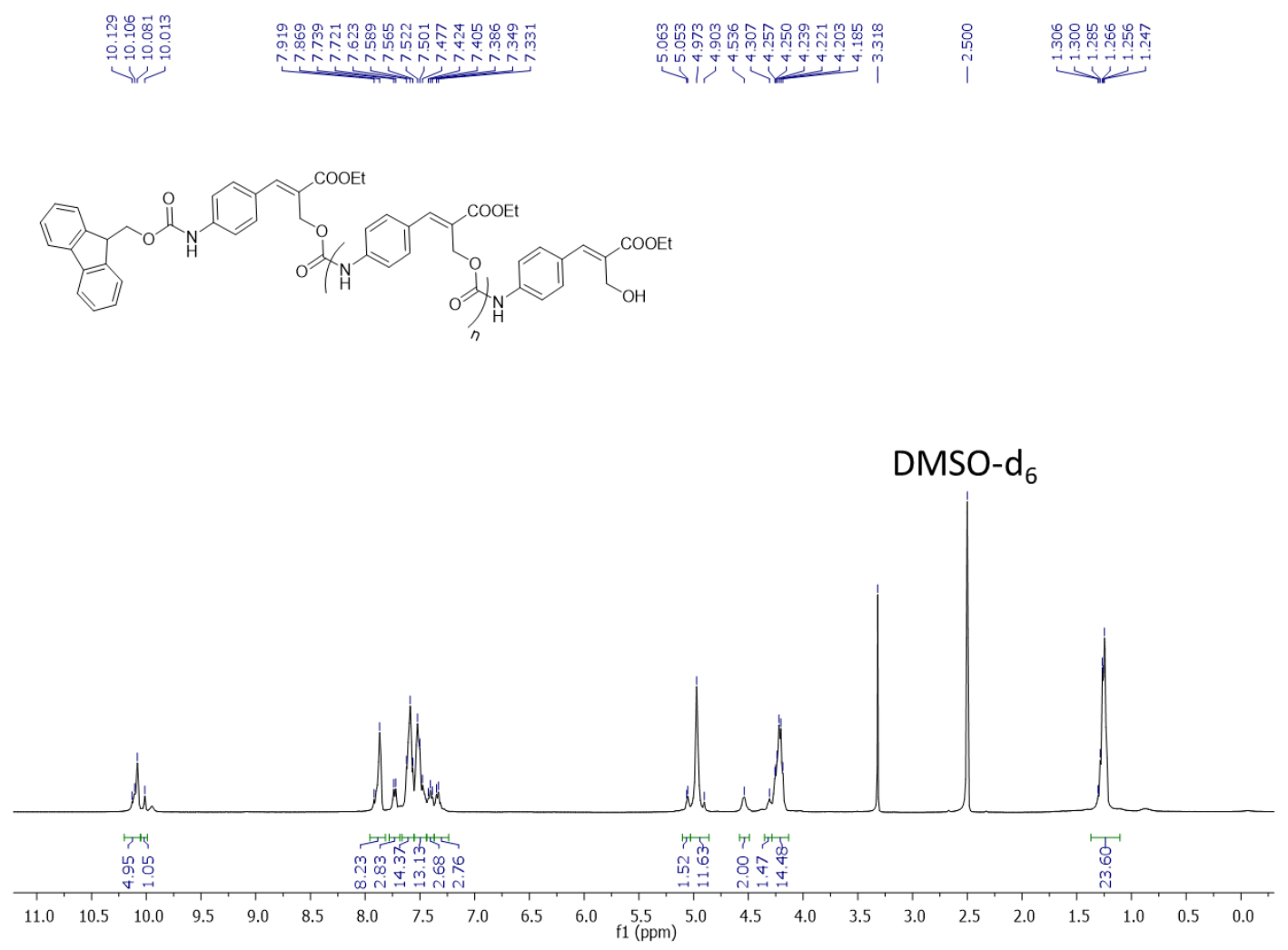

Figure S28: ${ }^{1} \mathrm{H}$ NMR of Polymer P1. 

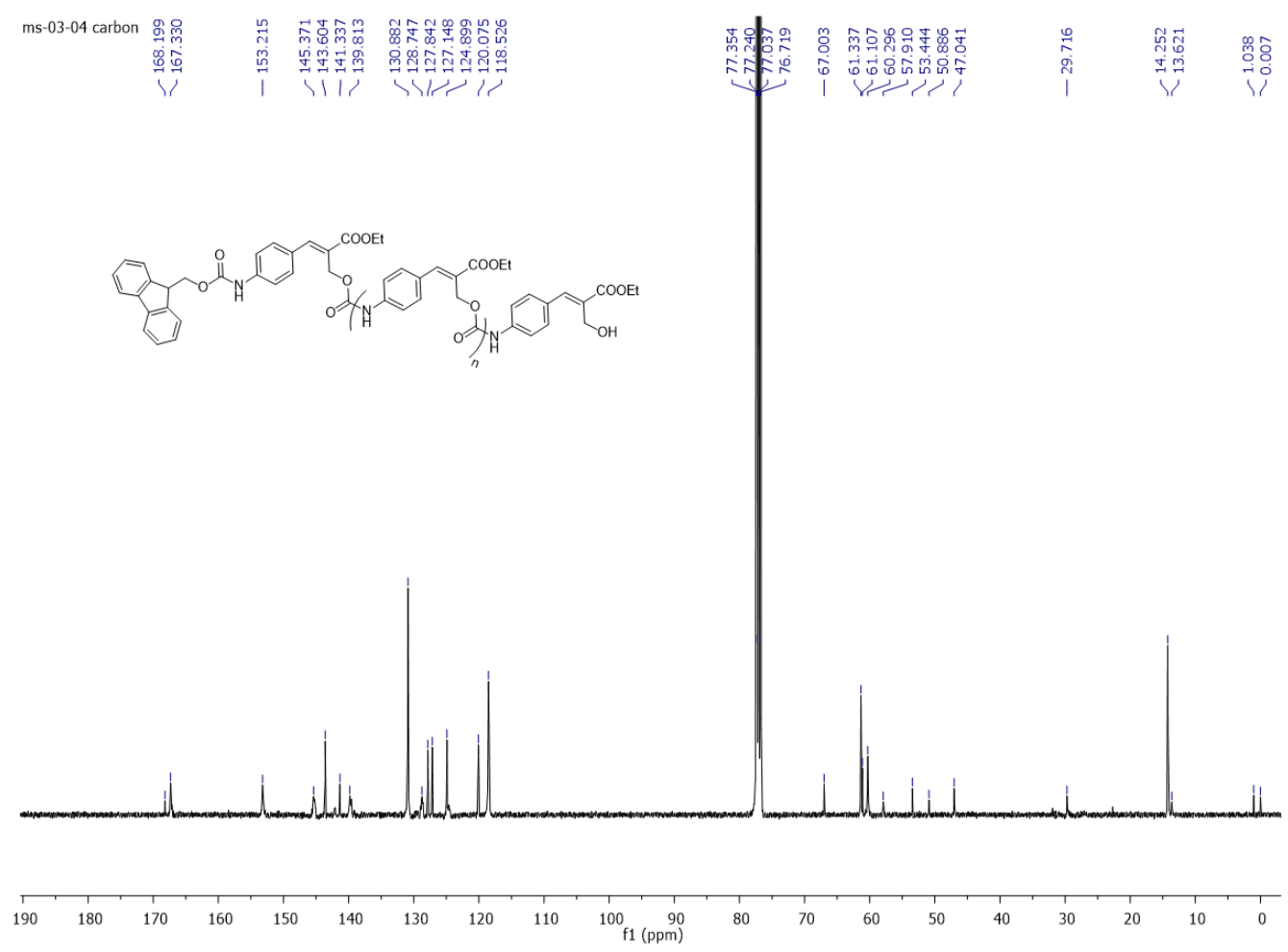

Figure S29: ${ }^{13} \mathrm{C}$ NMR of Polymer P1.
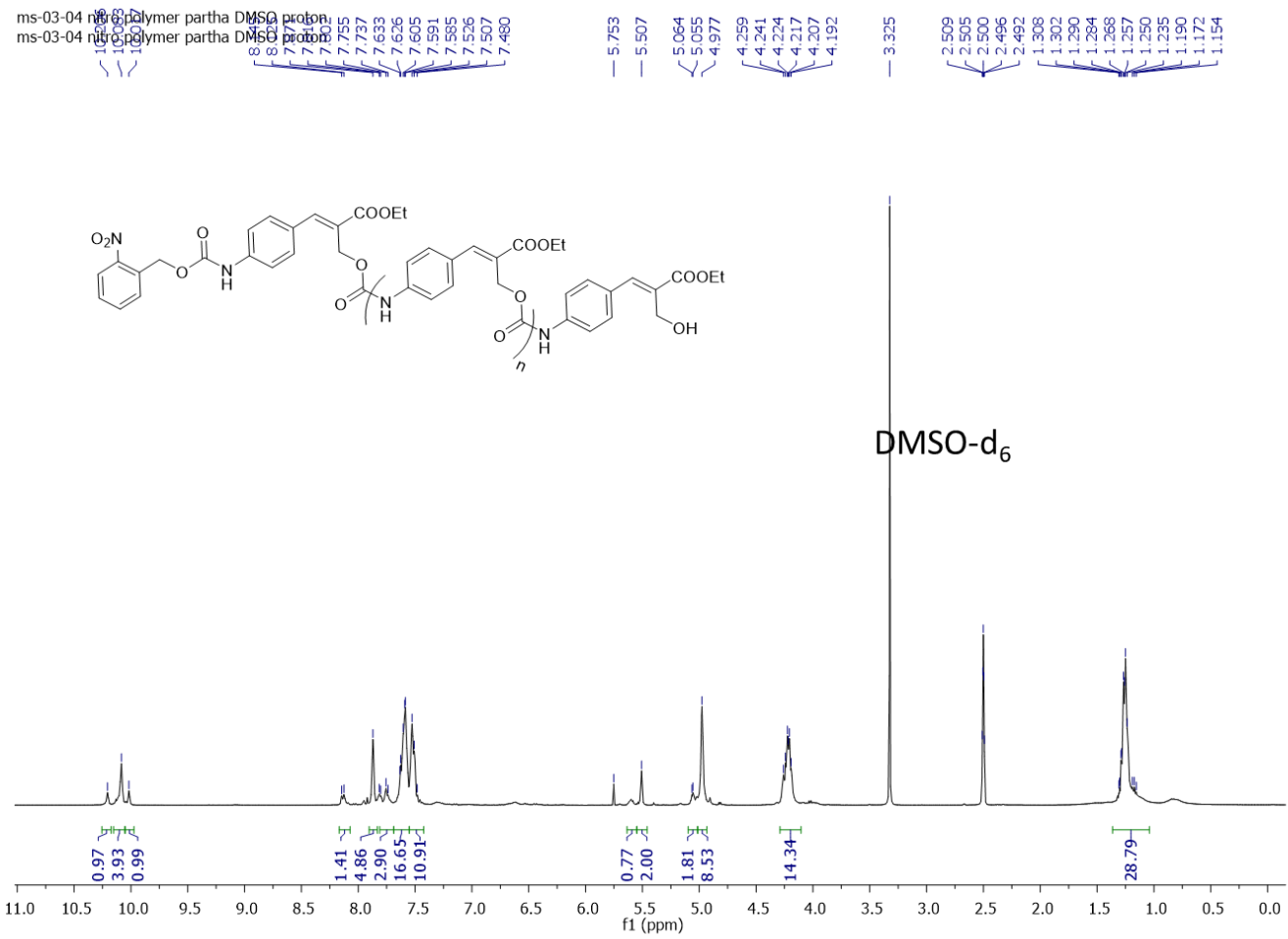

Figure S30: ${ }^{1} \mathrm{H}$ NMR of Polymer P2. 

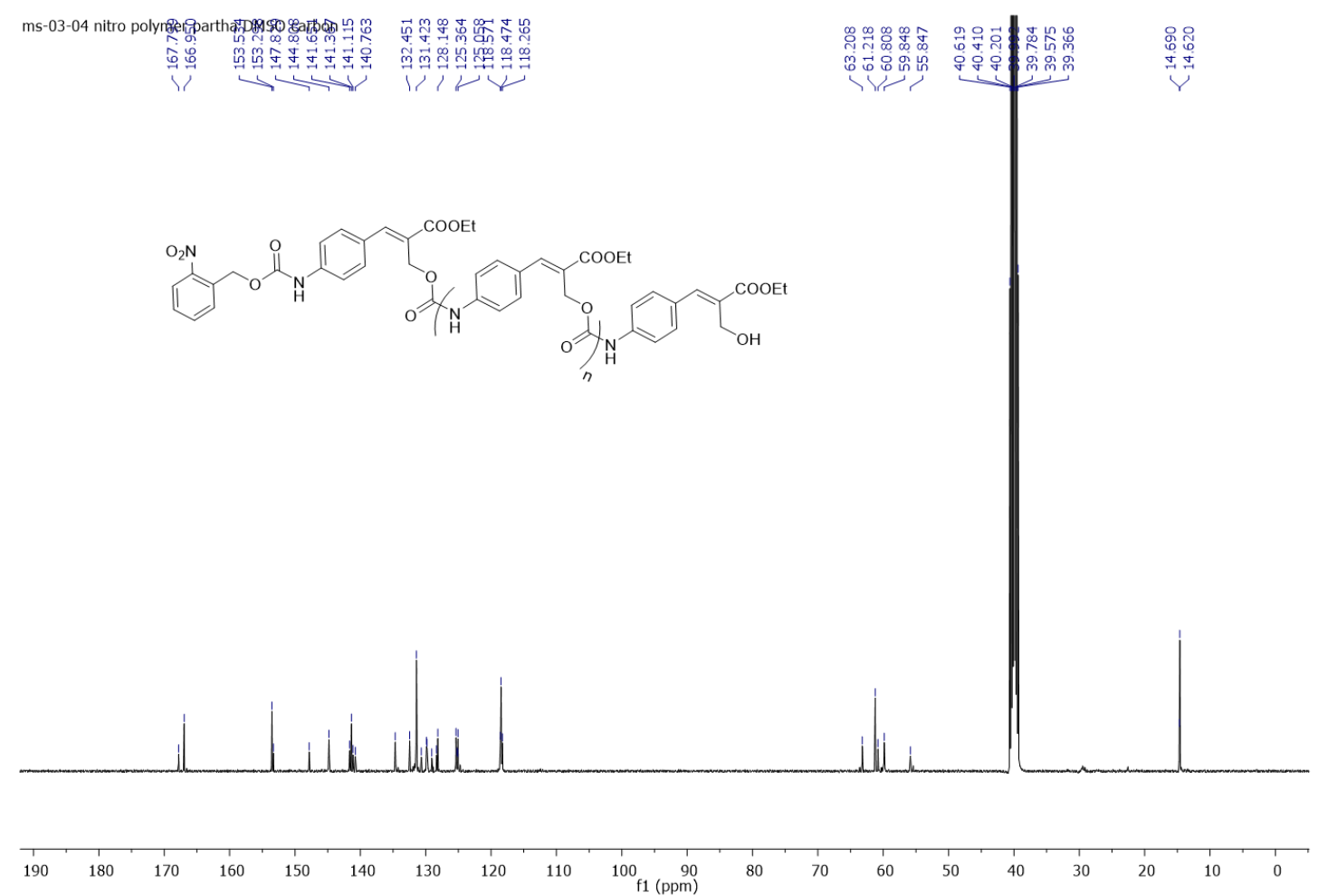

Figure S31: ${ }^{13} \mathrm{C}$ NMR of Polymer P2. 

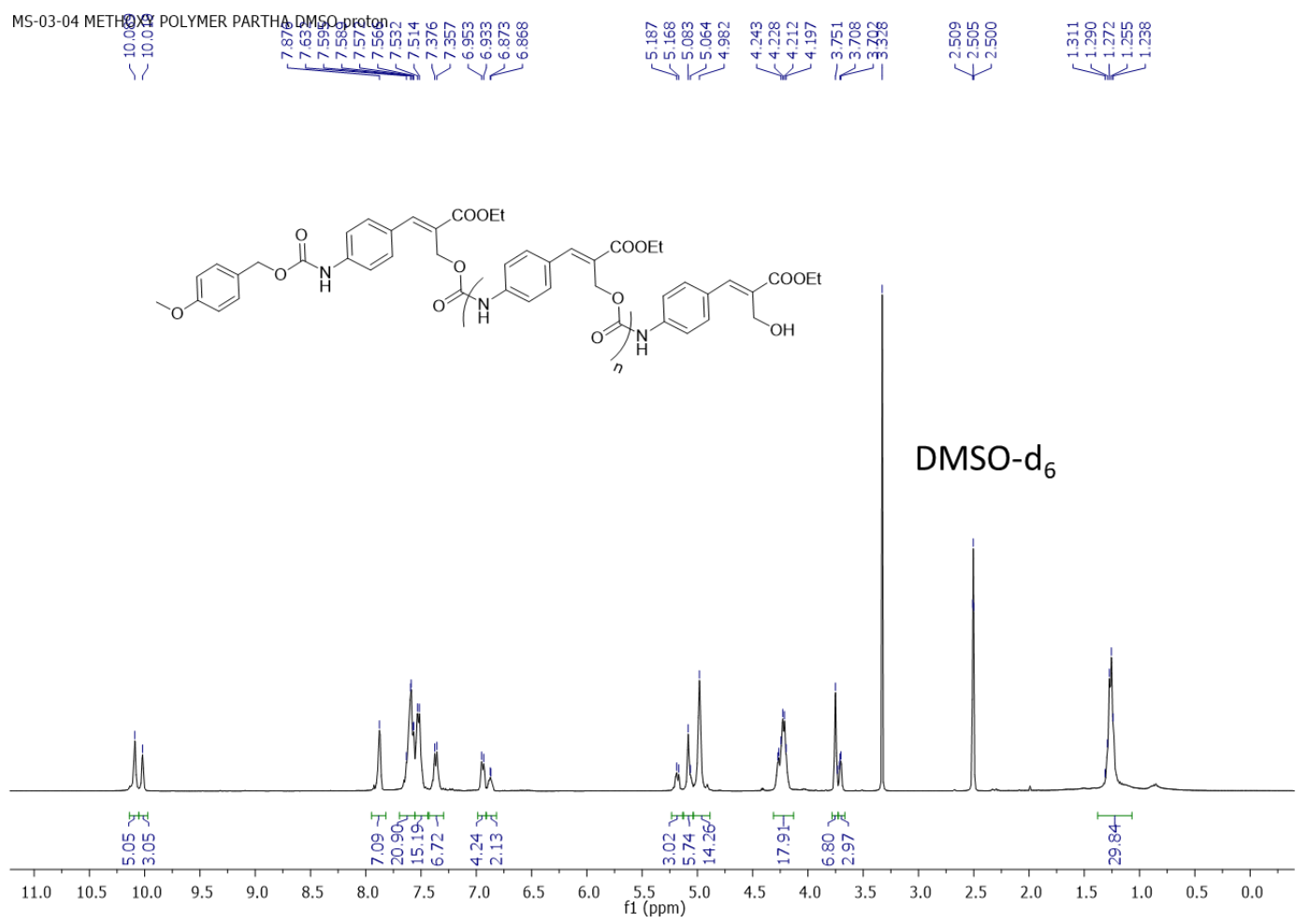

Figure S32: ${ }^{1} \mathrm{H}$ NMR of Polymer P3.

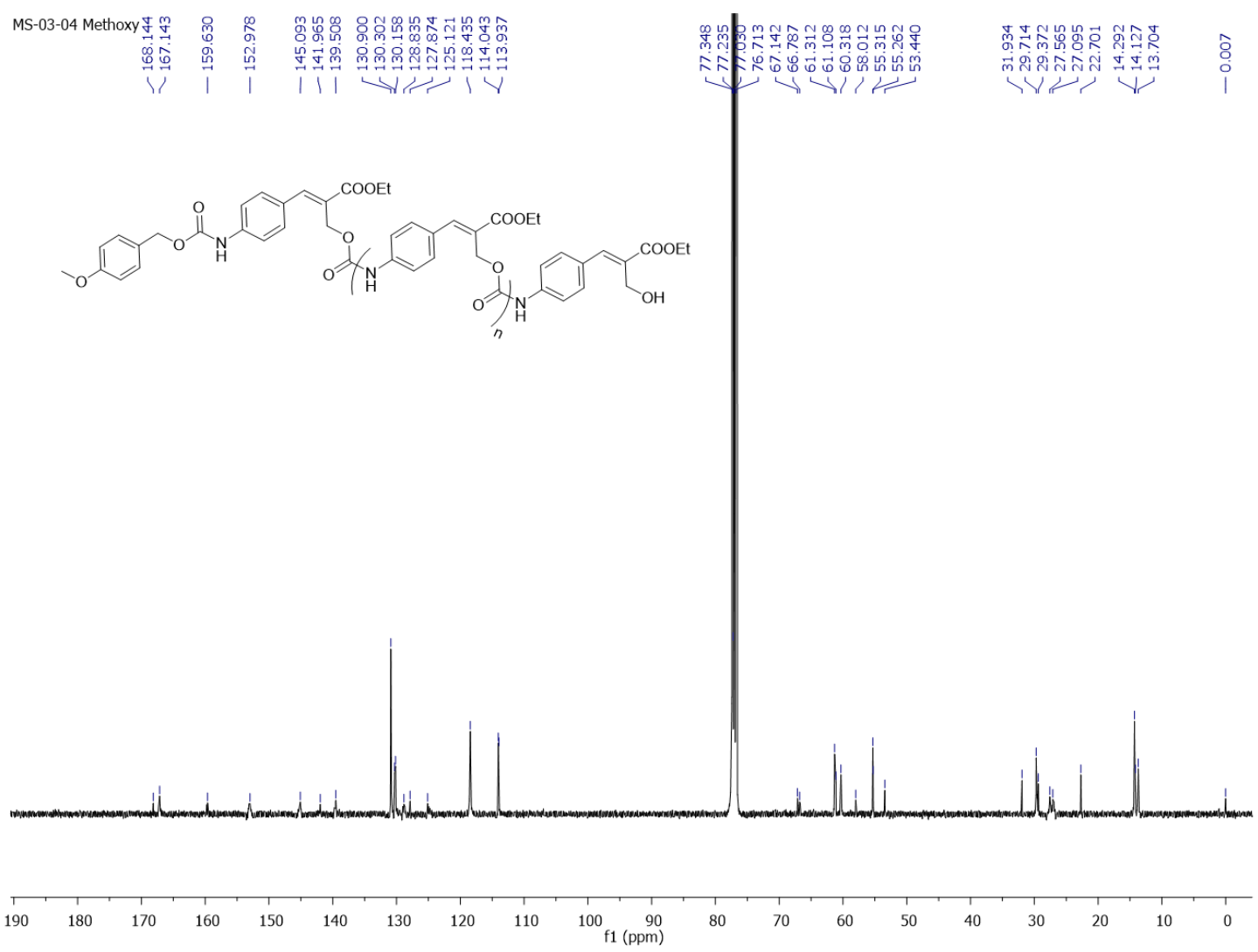

Figure S33: ${ }^{13} \mathrm{C}$ NMR of Polymer P3. 


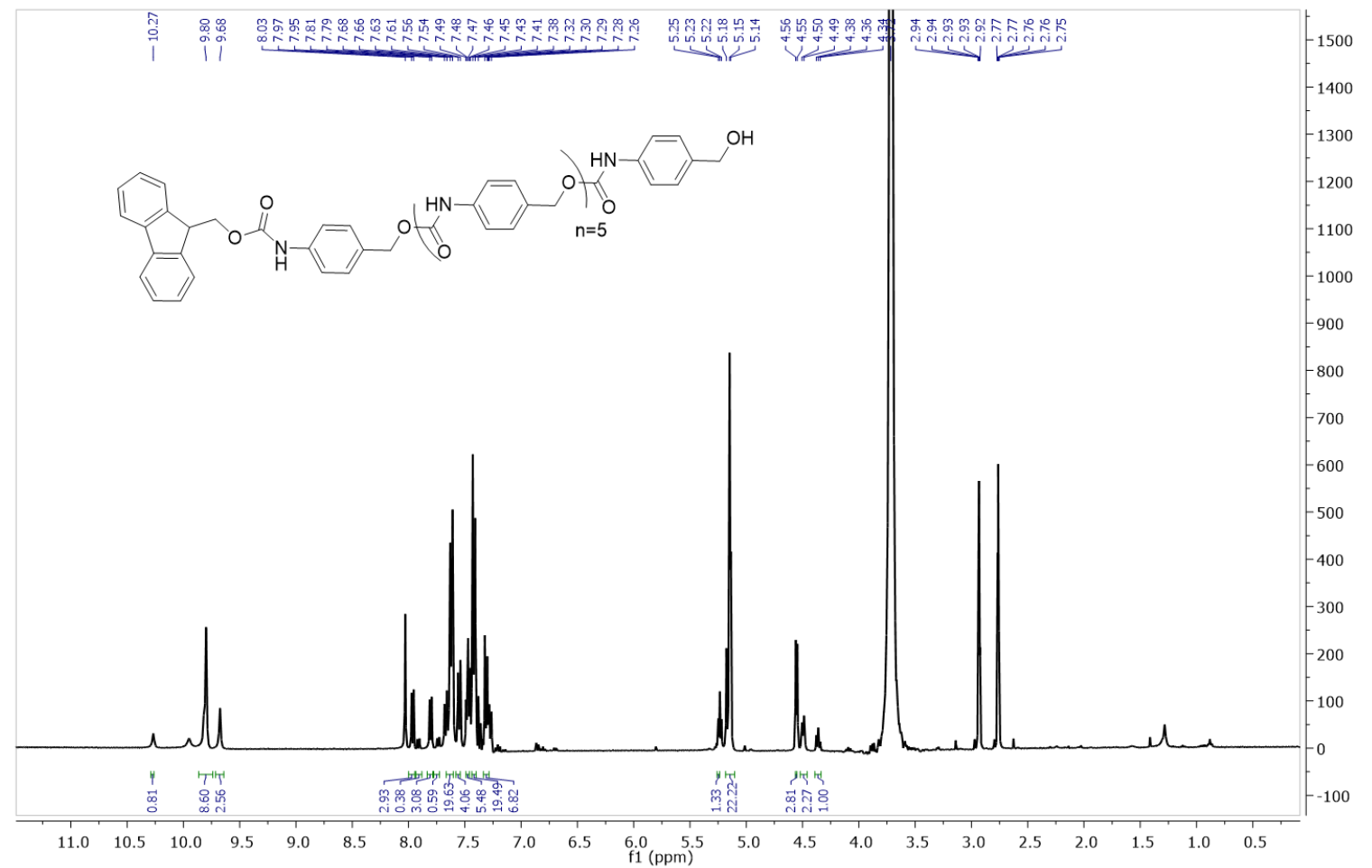

Figure S34: ${ }^{1} \mathrm{H}$ NMR of Polymer P4 


\section{ESI-MS-TOF spectra:}

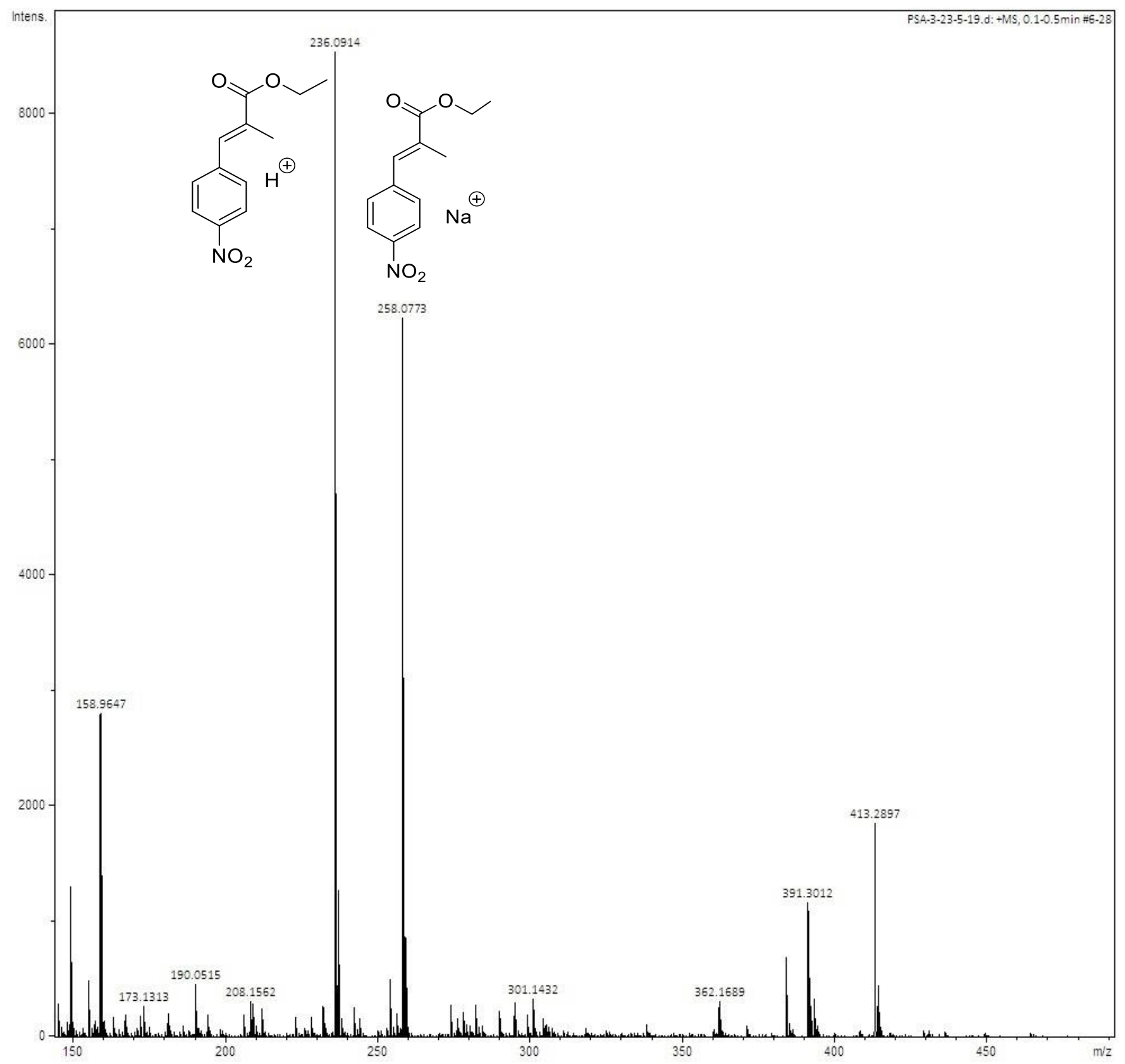

Figure S35: ESI-TOF-MS (+ve) Spectrum of Compound II. 


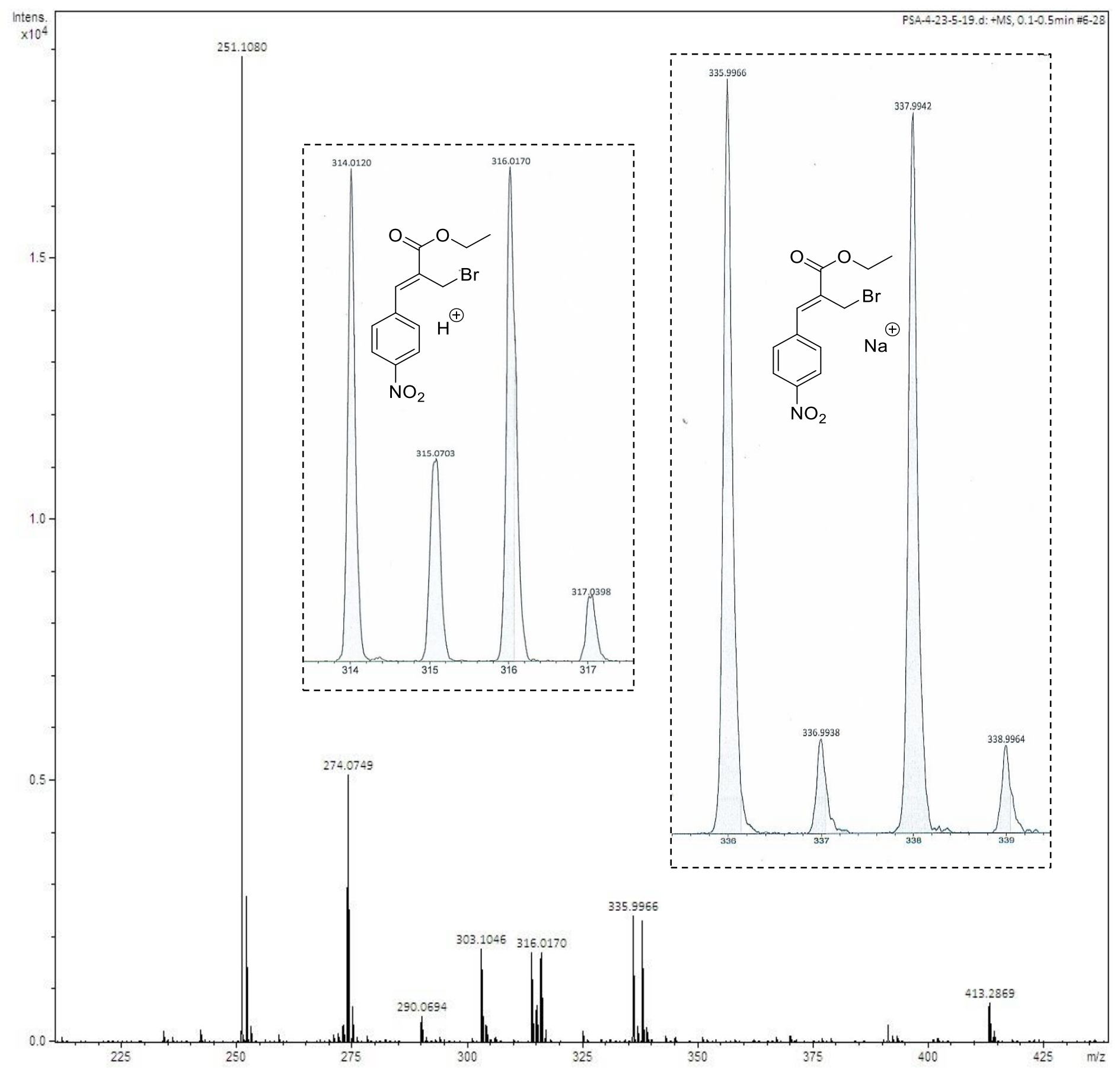

Figure S36: ESI-TOF-MS (+ve) Spectrum of Compound III. 


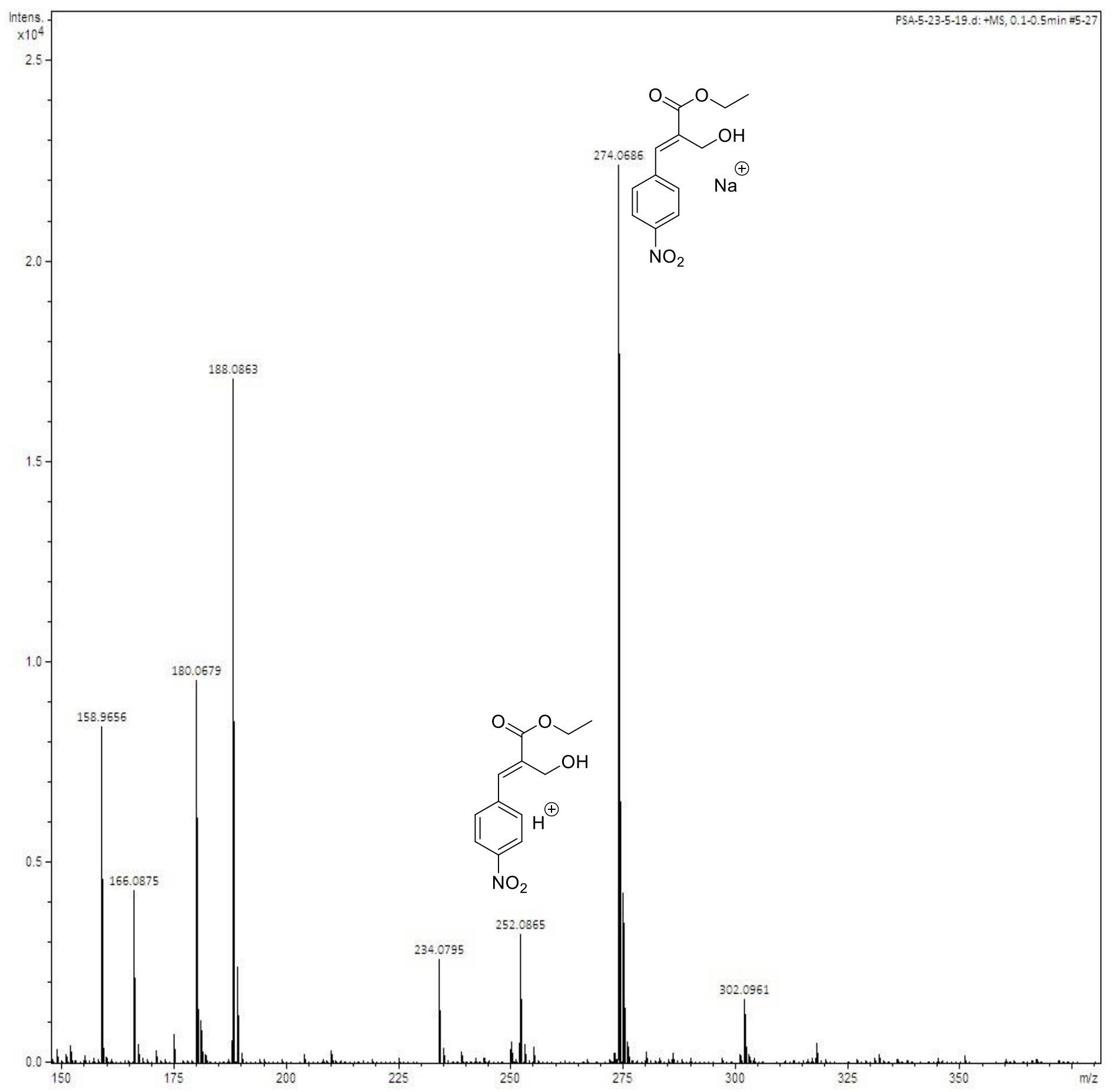

Figure S37: ESI-TOF-MS (+ve) Spectrum of Compound IV. 


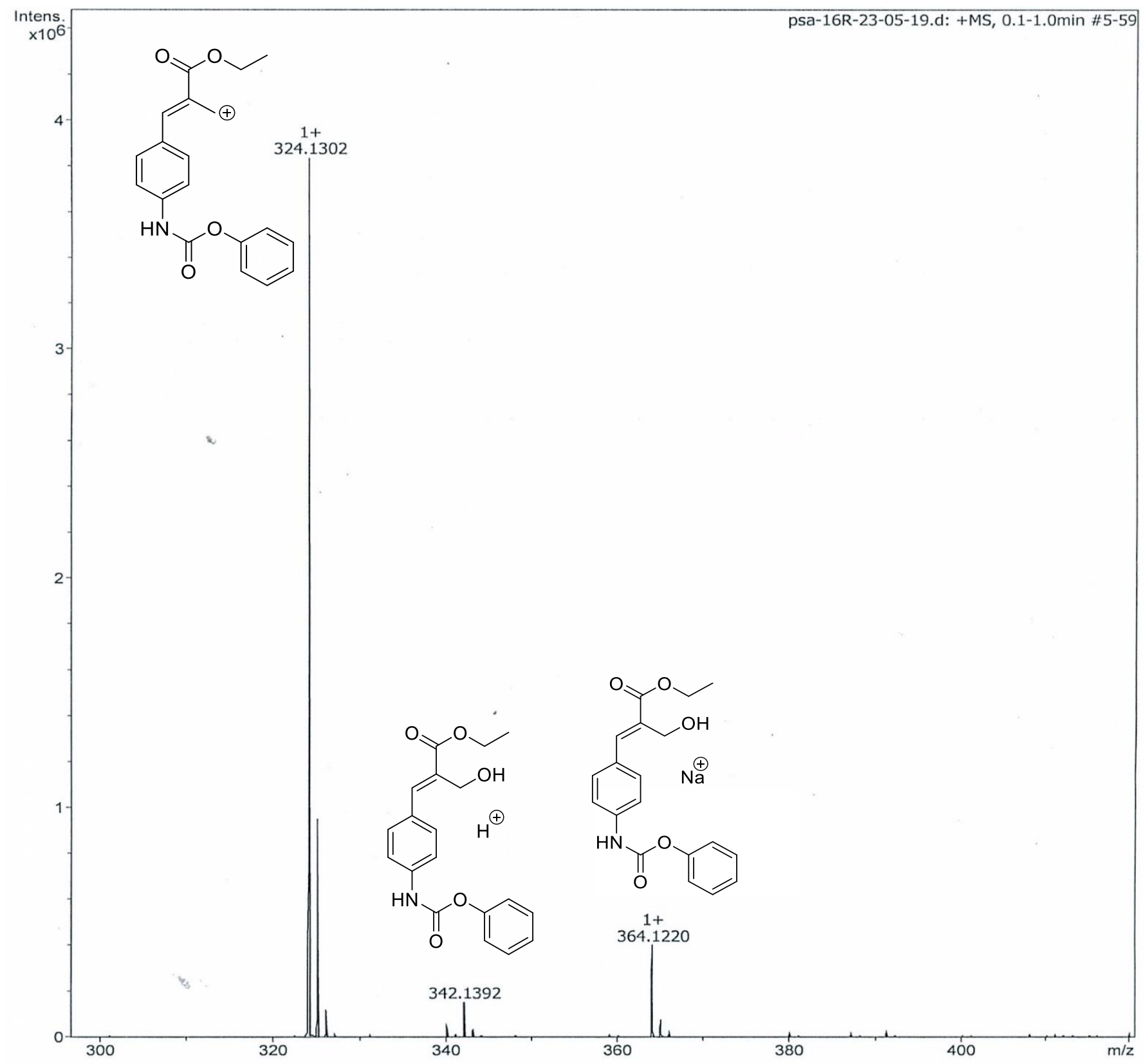

Figure S38: ESI-TOF-MS (+ve) Spectrum of Compound 7. 


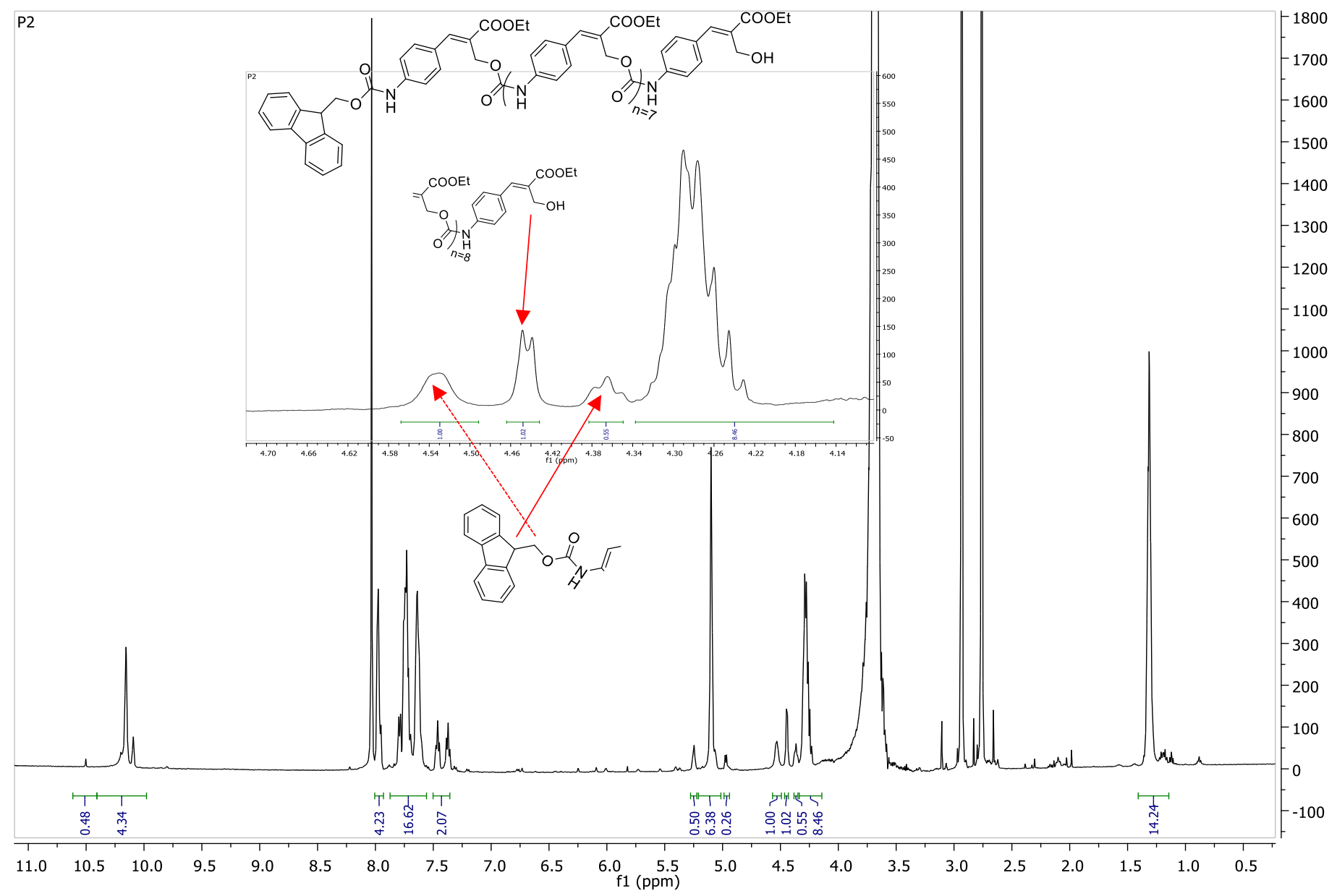

Figure S39: Detailed ${ }^{1} \mathrm{H}-\mathrm{NMR}$ (in DMF-d $\mathrm{d}_{7}$ ) analysis of $\mathbf{P 1}$ showed presence of FMoc group. Also the relative intensity of methylene protons from FMoc is same as the methylene proton of the terminal unit confirms the capping was $100 \%$ in each polymer chains. 


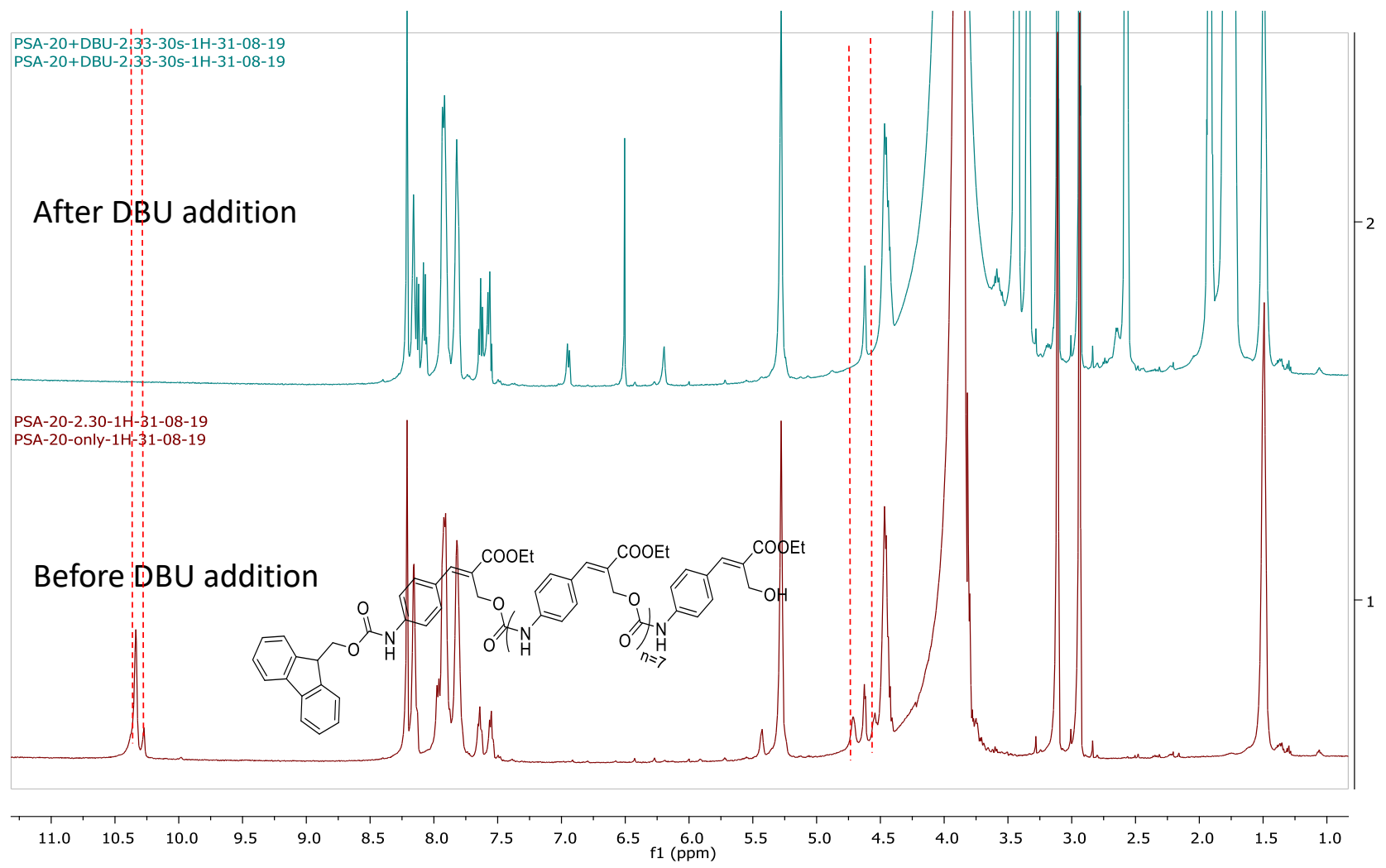

Figure S40: Comparative ${ }^{1} \mathrm{H}-\mathrm{NMR}$ (in DMF- $\mathrm{d}_{7}$ ) analysis of $\mathbf{P 1}$ before and after DBU treatment. Upon DBU treatment the FMoc group falls off almost immediately. 


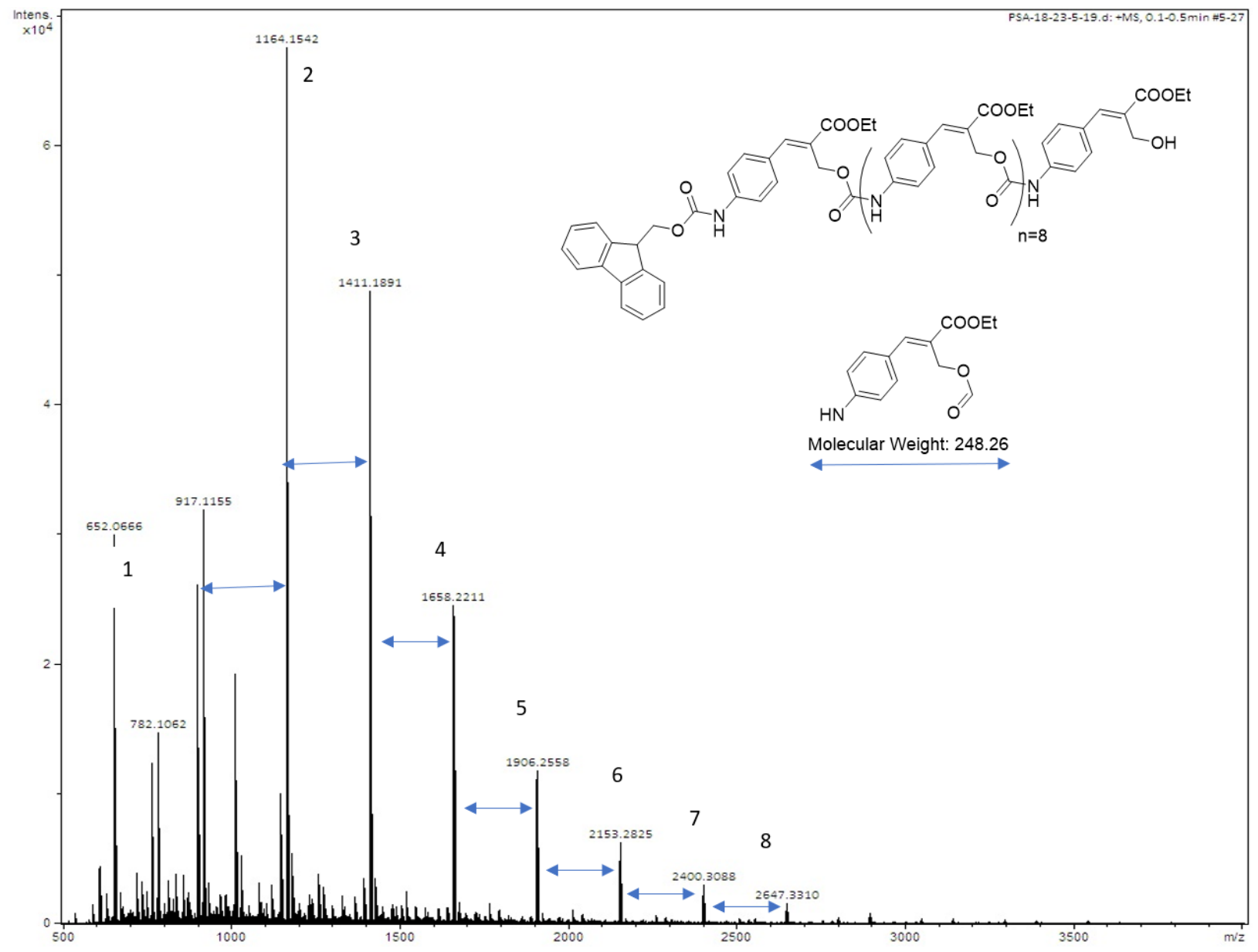

Figure S41: ESI-MS spectra of polymer P1. 